University of San Diego

Digital USD

2001-07-09

\title{
The Role of a Middle School Assistant Principal in Establishing and Maintaining Positive School Climate
}

Charles R. Girvin III EdD

University of San Diego

Follow this and additional works at: https://digital.sandiego.edu/dissertations

Part of the Leadership Studies Commons

\section{Digital USD Citation}

Girvin III, Charles R. EdD, "The Role of a Middle School Assistant Principal in Establishing and Maintaining Positive School Climate" (2001). Dissertations. 674.

https://digital.sandiego.edu/dissertations/674

This Dissertation: Open Access is brought to you for free and open access by the Theses and Dissertations at Digital USD. It has been accepted for inclusion in Dissertations by an authorized administrator of Digital USD. For more information, please contact digital@sandiego.edu. 
THE ROLE OF A MIDDLE SCHOOL ASSISTANT PRINCIPAL

IN ESTABLISHING AND MAINTAINING

POSITIVE SCHOOL CLIMATE

By

Charles R. Girvin III

A dissertation submitted in partial fulfillment

of the requirements for the degree of

Doctor of Education

University of San Diego

July 9,2001

Dissertation Committee

Robert Donmoyer, Ph.D., Chair

Edward DeRoche, Ph.D.

Kathleen Collins, Ph.D. 


\section{ABSTRACT \\ THE ROLE OF A MIDDLE SCHOOL ASSISTANT PRINCIPAL IN ESTABLISHING AND MAINTAINING POSITIVE SCHOOL CLIMATE}

Organizational theorists have for over 50 years used the concept of organizational climate to study and describe the effects of environment on the attitudes and behaviors of individual members and subgroups within organizations. Within the school setting, researchers and practitioners have increasingly used the concept of organizational climate to evaluate school effectiveness, particularly in middle schools where school climate plays a central role in middle school strategies and philosophies. Though extensive research has examined the relationship between climate and leadership in business, industry, and government, relatively few studies have examined the linkages between school climate and leadership within the school setting. The research that has been conducted in education has tended to focus exclusively on the influence of the school principal. Noticeably absent from the literature is any reference to the relationship between an assistant principal's attitudes and behaviors and school climate.

This study responds to the need to examine the relationship between a middle school assistant principal's leadership and the organizational climate within a middle school. It is a qualitative case study that employs interviews, observations, and document and artifact reviews to investigate the effect that the attitudes and behaviors of a middle school assistant principal has on a school considered by its district leadership and county office of education to have a positive school climate. The study is conducted within the conceptual framework of four school climate indicators: order and discipline, trust, academic program, and facilities. Two research questions guide the study: (a) Did the 
evidence support the assumption that a positive climate exists in this school, and (b) if so, what assumptions and behaviors of the assistant principal appear to contribute to the establishment and maintenance of that climate?

The findings of the study reveal that a positive climate exists at this school in all four school climate categories. The findings also indicate that the assistant principal's attitudes and behaviors have had a significant influence in the establishment and maintenance of this climate. His impact on the climate category of order and discipline is particularly profound. The evidence reveals that he maintains, with few exceptions, a high level of trust with all of his constituent groups and that this trust, in turn, forms the basis of his effective interpersonal relationships with individuals and subgroups within the school's community. There is no evidence that this assistant principal is involved with the school's academic program in any meaningful way except to provide a safe, orderly environment in which teaching and learning can take place. In the climate category of facilities, this assistant principal makes meaningful contributions to the maintenance and upkeep of the school, but does not have a primary role in this area of school climate. These findings form the basis for recommendations for middle school assistant principal policy and practice with regard to the establishment and maintenance of positive school climate within the middle school setting. 


\section{DEDICATION}

To My Wife

Nancy Jean 


\title{
ACKNOWLEDGEMENTS
}

\author{
Dr. Jim Raymond
}

for his encouragement and support

\section{Dr. Bob Donmoyer}

for his inspiration and guidance

\author{
My Wife Nancy \\ for her mentoring, editing, and infinite patience
}




\section{TABLE OF CONTENTS}

Dedication --.-

Acknowledgements --.--

Table of Contents --

List of Tables --1x

CHAPTER I. INTRODUCTION - 1

Background to the Study -- 1

Statement of the Problem --.--

Purpose of the Study - 5

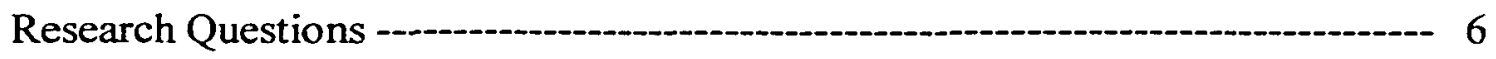

CHAPTER II. REVIEW OF THE LITERATURE -

Introduction --.-- 7

The Concept of Organizational Climate - -

School Climate --

Research on School Climate --_- 13

School Climate Descriptors --_- 16

Middle School and School Climate -

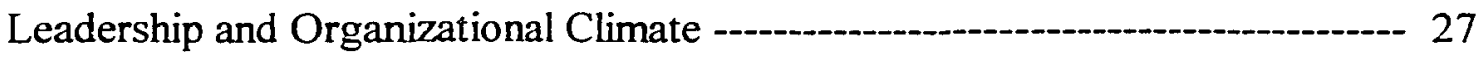

Leadership and School Climate -..-

Summary --1--- 37

CHAPTER III. RESEARCH DESIGH AND METHODOLOGY --_-a-_- 40

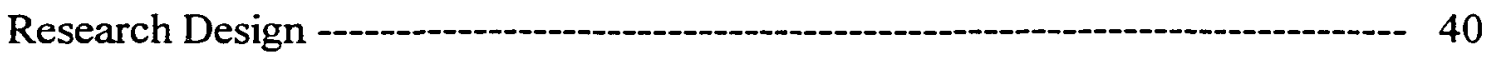

Methodology - 41 
Theoretical Assumptions

Conceptual Framework -- 44

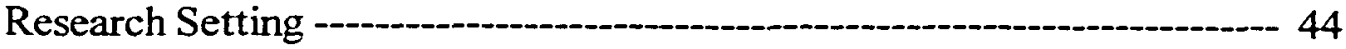

Researcher Role -.-1.-- 47

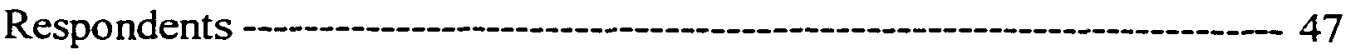

Data Collection --_-1.-- 52

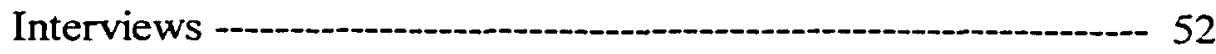

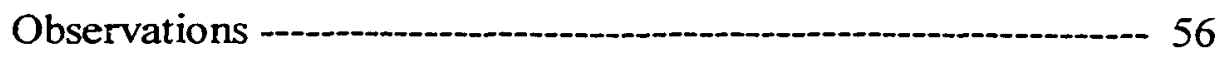

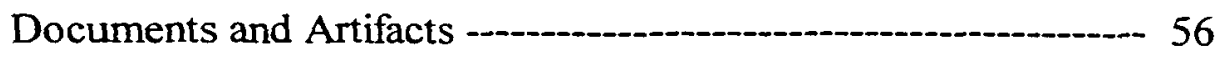

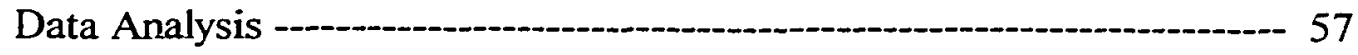

Limitations of the Study - 59

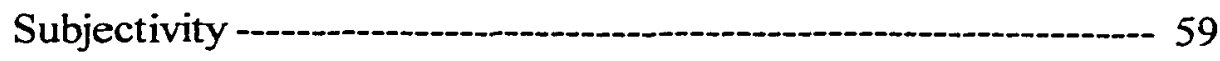

Backyard Research --_-_- 59

Generalizability -

CHAPTER IV. FINDINGS: DOES A POSITIVE CLIMATE EXIST AT

VALLEY MIDDLE SCHOOL? -

Introduction -

Order and Discipline -

Expectations - 66

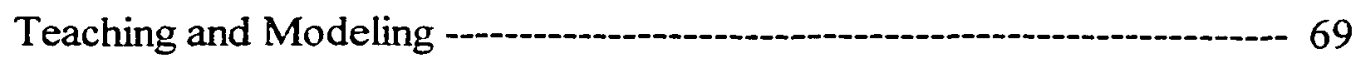

Observed Behavior -

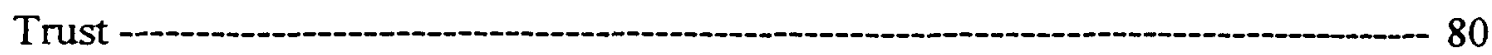

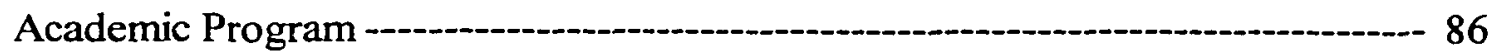


Facilities

Summary

CHAPTER V. FINDINGS: THE RELATIONSHIP BETWEEN THE ASSISTANT

PRINCIPAL'S ATTITUDES AND BEHAVIORS AND VALLEY MIDDLE

SCHOOL'S CLIMATE

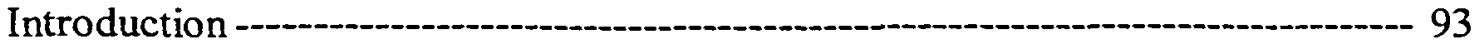

Order and Discipline -

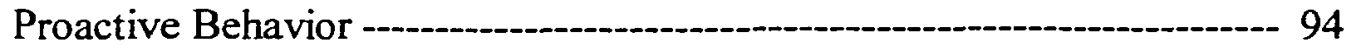

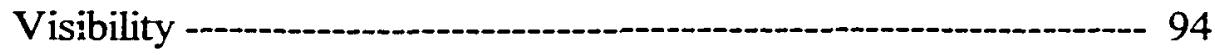

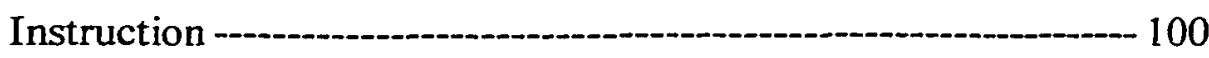

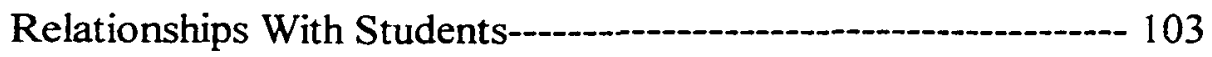

Reactive Behavior -

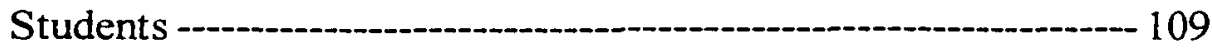

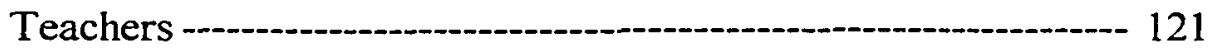

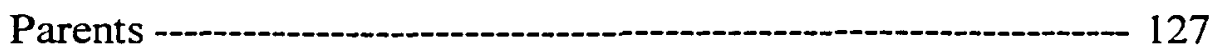

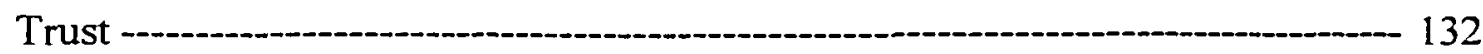

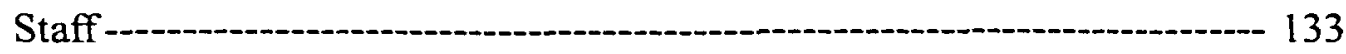

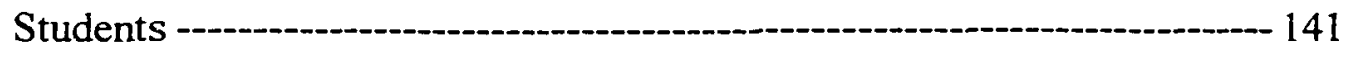

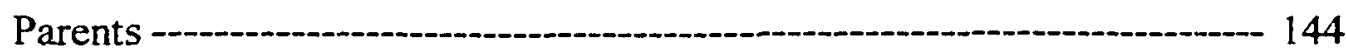

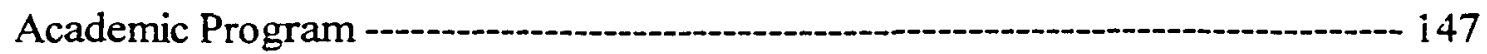

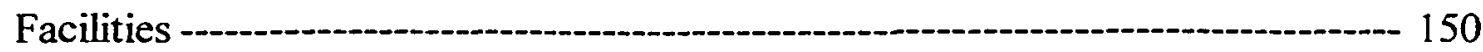

Summary --15

vi 
CHAPTER VI. SUMMARY, DISCUSSION, RECOMMENDATIONS FOR

POLICY AND PRACTICE, AND SUGGESTIONS FOR FUTURE RESEARCH --- 159

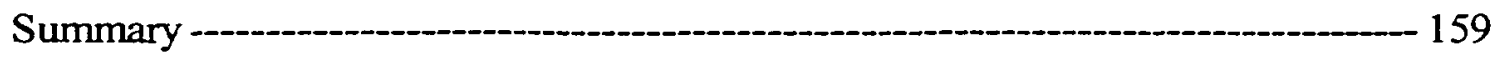

Background --159

Research Questions --_-_- 161

Research Design ---_- 161

Theoretical Assumptions --1- 162

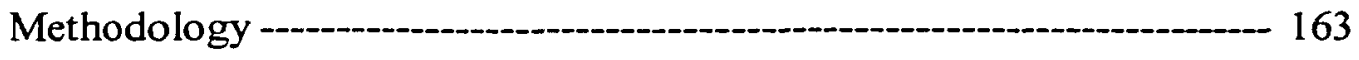

Findings --- 164

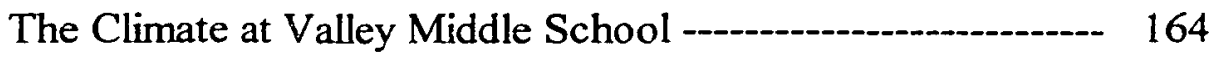

The Relationship Between the Assistant Principal's Attitudes

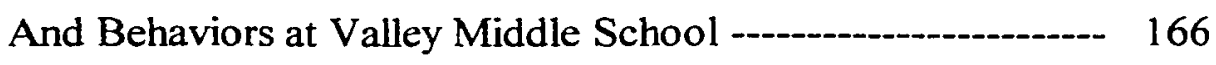

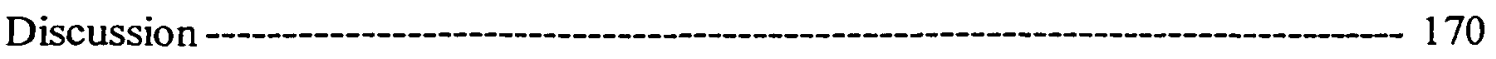

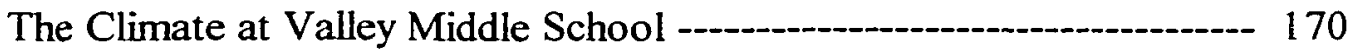

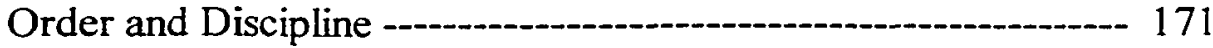

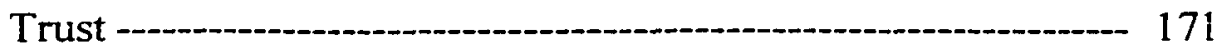

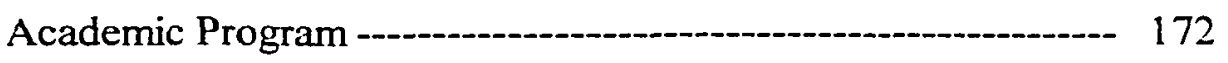

Facilities -

The Relationship Between the Assistant Principal's Attitudes and

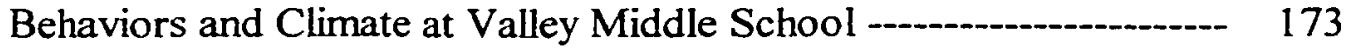

Order and Discipline -

Trust --10-10 176

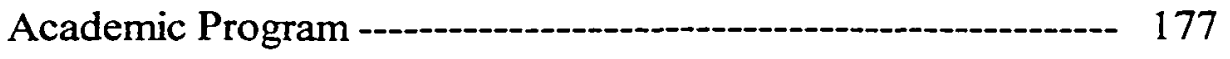

vii 
Recommendations for Policy and Practice

Recommendations for Future Research

References 


\section{LIST OF TABLES}

Table

Page

$1 \quad$ Comparison of Suspension Statistics Between District Middle Schools ------- 73

2 Attendance Rates for Academic Years 1997/1998-1999/2000 74 


\section{CHAPTER I}

\section{INTRODUCTION}

\section{Background to the Study}

Organizational theorists have for years conducted studies on the effects of environment on the attitudes and behaviors of both individual members and subgroups within organizations. What has emerged from this research is a concept that most researchers in the past have termed organizational climate (see, for example, Kozlowski \& Doherty, 1989; McGregor, 1960; Tagiuri, 1968). In recent years, leadership and management theorists who have worked in the areas of business and industry have increasingly substituted the term culture for climate (see, for example, Bennis, 1997; Heifetz, 1994; Kotter, 1996). Educational researchers and practitioners, however, continue to use the original concept of climate to study the relationship between the environment in a school setting and the attitudes and behaviors of members and subgroups of the school community (see, for example, Freiberg, 1998; Griffith, 1999; Hoy \& Hanrium, 1997).

The theoretical framework formulated by these organizational and human relations theorists assumes that individuals in an organization form perceptions regarding their organization's climate based on the effect that they perceive that climate to have on their personal and professional lives. This process is believed by researchers to be interactive and reciprocal in nature in that organizational climate produces responses from individuals and groups within the organization that can in turn alter the original climate (see, for example, Indik, 1968; Likert, 1967; Litwin \& Stringer, 1968). Over time, this process results in consensus among organization members regarding the nature 
of the organization's climate and the effect that it has on its members. This consensus, in turn, has a profound influence on the motivation and behaviors of individuals and subgroups within the organization.

Researchers and practitioners in the field of education have used the theoretical construct of organizational climate extensively within the school setting in attempts to evaluate school effectiveness (see, for example, Anderson, 1982; Halpin \& Croft, 1963: Hoy \& Hannum, 1997). In focusing on school climate, they have attempted to determine the effects of different climate descriptors on student achievement and social and emotional development. Scholars and educators who have studied school climate, however, have had difficulty in achieving consensus on what the primary climate descriptors should be. Nevertheless, some agreement has emerged from school research that there exists a set of internal climate characteristics that is unique to each school site, that influences the behaviors of all members of the school organization, and that affects student academic achievement and behavior (Anderson, 1982; Hoy, Tarter, \& Bliss, 1990).

Attempts to identify these characteristics have led to a wide range of descriptors. Anderson (1982), for example, listed 27 such factors in her meta-analysis of school climate research. Other researches have focused on just one descriptor (Borger, Lo, Oh, \& Walberg (1985). Four broad climate categories, however, recur throughout school climate literature. The first of these categories, widely considered critical to creating a positive school climate, is order and discipline (see, for example, Anderson, 1982; Bernstein, 1992; Borger, Lo, Oh, \& Walberg, 1985). Order and discipline refers to student behavior toward both adults and one another, security of the campus from outside 
threats, and the absence of weapons and other dangerous items or illegal substances from the school.

Similarly, most studies have included the academic program of a school as a critical factor affecting the school's climate (see, for example, Howard, Howell, \& Brainerd, 1987; Hoy \& Hannum, 1997; Stockard \& Mayberry, 1992). This descriptor encompasses the content of the instructional program, effectiveness of its delivery, and the level of academic performance standards expected of students.

Trust is another climate factor considered important by most researchers. Consequently, its effect on climate has often been studied alone (see, for example, Hoy, Tarter, \& Bliss, 1990; Tarter, Sabo, \& Hoy, 1995). This element of climate addresses the nature of interpersonal relationships between both individuals and identifiable groups within a school.

Finally, the state of a school's physical plant, or facilities, is another theme common throughout school climate literature (see, for example, Brown, 1984; Welch, 1997). This climate descriptor refers to the physical condition of a school, including its grounds, buildings, and electrical and mechanical support systems.

Recent research in the field of middle level education, grades six through eight, indicates that school climate has particularly significant and wide-ranging effects on student academic performance and social development (Hoy \& Hannum, 1997; Lake, 1989; Tarter, Sabo, and Hoy, 1995). These studies suggest that middle grade adolescents are unique with distinct differences in physical, social, emotional, and intellectual development from both elementary and high school students. Middle school advocates argue that the effectiveness of middle level schools depends upon the degree to which 
middle schools respond to these developmental needs and characteristics (Maynard, 1986; Toepfer, 1988). As a result, middle school theoreticians and practitioners have achieved a high level of consensus regarding middle school specific philosophies and strategies. The central theme that seems to tie all of these philosophies and strategies together is the concept of school climate (Hoy, Hannum, \& Moran, 1998; Lake, 1991).

If climate does play such a critical role in middle school effectiveness, as evaluated by such criteria as student achievement and social and emotional well being, it would appear important to examine the critical elements that influence climate in the middle school setting. Intuitively, leadership would be expected to be one of these critical influences. This assumption is supported by the work of many organizational and leadership theorists (see, for example, Graen \& Scandura, 1987; Kozlowski \& Doherty, 1989; Likert, 1967; McGregor, 1960) who have argued that a leader's assumptions and actions result in processes that play a critical role in the formation of climate and, in turn, have a profound impact on the behavior of organization members.

Statement of the Problem

Though extensive research has examined the relationship between climate and leadership in business, industry, and government, relatively few studies have examined the linkages between school climate and leaders within the school setting (Griffith, 1999). The research that has been conducted in the realm of education has tended to focus exclusively on the influence of the school principal (see, for example, Griffith, 1999; Hoy \& Feldman, 1987; Tarter \& Hoy, 1998). Noticeably absent from the literature on leadership and climate is any reference to the relationship between an assistant principal's behaviors and school climate. Neither researchers nor practitioners have systematically 
examined the role of the middle school assistant principal with regard to critical factors that affect middle school climate, such as supervision of instruction or the establishment and maintenance of processes, structures, and activities that influence organizational members' attitudes and behaviors (Greenfield, 1985). This would appear inconsistent with the theory that leadership and organizational climate are intertwined in that an assistant principal is exceeded in positional authority by only the principal at a school site and thus could be expected to have a significant effect on his/her school's climate. Accordingly, it would appear that a need exists to examine the relationship between a middle school assistant principal's leadership and middle school climate.

\section{Purpose of the Study}

This study was a case study of one middle school, considered by its district leadership and county office of education to have a positive school climate, and its assistant principal within the context of the four climate indicators: order and discipline, trust, academic program, and facilities. The purpose of the study was to respond to the need to examine how a middle school assistant principal contributes to the establishment and maintenance of a positive school climate.

Accordingly, the assumptions and behaviors of the school's assistant principal, in addition to his interpersonal relationships with the various members of the school community, were studied in an attempt to determine how these behaviors influenced the school's climate. This attempt to describe the role of a middle school assistant principal in establishing and maintaining positive school climate contributes to the research on the relationship between school leadership and school climate. In particular, the study responds to the need to examine the relationship between a middle school assistant 
principal's leadership and the organizational climate within a school that exists as a result of a lack of prior inquiries into this relationship at the assistant principal level.

\section{Research Questions}

The following research questions guided this study: (a) Did the evidence support the assumption that a positive climate existed in this school, and (b) if so, what assumptions and behaviors of the assistant principal appeared to contribute to the establishment and maintenance of that climate?

Though much could be gained from an examination of the role of school leadership in creating a negative climate, I had greater interest as both a practitioner and researcher in the assumptions and behaviors of an assistant principal that foster positive school climate. It was therefore critical to the study that the first research question be asked in support of the second and central question of the study that focused on the attitudes and behaviors of an assistant principal that support a positive school climate, not a negative one. I was fully prepared to adjust the study accordingly were the evidence to suggest that a positive climate did not exist at the school in order to investigate the assistant principal's role in the failure of the school's leadership to establish and maintain a positive climate. 


\section{CHAPTER II}

\section{REVIEW OF THE LITERATURE}

\section{Introduction}

Organizational theorists have argued that the climate of an organization has subtle yet profound effects on the attitudes and behaviors of its members (see, for example, Kozlowski \& Doherty, 1989; Litwin \& Stringer, 1968). This appears to be the case in a school setting in which a school's climate seems to influence all members of a school's community and, in turn, has significant impact on students' achievement and their social and emotional development (Anderson, 1982; Halpin \& Croft, 1963; Hoy \& Hannum, 1997).

Though there has been little agreement among researchers as to the precise definition of school climate, a number of common descriptors of climate recur throughout the literature that can be used to evaluate the climate of a school (see, for example, Anderson, 1982; Howard, Howell, \& Brainerd, 1987). At the middle grade level, climate appears to be the central theme that ties together middle school philosophies and strategies (Hoy \& Hannum, 1997; Lake, 1991).

From a systems perspective, the concepts of climate and leadership appear to be implicitly entwined. Leadership theorists have argued that a leader's assumptions and actions are primary determinants of the climate of an organization (see, for example, Graen \& Scandura, 1987; Kozlowski \& Doherty, 1989; McGregor, 1960). There is little evidence, however, of educational research that attempts to examine the relationship between leadership and climate in a school setting (Griffith, 1999). That which has been done has tended to focus on the site principal (see, for example, Griffith, 1999; Hoy \& 
Feldman 1987; Tarter \& Hoy, 1988). Conspicuously absent are attempts to examine the role of other leaders, such as teacher leaders and assistant principals, in establishing and maintaining school climate.

\section{The Concept of Organizational Climate}

Organizational psychologists interested in leadership and management have attempted to identify and describe the subtle yet profound effects that an organization's environment has on the attitudes and behaviors of its members. In almost all cases, they have termed this phenomenon organizational climate.

The concept of organizational climate can be traced to the works of Lewin and his associates in the 1950s and their attempts to develop a field theory of motivation within organizations (Litwin \& Stringer, 1968; Kozlowski \& Doherty, 1989). These early researchers regarded climate to be the key functional link between a person and his/her environment. The theory that evolved identified situational variables that could be measured to examine the effects of climate on an individual's motives and specific behaviors. Measurement of these determinants, conducted initially in clinical studies where the overall situation and the various inputs could be carefully controlled, proved to be difficult. Nevertheless, these efforts, along with estimates of expectancies made by field researchers, formed the foundation of the works of later human relations theorists such as Likert and McGregor (Litwin \& Stringer, 1968).

McGregor (1960) is cited frequently by later organizational theorists regarding climate. He noted in his discussion of climate that the term is used in widely disparate contexts, yet refers consistently to some feature or characteristic of an environment that has consequences for the behavior of an individual or group and to which the person or 
persons are somehow sensitive. He felt that changes in organizational climate lead to changes in the behavior of organization members when other variables remain constant. Nevertheless, McGregor did not attempt to provide a precise definition of the term. In addition, he did not examine the broader implications of climate with regard to individual and group behaviors within an organization despite the fact that he used the concept of a psychological climate to support his analysis of effective management.

Building on the work of McGregor, Likert (1967) conceptualized four systems of management that he believed resulted in distinctly different organizational climates. $\mathrm{He}$ advocated management that supports a climate characterized by supportive relationships, group decision-making, and high performance goals. Like McGregor, however, he made no attempt to clearly define the term climate.

Other theorists of the same period, such as Indik (1968), also believed that climate reflected a complex social system in which individuals, groups, and organizations exist. Indik (1968) felt that representation of the meaning of organizational features, events, and processes can be determined as a result of interactions between individuals within this system context and with each other. He argued that climate-related variables in turn constitute influences that create responses from individuals and small groups in organizations. Like other theorists, he believed that these variables could be measured and subsequently manipulated to influence organizational climate and thus member behaviors.

Subsequent to their own research and review of the work of earlier theorists, Litwin \& Stringer (1968) articulated a framework in which climate mediates the effects of organizational system factors on individual motivation and resultant behaviors. They 
viewed climate as a concept that describes the subjective nature or quality of the organizational environment whose properties can be perceived or experienced by members of the organization. To them, the term organizational climate refers to " a set of measurable properties of the work environment, perceived directly or indirectly by the people who live and work in this environment and assumed to influence their motivation and behavior" (p. 187). They identified structure, support and encouragement, emphasis on reward versus punishment, and high performance standards to be the dimensions or variables that most affect organizational climate positively. They held that these variables affect the relationship between the organizational context and individual and group responses, thus providing a basis for explaining and predicting member and group behaviors.

Tagiuri (1968), who was a contemporary of Likert, Litwin, and Indik, is cited often in recent climate studies, including many conducted in the field of education. Noting that climate concepts are often defined operationally, he stated a need to shift from an operational to a more formal definition of climate. Acknowledging that it is difficult to establish a general, formal definition that is not of limited utility because it encompasses too much, he attempted to delimit the concept by ascribing to it certain empirically established attributes. Working within a framework that included 14 such attributes that he readily acknowledged to be arbitrary, he suggested the following "crude" definition: "Climate is the relatively enduring quality of the total environment that (a) is experienced by the occupants, (b) influences their behavior, and (c) can be described in terms of a particular set of characteristics (or attributes) of the environment" (p. 25). 
As summarized by Kozlowski \& Doherty (1989), the framework developed by these organizational theorists regards the formation of climate perceptions to be an individual level process, but also assumes it to be interactive and reciprocal. Implicit within this concept is the notion that similar individuals are attracted to the same sort of settings, are socialized in similar ways, and share their interpretations of reality with others in the setting. This over time results in consensus on climate perceptions. These perceptions can in turn be aggregated to represent organizational climate constructs that become important determinants of motivation and behavior of individuals and subgroups within the organization.

\section{School Climate}

The effect of different variables within a school setting on student achievement and social and emotional development has been of interest to both scholars and practitioners for many years. Much of this interest has focused on the school workplace using the construct of school climate. As a result, researchers of educational organizations, teachers, administrators, and parents have often used the term when attempting to evaluate school effectiveness.

As is the case with the more general concept of organizational climate, there is little agreement, however, as to what specifically this conceptually complex and vague term means. School climate tends to be a global construct in school effectiveness literature that researchers often use loosely to group together studies of school environment, learning environment, learning climate, sense of community, leadership, academic climate, and social climate (Hoy \& Hannum, 1997). Indeed, it is not uncommon for the term to be used in a study without being defined at all (Benton \& 
Bulach, 1995). Thus, the definition and mearing of school climate remain elusive despite years of substantial empirical investigation (Anderson, 1982; Hoy, Tarter, \& Bliss, 1990).

Halpin and Croft (1963) were among the first to attempt such a definition when they defined school climate as the personality of the school, stating, "Personality is to the individual what climate is to the organization" (p. 1). Hoy and Hannum (1997) more recently characterized school climate as follows:

The organizational climate of a school is the set of internal characteristics that distinguishes one school from another and influences the behavior of its members. In more specific terms, school climate is the relatively stable property of the school environment that is experienced by participants, affects their behavior, and is based on their collective perceptions of behavior in schools. (p. 291)

In formulating this definition, Hoy and Hannum seem to have been influenced by earlier organizational theorists such as Tagiuri (1968) whose definition of organizational climate closely parallels their definition of school climate. Building on this concept, Dietrich and Bailey (1996) introduced more specific descriptors in their definition of school climate when they described it as "a comprehensive structure made up of a school's culture, physical plant, organizational structure, social relationships, and individual member behaviors" (p. 16).

The body of literature on school climate thus seems to support Freiberg's (1987) position that, "The climate of a school may be compared to the air we breathe. We ignore it until it becomes noticeably offensive" (p. 1). Freiberg (1998) nevertheless did not attempt a precise definition of the term, stating, "No single factor determines a school's climate. However, the interaction of various school climate factors can create a 
fabric of support that enables all members of the school community to teach and learn at optimum levels" (p. 22).

This wide range of climate descriptors supports Anderson's observation that 'the field of school climate research is in many ways reminiscent of the seven blind men who gave seven different descriptions of an elephant based on the one part each one could touch" (p. 376). The image tends to vary considerably depending on the environmental dimensions considered important to each researcher.

\section{Research on School Climate}

This difficulty in defining school climate appears to be in large part the result of the diversity of climate typologies that have evolved and the wide variety of approaches that researchers have used in developing holistic constructs of school environment (Anderson, 1982; Stockard \& Mayberry, 1992). Though researchers have generally based their work on the premise that schools are social organizations that provide a context in which students and staff interact, the differences in theory base guiding their work and the wide range of variables that they have studied have led to little consensus regarding the specific meaning of school climate and the variables that influence it.

Some researchers have used the insights of organizational psychologists and social psychologists to develop standardized measures to assess school climate (Stockard \& Mayberry, 1992). The background and training of those who have taken this approach have normally been in multivariate statistics and psychology or social psychology. This approach has utilized quantitative techniques and multivariate analyses to identify patterns of perceived behavior with the assumption that organizations are rational instruments to accomplish the shared purpose of participants. 
Other scholars have used qualitative and ethnographic strategies and methodologies of anthropology and sociology to examine the character or atmosphere of schools (Hoy \& Sabo, 1998). In so doing, they have focused on the organization as a whole and how its cultural elements function to maintain a social structure with the view that the climate of an organization is a natural outgrowth of a particular time and place.

Though there exists no clear consensus regarding these methodological issues, some agreement does appear to emerge from school climate research, regardless of the methodology used. This includes: (a) schools do possess something called climate that is unique to each site, (b) the variables, though discernible, are complex and difficult to describe and measure, and (c) climate affects student outcomes, including cognitive and affective behavior (Anderson, 1982; Freiberg, 1998; Griffith, 1999).

The problem for researchers who have accepted this holistic concept of school climate is how exactly to define and then measure its contributing variables. Most researchers cite Halpin and Croft (1963) as the first to attempt to do so. Utilizing the concept that organizations have their own personalities, these two early researchers developed a 64-item Likert-type item instrument, known as the Organizational Climate Descriptive Questionnaire (QCDQ), that teachers and principals used to describe the interaction patterns in elementary school settings. The instrument used perceptions of participants to define climate and employed quantitative methodologies to identify climate profiles that attempted to predict school effectiveness. Halpin (1966), after use of the QCDQ, concluded that schools vary in climate by stating "anyone who visits more than a few schools notes quickly how schools differ from one another in their feel" (p. 131). He added that "as one moves to other schools, one finds that each appears to 
have a personality of its own" (p. 131).

The work of Halpin and Croft (1963) served as a model for a great deal of subsequent research, such as that conducted by Hoy and his associates, that utilized quantitative techniques and multivariate analyses to identify patterns of perceived behavior in schools. In contrast to Halpin and Croft (1963), who conceptualized school climates as organizational personalities that existed along an open-to-closed continuum, Hoy and his associates analyzed school climate in the context of what they termed organizational health. Building on the work of Halpin and Croft (1963) and organizational theorists such as Miles (1969), they developed a revised OCDQ that is a 50 -item instrument with six dimensions that attempts to describe the behavior of teachers and principals within the conceptual framework of organizational climate. They concluded from their studies that school climate is a relatively stable quality of the school environment that is experienced by all participants, affects their behavior, and is based on their collective perceptions of behavior in their schools (Hoy \& Hannum, 1997; Hoy \& Sabo, 1998; Hoy, Tarter, \& Bliss, 1990; Tarter, Sabo, \& Hoy, 1995). Additionally, Hoy and Sabo (1998) concluded that "positive school climate is not only a potential means to improve schools, it is an important concept in its own right" (p. 2).

In contrast to these researchers who attempted to use quantitative measures grounded in the methodologies of organizational and social psychologists, many recent researchers and practitioners have taken a more global and heuristic approach to defining and measuring school climate. In so doing, they have focused more on social processes and cultural dimensions within the school setting. Using this qualitative approach in attempting to develop a description of the unique characteristics of schools as social 
organizations, they have attempted to identify the various components of school climate in order to allow practitioners to manage them with the goal of increased student achievement (Stockard \& Mayberry, 1992).

Many of these researchers have thus viewed school climate as both a means and an end. They have argued that a positive climate makes school a place in which both teachers and students want to be and also serves the pragmatic purpose of improving productivity toward important goals such as improved academic achievement (Fox, 1973). They have maintained that accurate evaluation of the factors affecting climate accompanied by effective management of those factors will have an effect on students and teachers alike that leads to improved attitudes and morale and more effective learning environments (Freiberg, 1998).

\section{School Climate Descriptors}

Though little agreement seems to exist among researchers as to the precise definition of school climate, there appears to be a general consensus, regardless of the methodologies employed to study the concept, that schools do possess something called climate that is unique to each organization and that it affects student outcomes, both cognitively and behaviorally (Anderson, 1982; Stockard \& Mayberry, 1992; Hoy, Hannum, \& Moran, 1998). As a result, most researchers have attempted to identify the variables that affect climate in order to investigate their influence on student academic achievement and social growth and development. From these studies, a wide range of independent variables emerges in the literature.

Halprin and Croft (1963) identified 64 variables grouped under eight dimensions of organizational life in their OCDQ. They divided the eight dimensions equally between 
what they called characteristics of the group (disengagement, hindrance, esprit, and intimacy) and characteristics of the principal as a leader (aloofness, production emphasis, thrust, and consideration). Using these variables, they attempted to measure the domain of the climates of elementary schools along a continuum of open to closed.

Working within the theoretical framework that the organizational climate of a school consists of a set of internal characteristics that distinguishes one school from another and influences the behavior of its members, Hoy and his associates developed a revised OCDQ built on the earlier work of Halprin and Croft (1963). Their revised version of the instrument focused on six variables divided between two domains that they labeled principal-teacher interactions (directive, restrictive, and supportive principal behaviors) and teacher-teacher interactions (collegial, committed, and disengaged teacher behaviors) (Hoy \& Sabo, 1998; Tarter, Sabo, \& Hoy, 1995). In identifying these variables, the researchers were influenced by Deming's (1983) principles of total quality management, particularly with regard to principal-teacher interactions.

In contrast to the quantitative methodologies employed by researchers such as Halpin, Croft, and Hoy, others have taken a more holistic and heuristic approach. They have attempted to identify factors that can be examined and managed utilizing qualitative methodologies. Anderson (1982), for example, in her review and analysis of school climate literature, identified 27 such "variables" grouped in four domains. The first domain is ecology variables that focus primarily on age and condition of school facilities. The second, milieu variables, stresses teacher and student morale. Her social system variables include the interpersonal relationships addressed by Halpin, Croft, and Hoy, but also include the academic program and institutional organization factors as well. The 
fourth and last domain, culture variables, addresses such things as expectations, cooperative relationships, and recognition.

The factors that Fox (1973) felt are critical to school climate are more succinct, but closely parallel those of Anderson. He suggested that school administrators look for at least eight factors in evaluating school climate: respect, trust, high morale, opportunities for input, continuous academic and social growth, cohesiveness, school renewal, and caring. He viewed a positive climate as one in which all members of the school community see themselves as persons of worth where students and teachers alike demonstrate respect for one another. He defined trust as confidence that others can be counted on to behave honestly and do what they say they will do. To him, a positive climate meant that members of the organization feel good about the school, feel a part of it, and have the opportunity to provide input in making important decisions. A strong academic program and continuous improvement projects school-wide are also vital according to Fox. Finally, he felt that every member of the school community needs to feel that others are concerned about him/her as a human being.

The work of Howard, Howell, and Brainerd (1987), which is cited often in recent research, included a list of climate variables that parallels closely those of Anderson and Fox. These were quality academic programs, respect between students and staff, trust, high morale, a sense of belonging, openness to change and improvement, caring among all members of the school community, clearly defined behavior with consistent rewards and discipline, opportunity for input, and clean, graffiti-free facilities that are in good repair.

Other researchers have tended to take a more global view of climate variables. 
Stockard and Mayberry (1992), for example, saw the factors affecting climate as involving four broad areas: academic expectations and excellence, strong and collaborative school leadership, orderly environments and school coherence, and high student and teacher morale. They referred to a large number of studies that demonstrate that schools in which both students and staff value academic excellence tend to have high levels of academic achievement. In their view, strong administrative leadership that balances high concern for task accomplishment with cohesive social relations is a critical dimension of effective school environments. They felt that an orderly environment promotes a positive climate in three ways: (a) it provides a setting within which student and teacher opportunity to conduct task-related work is maximized, (b) it promotes a sense of efficacy among teachers and students, and (c) it provides the consistency and stability that appear to promote higher achievement. Finally, they believed that school members' perceptions and attitudes about their environment affect attendance and achievement of both teachers and students.

Bulach and Malone (1994) developed a definition of school climate that incorporated similar variables but grouped them under two psychological and institutional attributes of organizations. The psychological attributes included collaboration, environment, openness, and trust. Order, leadership, involvement, instruction, and expectations comprised the list of institutional attributes. The variables used by Griffith (1999) in his study of the effect that a change in principals has on school climate paralleled closely those of Bulach and Malone (1994). His list included facilities, order and discipline, helpfulness of school staff, teacher-student relationships, academic instruction, and satisfaction. 
In some cases, the literature has focused on only one variable when attempting to define and evaluate school climate. The most common of these appears to reside within the overarching term, order and discipline. According to those who take this view, the image of a school that has a positive climate is one that is free of drugs, violence, and weapons. Within this construct, Borger, Lo, Oh, and Walberg (1985), after reviewing studies of school effectiveness from 1970 to 1983 , observed that the most consistently mentioned climate variable in 205 independent studies was a safe, orderly environment characterized by clear and consistent rules. Using data obtained from a nationally administered survey, Bernstein's (1992) study of school climate focused entirely on order and discipline. It considered only survey questions that addressed physical conflicts amongst students, robbery or theft, vandalism of school property, student use of drugs, student use of alcohol, student possession of weapons, physical abuse of teachers, and verbal abuse of teachers. This emphasis on order and discipline seems to be part of a common theme throughout the literature on climate. Kaplan and Evans (1997) summarized this situation by stating, "Only when teachers and students feel safe can learning occur. None of the culture-building activities could be strongly addressed without dealing directly and effectively with school safety" (p. 4).

Another variable that appears on lists throughout much of climate literature, that at times stands alone, is the physical environment of the school site. Those who have focused on this factor have held the view that material cleanliness and state of repair and modernization of school buildings are the key elements impacting school climate. This group has tended to be practitioners more than researchers who have relied on experience rather than systematically collected data to ground their conclusions. Welsh (1997) and 
Foster-Harrison (1997) are representative of school administrators who have argued that the physical condition of facilities is a critical indicator of school climate. Black (1997) shared this view but emphasized cleanliness in her focus on physical environment. She felt that "clean schools transmit values far different from dingy schools" (p. 32). To Brown (1984), vandalism of school buildings and property is a key indicator of underlying problems. His position was that human beings do not destroy that which is important in their lives. Thus, he felt it is important to look to the sociological implications of vandalism and their impact on overall climate. All of these observers have shared the common position that the physical appearance and state of repair of school facilities are critical variables that not only contribute directly to a school's climate, but also are also clear indicators of deeper underlying symptoms of other climate factors.

The concept of trust is a third variable, common throughout the literature, that has been considered important enough by many researchers to be examined alone. This was the case with Tarter, Sabo, and Hoy (1995) when they utilized a modified form of the OCDQ, adapted for middle schools, to conduct a study in 87 schools that examined trust effectiveness relationships and their effect on climate. They concluded from the study that an atmosphere of openness and professionalism that leads to trust and cooperation among teachers and school leadership is critical to promotion of effective schools. Similar results were obtained in a study conducted by Hoy, Tarter, and Bliss (1990) in 57 secondary schools involving 872 teachers. Again using a modified OCDQ, they concluded that schools with open climates that foster trust are desirable ends in outcome themselves. As such, they argued that trust is important even when unrelated to other 
variables.

\section{Middle School and School Climate}

The term middle school appears to mean different things to different people. Many think of a middle school as a building; others view it as nothing more than a particular grade configuration; while others advocate a unique educational philosophy for the grade levels between elementary and high school (Hoy \& Hannum, 1997). The view that middle schools are little more than junior high schools with a slightly different grade configuration does not appear to be supported by research.

Since the publication of $A$ Nation at Risk in 1983, many initiatives have been put into place to implement educational reform at all grade levels. Two influential reports, Caught in the Middle: Educational Reform for Young Adolescents in California Public Schools (Superintendent's Middle Grade Task Force, 1987) and Turning Points: Preparing American Youth for the $21^{\text {st }}$ Century (Task Force on Education of Young Adolescents, 1989), have focused on the middle level grades. Both called for radical change in the structure and practices of traditional junior high schools with increased emphasis on the unique needs of young adolescents in the middle years. This has led to middle level education practices such as inter-disciplinary team structures, a childcentered philosophy, heterogeneous groupings for most subjects, specialization of subjects, inter-disciplinary units, focus on a core curriculum, exploratory electives, teambased guidance and counseling, and teaching strategies designed specifically for young adolescents (Hoy \& Hannum, 1997; Hoy \& Sabo, 1998; Tarter, Sabo, \& Hoy, 1995).

As noted by Lake (1989), these strategies had their genesis in the junior high school movement that began over 100 years ago when Charles Eliot, president of Harvard 
University, advocated a change from eight years of elementary education followed by four years of secondary education to six years of each. This moved the middle grades of seven and eight to the secondary level where Eliot felt they more properly belonged. This vision was realized when, increasingly in the early $1900 \mathrm{~s}$, junior high schools began to develop, using the senior high school as their model. By the 1920s, however, dropout studies cited the need for a middle grade model that would more effectively facilitate the transition from elementary to secondary levels. Nevertheless, there was little change over the next 30 years despite the apparent need for continued reform.

This situation changed rapidly in the 1950s and 1960s with the middle school movement. Middle school advocates felt that the junior high model had failed because it imitated senior high school practices. They argued that middle grade adolescents are unique, with sharp differences in physical, social, emotional, and intellectual development from elementary and high school students (Maynard, 1986). Toepfer (1988), who is referenced frequently in middle school research, argued that the effectiveness of middle level schools depends upon the degree to which they respond to these developmental needs and characteristics. He maintained that a clear understanding of the unique needs of middle grade students is central to the structure of middle level programs, citing Donald Eichhorn's concept of transescence. Transescence describes the young adolescent stage of development that begins prior to the onset of puberty and extends through the early stages of adolescence. This period is characterized by dramatic physical, social, emotional, and intellectual changes and instability. Toepfer (1988) concluded that the middle school focus on transescent characteristics must be separate from both elementary and high schools, yet must be articulated with elementary and high 
school identities. Others, such as Brough (1990), noted that in addition to these innate personal problems of their age group, recent generations of young adolescents face many societal problems not present in the past. They argued that middle schools must also assist middle level students in dealing with these complex social issues.

Toepfer, Lounsbury, Arth, and Johnson (1986) argued that what is required in response to these unique characteristics of young adolescents are schools which accommodate early adolescent developmental needs in four essential ways: (a) flexible grouping, (b) student access to adult guidance, (c) a supportive and safe environment, and (d) staff with specialized knowledge and training. This position was supported by the Carnegie Foundation report, Turning Points: Preparing American Youth for the $21^{\text {st }}$ Century (Task Force on Education of Young Adolescents, 1989). This report made recommendations for middle school change based on eight essential principles, including smaller communities for learning, a core curriculum taught to all students, interdisciplinary team organization, more teacher and principal responsibility, specific middle grade teacher training, school promotion of health, family involvement, and school/community partnerships.

These have become the tenets of middle level practice and represent a high level of consensus among middle school theoreticians and practitioners as to what constitutes effective middle school principles and strategies. The central theme that seems to tie all of these middle school philosophies and strategies together is the concept of school climate. Plodzik and George (1989) maintained that a strong sense of community must exist amongst teachers and students in middle schools. Additionally, they noted the critical need for a strong academic program in the core curriculum that includes inter- 
disciplinary, thematic units with strong collaboration among team members. These are variables frequently identified in the literature on school climate. Maciver (1990) agreed with this position, noting that teachers must respond quickly, personally, and consistently to the needs of individual students. He emphasized the importance of the feeling of community within the school with close, coherent supervision and caring by adults.

This supportive environment seems to be no easier for middle school advocates to define than the general concept of school climate has been for other researchers and practitioners. Caught in the Middle (Superintendent's Middle Grade Task Force, 1987) attempted to describe school climate as "subtle but nevertheless definable realities that have the potential to affect student attitudes significantly about themselves, their educational values, and their academic achievement" (p. 81). Additionally, it stated that "every middle grade student should experience a positive school climate which reflects a strong, student-centered educational philosophy" (p. 80). Six characteristics of schools with supportive climates were cited by Caught in the Middle as having emerged from research conducted by the American Association of School Administrators:

(a) commitment to high academic standards, (b) strong belief on the part of teachers that they can make a difference, (c) knowledge on the part of all staff members regarding middle school philosophies, (d) acknowledgement of the effectiveness of positive reward systems, (e) commitment to high standards of personal and social behavior, and (f) commitment to common goals. The Quality Criteria developed as a result of Caught in the Middle by the Middle Grades Program Quality Review Task Force and the California State Department of Education (1989) added attitudinal or emotional issues, environment, and programs to the list of factors that influence school climate. The 
central tenet of all these philosophies is that all practice grows out of student needs and must be based on a positive school climate (Lake, 1991).

Middle school literature does contain reports of research that seem to validate the effectiveness of these concepts. Two years before Caught in the Middle appeared, George and Oldaker (1985) argued that when properly implemented, middle school principles were highly effective. Having studied 130 "exemplary" schoois, they discovered these schools overwhelmingly used middle school practices. Ninety percent used inter-disciplinary team organization, 93 percent had a home case advisor program, and 99 percent made ongoing efforts for personal development as well as academic achievement. Most administrators and teachers in these schools reported improvements in student behavior, academic achievement, attendance, self-esteem, and social development.

Lake (1989) cited a study conducted by Connors and Irvin which compared 93 middle level schools recognized in the 1987 National Secondary School Recognition Program with 154 randomly selected middle schools. The middle schools nationally recognized for their academic achievement and overall excellence were consistently further advanced in their implementation of middle school principles. This finding was supported by George and Shewey (1994) who cited numerous studies and extensive dissertation research conducted between 1984 and 1994. These studies indicated that schools in which middle school principles had been implemented were increasingly able to demonstrate positive outcomes in student academic achievement and personal development. They concluded that "the available evidence suggests that practitioners can, with confidence, continue to expect the implementation of middle schools to result 
in improved academic achievement, more positive personal development, and enhanced group citizenship for students involved" (p.116).

More recent research into student outcomes in relation to middle school implementation has supported this conclusion of George and Shewey (1994). This includes a six year study of 97 schools with 15,000 students and nearly 900 teachers in the state of Illinois conducted by Felner, Jackson, Kasak, Mulhall, Brand, and Flowers (1997). Results revealed that average student achievement scores in reading, mathematics, and language arts were significantly higher in schools with a high level of middle school principle implementation than in those with what the researchers classified as middle or low levels of implementation.

Based on this research, climate appears to be central to middle school philosophies and principles and its impact relatively significant. As stated by Hoy, Hannum, and Moran (1998), "Organizational climate of middle schools is important for student achievement" (p. 352). Middle schools seem to be a critical link between the self-contained setting of elementary schools and the departmentalization and specialization of high schools that is concerned with nearly all of the factors comprising school climate. As researchers and practitioners search for what makes a good middle school, it appears that they must, as stated by Hoy and Hannum (1997), "be concerned with such expressive outcomes as self-concept, creativity, and citizenship, as well as student achievement in basic skills and higher level cognitive activities" (p. 307).

\section{Leadership and Organizational Climate}

From a systems perspective, the concepts of climate and leadership appear to be implicitly entwined. The work of the human relations theorists discussed above has 
shaped current organizational theory in this regard. As a result of their research, they argued that a leader's assumptions and the processes that result from those assumptions are the primary determinants of the climate of an organization and, in turn, a basis for the social and motivational processes affecting individual behavior (Kozlowski \& Doherty, 1998). McGregor (1960), for example, maintained that,

The day-by-day behavior of the immediate superior and of other significant people in the managerial organization communicates something about their assumptions concerning management which is of fundamental significance. Many subtle behavioral manifestations of managerial attitude create what is often referred to as the psychological climate of the relationship. (p. 133-134) Likert (1967) agreed with this position when he argued that, The leadership and other processes of the organization must be such as to ensure a maximum probability that in all interactions and in al! relationships within the organization, each member, in the light of his [sic] background, values, desires, and expectations, will view the experience as supportive and one which builds and maintains his [sic] sense of personal worth and importance. (p. 47) Both of these theorists held that leadership processes affect variables such as trust, communication, recognition, and psychological closeness of superiors and subordinates, which in turn have direct influence on the formation and maintenance of climate perceptions.

In Evan's (1968) model, developed to describe how processes within an organization generate an organizational climate, he made executive decision making the key component influencing all outcomes. Evan (1968) felt that the decision making of 
organizational leaders has system-wide structural implications. He argued that the activities of top management have not only technical implications with regard to how outcomes are accomplished, but also result in development of norms designed to regulate the behavior of members. As such, these management decisions are central to the formulation of organizational climate.

Indik (1968) agreed with Evan's position that leadership plays a central role in development of climate, but suggested a more unit-specific focus on leadership processes in contrast to the organizational focus advocated by Evan and others. He argued that processes that characterize the interactions within the immediate organizational context have much closer links to member perceptions. In this model, the behaviors of immediate supervisors are likely to be salient features and to be interpreted as representative of organizational processes. According to Indik (1968), events taking place at higher levels are likely to be mediated by local leadership behaviors in view of the fact that an individual's immediate supervisor is the most tangible representative of management actions, policies, and procedures. Nevertheless, he still agreed that the nature of the actions of the leader provide the basis for members' climate perceptions.

In a classic study that is often referenced in organizational and leadership literature, Litwin and Stringer (1968) replicated the effects of leader behavioral styles on climate by creating three simulated organizations, each with a leader exhibiting a different leadership style. The study was designed to test the hypothesis that leadership style influences organizational climate and, in turn, the motivation and behavior of organizational members. This was a refinement of a classic study conducted by Lewin. Lippitt, and White (1939). The experiment was conducted over a two-week period 
comprising eight actual days of organizational life. Leadership style was varied with each distinct style expected to induce a different organizational climate. As a result of this study, Litwin and Stringer (1968) concluded that the most important and dramatic determinant of climate seemed to be the leadership style used by managers or by informal leaders. They maintained that the emphasis that a leader puts on adherence to rules, the kinds of goals and standards set, and, most important, the nature of his/her informal relationships and communications with organization members all have great impact on organizational climate.

Given this perspective, Graen and Scandura (1987) developed a model to describe vertical dyad linkage of leadership for integration with the climate framework. The lineage of the dyadic perspective on the leadership process that was hypothesized by this theory was consistent with the interactionist approach of theorists such as Indik, Litwin, and Stringer. The model described a sequence that consists of three phases: role taking, role making, and role routinization. In the course of this sequence, relations between leaders and members emerge from a series of dyadic interactions and exchanges that Graen and Scandura (1987) called the role-making process. As relationships form, the supervisor and subordinates negotiate and reach agreement on numerous aspects of their relationships. These aspects include such features as the degree of information sharing, the extent of subordinate influence in decisions, the degree of subordinate authority and autonomy, the amount of supervisor support, and the degree of concern and trust exhibited by the supervisor. The key variable in the role-making process, negotiating latitude, represents the nature and quality of the relationships that develop through these interactions. Graen and Scandura (1987) argued that in order to reach the point of role 
routinization in which the behaviors of superior and members become interlocked, a climate must be established by superiors in which they exchange positional and personal resources such as information sharing, shared decision making, task design, recognition, and personal concern and support for subordinates.

Building on the work of Graen and Scandura (1987), Kozlowski and Doherty (1989) conducted a study that focused on the principal process variable, negotiating latitude, with the hypothesis that high quality leader-member interactions for negotiating latitude would result in more positive perceptions of climate. Their research was conducted in a Fortune 500 manufacturing organization, utilizing surveys of supervisors and subordinates. They concluded that the results of the study were consistent with the theoretical model that integrates climate and leadership processes. They interpreted their findings to imply that the nature of interactions between leaders and their subordinates serves to mediate and structure subordinate interpretations of relevant organizational features, events, and processes (Kozlowski and Doherty, 1989).

As a result of his study of organizational culture and leadership, Schein (1992) articulated even stronger views regarding the effects of leadership on climate. Working within the framework that climate is a major component of what he labeled culture. he maintained that "dynamic processes of culture creation and management are the essence of leadership and make one realize that leadership and culture are two sides of the same coin," adding, "I believe that cultures begin with leaders who impose their own values and assumptions on a group" (p.1). He argued that if the group is successful and assumptions come to be taken for granted, the culture begins to define what types of leadership are acceptable. In other words, the culture starts to define the leader. He 
maintained, however, that if the group's survival is threatened because elements of its culture have become maladapted, it is ultimately the function of leadership to recognize this situation and take action to correct it. He felt that within this context, leadership and culture are conceptually intertwined. He used this framework to conclude. "If one wishes to distinguish leadership from management or administration, one can argue that leaders create and change cultures, while managers and administrators live within them" (p. 2).

These arguments paralleled closely those of Heifetz (1994) who maintained that in well-established organizations, a leader might play primarily a symbolic role as the embodiment of cultural norms. Though he referred to these norms as culture rather than organizational climate, he defined his concept of culture in the same manner as other organizational theorists define climate. He held that during long periods of stability, the role of the leader in organizational culture may even seem to vanish, but never disappears entirely. Heifetz agreed with Schein (1992) that when a disparity exists between the values of the organization and circumstances that it faces, it is the responsibility of the leader to bring about adaptive change that closes the gap between the environment and the norms and values of the climate in which the organization operates.

Other recent leadership researchers and theorists, such as Bennis (1997), have supported these positions. Though Bennis did not use the term climate, he placed great emphasis on the role of an organizational leader in empowering members in the transformational sense articulated by Burns (1978). This, to Bennis, requires leadership that establishes an environment in which people feel significant, where learning and competence matter, where members function as a team with unity, where there is trust among members, and where people want to be. All of these traits have been included in 
lists of variables formulated by many other organizational theorists in order to evaluate climate. Bennis (1997) summarized his position regarding the relationship between leadership and climate when he stated, "If I have learned anything from my research, it is this: The factor that empowers the workforce and ultimately determines which organizations succeed or fail is the leadership of those organizations" (p. 81).

\section{Leadership and School Climate}

Despite the fact that the concepts of leadership and organizational climate are intertwined throughout organizational and leadership literature, there is little evidence of educational research that attempts to relate the concepts of school leadership and school climate (Griffith, 1999). Extensive research has been conducted in attempts to identify effective school leadership practices focusing on such things as instruction, resource allocation, interpersonal relations, vision, and goal setting. The few empirical studies that have examined the conceptual linkages between school leadership and climate have tended to focus on single dimensions of climate such as trust.

In one such study, Hoy and Feldman (1987) attempted to evaluate the influence that organizational climate of schools has on school effectiveness within the conceptual framework of school health. In their study, they identified seven dimensions of school health: institutional integrity, principal influence, consideration, initiating structure, source support, morale, and academic emphasis. Within this framework, the influence that a principal has on school climate variables was examined directly and indirectly in the following ways: (a) the degree of influence the principal has in maintaining an environment that protects the educational integrity of the school's program, (b) the effect that principal behavior has on the welfare of teachers, (c) the role of the principal in 
maintaining high teacher morale, and (d) the degree of principal involvement in establishing high academic goals. Academic emphasis is the only one of these variables that has been identified often in other studies as a key indicator of school climate. The other three dimensions appear, however, to indirectly affect school climate and provide a context for evaluating leader influence on climate variables such as trust. As a result of their study, Hoy and Feldman (1987) concluded that the leadership and support of a principal are key elements of climate in that they strongly influence teacher welfare, program integrity, teacher morale, and academic expectations.

At about the same time that Hoy and Feldman (1987) were examining the principal's role in establishing school climate in the conceptual context of organizational health, Tarter and Hoy (1988) conducted a study to examine the effect of principal behaviors on the key climate variable of trust. The empirical phase of their investigation was guided in part by the following hypotheses: (a) each aspect of school health is positively related to faculty trust in the principal; (b) the greater the general state of school health, the greater is faculty trust in the principal; and (c) principal influence, support, consideration, and concern for teacher welfare are the best predictors of faculty trust in the principal. They concluded from their results that most aspects of a school's organizational health are related in predictable ways to faculty trust in the principal. They argued that the principal who is friendly, supportive, open, and collegial in interactions with teachers is able to command respect and trust from teachers. In addition, they found that morale, including principal influence in this area, and the ability of the principal to maintain the integrity of the school's program against outside forces combine to provide the most influence on faculty trust in colleagues. Tarter and Hoy 
(1988) concluded from their study, "We suspect that the effective principals are not only intellectual leaders in their schools, but are also colleagues who serve and support. They build confidence and trust" (p. 23).

Tarter and Hoy worked together on a subsequent study, this time with Kottkamp (1990), to attempt to measure the correlation between school health and teacher commitment. They defined organizational commitment as a member's identification with an organization that is characterized by a belief in and acceptance of the organization's goals and values along with a willingness to exert substantial effort on behalf of the organization. Thus, commitment is defined in terms of member attitude and represents not just loyalty and compliance, but rather complete support of organizational ventures and values. As with previous studies, this research did not address climate variables directly but incorporated the concept of climate in the definition of school health employed in the study. Tarter, Hoy, and Kottkamp (1990) concluded from their results that the principal is a major contributor to the commitment of teachers as well as the general interaction patterns of a faculty. They maintained, "There is little doubt that the leadership of the principal also is important in developing teacher commitment to the school" (p. 240). They argued that the principal's influence on climate variables such as trust, the academic program, and an environment that fosters high morale makes significant and unique contributions to teacher commitment. They concluded, "The principal who can improve the setting of the classroom by influencing the larger social system earns the commitment of the teachers" (p. 241).

A similar study conducted by Hoy, Tarter, and Witkoskie (1992) tested the relationship between supportive leadership and a climate of trust and perceived school 
effectiveness. Once again, Hoy and his associates concluded that supportive leadership, defined as behavior that reflects a concern for teachers, has a direct relationship to school effectiveness and faculty trust in the principal. Building on this and previous studies, Tarter, Sabo, and Hoy (1995) focused on middle schools in an attempt to evaluate the degree that climate affects faculty trust and school effectiveness. Three questions guided their inquiry: (a) what is the path that links principal behavior with middle school effectiveness, (b) how does the leadership of principals promote trust and effectiveness in middle schools, and (c) how do aspects of trust influence middle school effectiveness? Using a revised form of Halpin and Croft's (1963) Organizational Climate Description Questionnaire, they obtained results that they felt supported the hypothesis that effective school principals are actively engaged in the organizational life of a school and support the faculty. They concluded that what is important to effectiveness in middle schools is a culture of trust where teachers have confidence in the ability of the principal to establish and maintain a climate that is supportive, is an orderly learning environment, and is characterized by high achievement goals.

Griffith (1999) was one of the few researchers to attempt to evaluate directly the relationship between school leadership and climate. Using frequently identified climate variables such as order and discipline, facilities, academic program, and trust, he examined the influence that a change in principals appeared to have on the major dimensions of climate. He concluded from his results that effective principal leadership has a major impact on school climate by influencing student performance indirectly through high goals and expectations, promoting a positive and orderly learning environment, efficiently allocating resources, and facilitating communications throughout 
the community to build trust.

As was the case in all of these studies, the literature on school leadership tends to focus exclusively on the influence of the school principal. Conspicuously absent is any reference to studies that have examined the assistant principal's role with regard to school climate in any comprehensive way. Greenfield (1985), for example, concluded the following from his review of existing research on assistant principals: "Neither educators nor others have questioned or systematically examined the role of the assistant vis-à-vis supervising and managing instruction and maintaining or developing organizational and personnel processes, structures, and activities associated with organizational stability, morale, and productivity" (p. 7). As a result, he called for the conduct of in-depth case studies of assistant principals paralleling the approach taken by Wolcott (1973) in his case study of a school principal, The Man in the Principal's Office. To date, that call has not been answered. Research that has been conducted on the role of assistant principals has tended to address such factors as the relationship between job satisfaction and career stability of assistant principals. No evidence of in-depth case studies that attempt to directly correlate assistant principal behaviors with school climate could be found.

\section{Summary}

Organizational climate is a general concept used by organizational and social psychologists and researchers from other fields who have attempted to identify and describe the effects that an organization's environment has on the attitudes and behaviors of its members. Climate can be both a descriptive and an evaluative term that is based on perceptions of members of an organization. It arises from organizational practices and influences members' attitudes and behaviors. 
Within this context of organizational climate, researchers and practitioners have for years been interested in the relationship between school climate and student achievement and social and emotional development. Because school climate has been studied using a wide range of variables and methodologies, a clearly defined body of research has not emerged. As a result, definitions of school climate in the literature vary greatly and are based often on anecdotal rather than empirical evidence. Nevertheless, a consensus emerges that school climate is a relatively distinct property of a school's environment that distinguishes one school from another and influences the behaviors of its members. A number of dimensions of this property that appear to be significant factors influencing climate recur throughout the literature. These include order and discipline, trust, a strong academic program, and condition of facilities.

Climate would appear to be particularly important in the middle school setting. Middle schools provide a critical link between the self-contained setting of elementary schools and the departmentalization of high schools during a period when early adolescents are going through immense physical and emotional changes. A climate that provides a safe and supportive environment in which middle school students can not only advance academically but also develop socially and emotionally appears central to the middle school philosophy and critical to its strategies and methodologies.

Leadership and climate are intertwined throughout the literature. Organizational and leadership theorists alike hold that a leader's assumptions and behaviors are significant, if not primary, determinants of an organization's culture and climate. Though few studies can be found that address directly the correlation between leadership and climate in the school setting, a body of research exists that examines the relationship 
between principal behaviors and variables that are implicitly related to climate dimensions. What emerges from these studies is a consensus that a principal's behaviors have a profound impact on the climate of his/her school.

Past studies have focused on the role of principals when studying the relationship between leadership and variables that influence school climate. Nothing could be found in the literature that addresses the relationship between middle school assistant principal behaviors and middle school climate despite the fact that the assistant principal is exceeded in positional authority by only the principal at a school site. Accordingly, it would appear that a need exists to examine the correlation between a middle school assistant principal's leadership and school climate by studying the influence that a middie school assistant principal's attitudes and behaviors have on the four school climate variables that emerged from this literature review. 


\section{CHAPTER III}

\section{RESEARCH DESIGN AND METHODOLOGY}

\section{Research Design}

This study was a qualitative case study that examined the relationship between a middle school assistant principal's leadership and the organizational climate within his school. Yin (1984) defined a case study as an "empirical inquiry that investigates a contemporary phenomenon within its real life context when the boundaries between the phenomenon and context are not clearly evident and in which multiple sources of evidence are used" (p. 23). He argued that the case study is the preferred research strategy when the investigator has little control over events and when "how" and "why" questions are the focus of the study. Patton (1987) built on this position of Yin (1984) when he stated,

Case studies become particularly useful where one needs to understand some particular problem or situation in great depth, and where one can identify cases rich in information-rich in the sense that a great deal can be learned from a few exemplars of the phenomenon in question. (p. 19)

Because educational research has normally focused on such complex, information-rich problems and situations in the real life context of the educational setting, case studies, particularly qualitative ones, have been used extensively throughout the field of education for nearly 30 years to examine educational processes and problems in attempts to affect and improve practice (Merriam, 1998). Case studies in education provide the thick description and experiential perspective that are critical to qualitative research. They are holistic and lifelike and therefore present a clear picture of the actual 
participants and their behaviors in their natural setting. Because they can be structured in such a manner as to focus on the purpose of the study without attention to excessive technical detail, essential information can be presented to the intended audience. Finally, and most importantly, the case study uses the language of intended audiences, thereby building on their "tacit knowledge" in a manner appropriate to the understanding and language of the readers (Guba \& Lincoln, 1981).

The intent of this study was to examine the assumptions and hehaviors of a middle school assistant principal. Though other members of the school organization were interviewed, the focus was on his leadership with regard to its effect on his school's climate. The research was thus bounded around the single entity of the assistant principal, thereby suggesting the appropriateness of a case study design. In addition, I sought to understand how and why the assistant principal's actions and beliefs affected his school's climate in the complex social setting of the school's organization and, in turn, provide a thick, rich description of the findings in the language of intended readers. Since all of these considerations are elements of a case study, I chose a case study design for this research.

\section{Methodology}

I chose to conduct a qualitative inquiry in this study. Glesne (1999) describes a qualitative study as one that "focuses on in-depth, long-term interaction with relevant people in one or several sites" (p. 5). In such an inquiry, the researcher is the main research instrument, employing mostly the techniques of participant observation and indepth interviewing to gather data. Because this necessitates the researcher to frequent the site where the participants in the study are located and events of interest naturally occur, 
qualitative research is often referred to as naturalistic (Bogdan \& Biklen, 1998).

The objective of the qualitative study is to understand the phenomenon of interest from the ernic, or insider's perspective, rather that the etic, or outsider's view (Merriam, 1998). Lincoln and Guba (1981) argued that to do this, the researcher must possess qualities that are uniquely human. These include:

The capacity to be responsive, to be flexible, to see social organizations as holistic entities rather than as components, to rely on both prepositional and tacit knowledge, and to search for that which is expert, which is atypical, idiosyncratic, unique, singular, or uncharacteristic of the mainstream. (p. 151)

These qualities allow the researcher to provide detailed information that is richly descriptive of the meaning participants have constructed of their world within the context of their organizational environment in order to convey what was learned about the topic of interest (Bogdan \& Biklen, 1998; Merriam, 1998; Patton, 1990).

In the educational setting, realities are socially constructed and context-related. The naturalistic inquiry is thus preferable for behavioral studies conducted in the field of education in that it seeks to understand in detail how such people as teachers, administrators, and students think and have developed the perspectives that they hold (Bogdan \& Biklen, 1998; Lincoln \& Guba, 1981). Organizational and leadership theory argues that the relationship between leadership and organizational climate is also socially constructed, context-related, and interactive, thereby suggesting a match between the naturalistic methodology and investigations of leadership and climate. Since this study sought to describe the relationship between the leadership of an assistant principal and organizational climate in an educational setting, a qualitative, or naturalistic, inquiry was 
the appropriate methodology to use.

\section{Theoretical Assumptions}

Many advocates of qualitative research argue that an inductive strategy is critical to the qualitative approach in which the emic, or insider's perspective, is used to build abstractions, concepts, or theories rather than starting from existing theory (Merriam, 1998; Rubin \& Rubin, 1995). Nevertheless, two theories that emerged from the literature guided this study in its investigation of the attitudes and orientation of insiders in a school organization regarding the effect that the school's assistant principal's actions and behaviors had on the school's organizational climate.

The first theoretical assumption with which I entered the study was that a unique climate existed at the school I intended to study that could be described utilizing qualitative strategies. Organizational theory supported this assumption in that it argues that every organization has a distinct climate that affects the attitudes and behaviors of organizational members (Indik, 1968; Likert, 1967; McGregor, 1960).

The second theoretical assumption was that leadership and climate are intertwined. This position, argued by theorists such as Evan (1968) and Schein (1992), guided the study in its attempt to address the central question of how the assistant principal's assumptions and actions influenced his school's climate.

Existing literature and personal experience as an assistant principal in an innercity middle school for one year and a suburban middle school for two years led me to conclude that it was reasonable to use these two assumptions to guide the study. In addition, evidence gathered in a pilot project that tested these assumptions supported my intention to use them to guide data collection and analysis. 


\section{Conceptual Framework}

The concept that emerged from the literature-that school climate can be examined using the four climate descriptors: order and discipline, academic program, trust, and facilities-was used to frame the study. Organizational members' attitudes regarding these four factors and members' perceptions of how the assistant principal's actions affected the four climate indicators guided the data collection and analysis processes.

Observations and document and artifact reviews were also framed by the concept that school climate can be evaluated using the descriptors order and discipline, academic program, trust, and facilities.

\section{Research Setting}

This study was conducted at Valley Middle School (a pseudonym), a sixth through eighth grade middle school located in an urban setting in Southern California. The school had a student population of 1,150 students, 78 percent of whom qualified for free or reduced lunch based on low family income. Fifty-three percent of the students were ethnic minorities. A large segment of the school's population spoke English as a second language with 17 different languages represented on campus. Eighty-six special education students were accommodated in self-contained classrooms because they were unable to function in a regular classroom setting. An additional 76 students received special education services while being mainstreamed on the regular campus.

Based on the annual academic performance index (API) that the state of California uses to evaluate all state schools, such a school is normally classified as under achieving by the California Department of Education because of low overall student academic performance. In addition, attendance rates are low and transience rates are high 
in similar schools as recorded in state-mandated reports. Discipline statistics and crime reports routinely indicate that discipline problems exist in such schools with low income, high minority student populations.

Valley Middle School was an exception to this stereotype. Its suspension and expulsion statistics were among the lowest for all middle schools in its district. Its average daily attendance rate was 97 percent despite the large incidence of transience within its community. The school's API since the beginning of the rating system placed it in the same range as schools with far more affluent communities and in the top five percent of schools with similar student populations. It conducted a character education program that had gained attention nation-wide and was used as a model for its school district. The school had been recognized as a California Distinguished School and Blue Ribbon School. As a model visitation site for its county, it was visited nearly every week by educators from throughout the state of California and from states throughout the United States.

I selected this school because of this large number of indicators that the site was meeting the needs of its students despite the many challenges that its student population presented. It appeared to provide a setting rich in opportunity to observe effective practices affecting school climate. Since research in education indicates the importance of climate to such success in a middle school (Anderson, 1982; Hoy \& Hannum, 1997; Plodzik \& George, 1989), I assumed that this site would provide an example of positive school climate that could be examined within the conceptual framework of the study while remaining open to the possibility that data collection and analysis might prove this assumption invalid. 
The reason that I was careful to select a school with a reputation for having a positive climate was because the purpose of the study was to examine how a middle school assistant principal contributes to the establishment and maintenance of positive school climate. Though much could have been gained from an examination of the role of school leadership in creating a negative climate, I had a greater interest as both a practitioner and researcher in investigating the factors that foster positive climate in middle schools. Since the literature indicated that climate and leadership are intertwined (Evan, 1968; McGregor, 1960; Schien, 1992), I felt it reasonable to expect to find evidence that the attitudes and behaviors of the assistant principal contributed to the school's positive climate, if indeed such a climate existed.

Since the study focused on the role of the assistant principal with regard to climate, it was critical to the study that the subject had adequate longevity in his position. This was another reason for the selection of this particular site. At the beginning of the study, the assistant principal had been in his position for over eight years. Prior to his arrival, the school had for years been underachieving academically based on district and state assessments. In addition, it had a reputation in its community for poor discipline that was supported by indicators such as suspension and expulsion statistics. It had been during the eight years of the assistant principal's tenure that this pattern had been reversed. This provided the opportunity to investigate the role that this individual played in this transformation and the impact that his actions had on establishing and subsequently maintaining the positive climate that appeared to exist at this site.

\section{$\underline{\text { Researcher Role }}$}

This study was a qualitative case study in education. The primary data collection 
strategies of such a study are in-depth interviews and participant observation (Bogdan \& Biklen, 1998; Glesne, 1999; Merriam, 1998). Thus, I was the primary data collection instrument. I played the role of interviewer (Bogdan \& Biklen, 1998; Rubin \& Rubin, 1995), focusing on the assistant principal, but also investigating perceptions of the assistant principal's influence on school climate held by teachers, other administrators, and key classified staff.

To explore the climate in the classrooms and common areas of the school within the framework of the four climate descriptors, I also functioned as an observer as participant (Glesne, 1999; Merriam, 1998; Patton, 1990). In addition, I operated in the observer as participant role extensively in observations of the assistant principal that were conducted to support findings as they emerged from interviews.

Finally, I examined documents and artifacts. This was done for purposes of triangulation to corroborate findings from observations and interviews and as independent sources of data to evaluate the school's climate. In addition, data obtained from document and artifact reviews were also used to shape new directions for ongoing observations and interviews.

\section{$\underline{\text { Respondents }}$}

The primary respondent in this study was the school's assistant principal who had spent his entire 30-year career in the school district. At the time of our first interview, he was in his ninth year in his position at Valley Middle School. Prior to coming to Valley, he had been assistant principal at another middle school for two years after serving in the same position at an elementary school for two years. Before entering administration, he had been a special education teacher his entire career, most of which had been spent 
working with emotionally disturbed and behavior disordered students at Valley Middle School. At this point, he considered himself a career assistant principal and stated emphatically that he had no intention of seeking any other position prior to his intended retirement date three years later.

The assistant principal and principal had been brought to Valley Middle School eight years before the study with a mandate from their district superintendent to change the reputation that the school had developed for low academic achievement and poor student discipline. Since that time, the school had become known within its district, county, and state for high academic achievement, a positive school climate, and an orderly campus. This occurred despite a dramatic change in the student population over the same period of time from a relatively homogeneous, high socio-economic student body to a low income, mostly minority group of students. Because the assistant principal had been given substantial credit within his school and district for contributing to this transformation, I chose him to be the focus of this investigation.

In order to increase confidence in findings from interviews and observations of the assistant principal, I interviewed other members of the site's management team. These included the principal, one of two counselors, and the Title I and bilingual programs facilitator who became a half-time assistant principal during the course of the study.

The principal of the school had a long professional history with the assistant principal. She had brought him to her previous school to replace an assistant principal who had been released from his assignment because of poor performance. After two years of working together, the two of them had been sent as a team to Valley to make the 
changes that the district felt were needed. At the beginning of the study, they had worked together for nearly ten years. Thus, the principal was able to provide opinions and observations that were based on a close, long-term professional relationship.

Nine months into the study, this principal was promoted to a district level position, and the site was assigned a new principal. At the time of this change, $I$ intended to interview the new principal in order to compare and contrast his perceptions regarding the assistant principal to those of his predecessor. As the data collection phase neared completion, however, it became apparent that the new principal's limited experience with the veteran assistant principal was insufficient to provide useful information. Accordingly, I reversed the decision to interview him.

The school had two guidance counselors who worked closely with the assistant principal on a daily basis. One had been in her position for six years after being a district school board member for four years. Prior to becoming a board member, she had been a classroom teacher at Valley for 18 years. During a significant part of her time in the classroom, she had worked with the assistant principal as a peer when he was a special education teacher at the site. The second counselor was new to the school, having transferred from another district middle school the year before. Because of the long-term relationship between the counselor who had been at the school for 24 years and the assistant principal, I felt she would be a rich source of information and thus chose to interview her as the representative of the counseling department. In view of the short tenure of the second counselor in her position, I elected not to include her in the interviews.

The final member of the management team at this school was the Title I program 
facilitator and bilingual program coordinator. When the study began, she taught half time and devoted the remainder of her day to her facilitator and coordinator duties. Her interaction with the assistant principal was significant in the course of carrying out her responsibilities for these two categorical programs. Shortly after the research began, she was taken out of the classroom and made a half time assistant principal along with her half time position as Title I program facilitator and bilingual program coordinator. As the study progressed, observations and interviews indicated that, in reality, she continued to devote nearly all of her time to the Title I and bilingual programs and was an assistant principal in name only. The only duties she had that fell under the official responsibilities of an assistant principal were to assist in lunch duty and after school supervision of students crossing the street at a busy intersection near the school. Nevertheless, her new title of half time assistant principal put her in even more contact with the full time assistant principal. In addition, what emerged from ongoing research was the fact that she was deeply involved with the academic program in her role as Title I program facilitator and bilingual program coordinator. In that capacity, she worked closely with the principal on initiatives to improve student achievement. In view of this close association with the subject of the study and since academic program was one of the four school climate indicators used to frame the study, I included her in the interview schedule.

Past studies have indicated that teacher attitudes and behaviors play a significant interactive role in shaping school climate (Halpin \& Croft, 1963; Hoy \& Sabo, 1998). Thus, teacher attitudes were critical to the study in that teachers arguably comprise the organizational subgroup whose attitudes and behaviors are most influenced by climate 
factors on a long-term basis in a school setting. Since the inter-disciplinary team leaders were the teacher representatives who worked most closely with the assistant principal regarding student issues, I interviewed one team leader from the seventh grade level and one from the eighth grade level. I assumed that, as teacher leaders, their attitudes and perceptions would reflect the assumptions and orientations of teachers school-wide regarding the school's climate and the assistant principal's influence on it. In addition, I interviewed two teachers who were not on inter-disciplinary teams. One was a veteran elective class teacher who was a mentor teacher for the district and was considered by all members of the management team to be a leader and role model on the staff. The second was a seventh grade teacher who had a group of students all day in his classroom who were placed with him because of their inability to meet the school's behavior expectations in a regular classroom. I was careful to select, in each case, teachers who appeared to be leaders on the campus who had worked with the assistant principal for the entire time that he had been at the school.

Equally important to a fuller understanding of the assistant principal's role with regard to climate were the attitudes and perceptions of classified employees. Accordingly, I interviewed the office manager, the in-school suspension aide, and the clerk-typist responsible for work orders. Since all of these support personnel worked closely with the assistant principal, they were sources of rich data that significantly enhanced the findings of the study.

Students were not included in the interview process. Though the information to be gained from student interviews would have been of value, it was not practical to interview a large enough sampling of the 1,150 students on campus to ensure that the 
attitudes of those interviewed would be indicative of student perceptions campus-wide. Student attitudes and behaviors are in large part the result of school climate (Anderson. 1982; Hoy, Hannum, \& Moran, 1998; Stockard \& Mayberry, 1992). Thus, I felt that I would be able to support the findings that emerged from interviews with staff members through the series of observations of student attitudes and behaviors conducted in classrooms and common areas of the campus throughout the course of the study.

\section{Data Collection}

Data were collected from three sources: (a) interviews with the site assistant principal, management team, teacher representatives, and key classified staff; (b) observations of the assistant principal throughout his workday and in various meetings; and (c) school and district documents and artifacts.

\section{Interviews}

According to Patton (1990), the purpose of interviewing is "to find out what is in and on someone else's mind" (p. 278). This he felt allows the interviewer to "enter the other person's perspective" (Patton, 1987, p. 109). In this fashion, I used interviews in order to gain insights into the respondents' attitudes and perceptions about their school's climate and the assistant principal's role with regard to it. My interview questions were mostly open-ended because, as argued by Patton (1987), "The truly open-ended question permits the persons being interviewed to take whatever direction and use whatever words they want" (p. 123). This strategy allowed the people whom I interviewed to express their thoughts freely, from their own frames of reference, and in their own language (Bogdan \& Biklen, 1998; Rubin \& Rubin, 1995). Open-ended questioning thus permitted me to "understand the world as seen by the respondents" (Patton, 1990, p. 24). 
Interviews were initially informal and unstructured. They were conversational in nature, consisting of grand tour questions designed to establish rapport and patterns on which to base subsequent interviews. Grand tour questions ask the respondent to take the interviewer through a place, time period, or sequence of events (Glesne, 1999; Spradley, 1979). In addition, they are particularly useful in the initial investigation of how respondents use unique terms and expressions (Rubin \& Rubin, 1995). For example, the initial grand tour question that I asked the assistant principal was, "Could you describe your typical day here at Valley Middle School?"

As the study progressed and themes and categories began to emerge, interviews became slightly more structured to include mini-tour questions. This strategy mirrors that of the grand tour question with the exception that it is more focused on specific events and shorter time frames (Spradley, 1979). For example, a mini-tour question that I asked of the assistant principal as the study progressed was, "Could you take me through your steps for dealing with a student referral from a teacher?"

In the latter stages of the study, more focused interview techniques, such as example questions (Patton. 1990; Spradley, 1979), were used. Such a question asked of the assistant principal was, "Could you give me an example of a parent complaint that you have received recently?" Opinion questions (Glesne, 1999; Patton, 1990) were another example of questioning used at this stage, such as, "What do you think the role of the inter-disciplinary team is in support of school-wide discipline?"

In all cases, more structured questions were used only for clarification and when topics that had been identified by data analysis of previous interviews and observations did not emerge spontaneously. At no time were highly structured questions utilized. 
Instead, questions remained open-ended as much as possible in order to minimize the imposition of predetermined responses from respondents (Glesne, 1998; Patton, 1990; Rubin \& Rubin, 1995).

Six interviews were conducted with the assistant principal. All took place in his office after school hours because it became clear early in the study that the only time he was available without interruption for more that a few minutes at a time was after students and staff had left the campus for the day. Although interviews were scheduled based on the convenience of the assistant principal, I knew from experience as a school administrator that the environment of a school varies significantly throughout the course of a school year. Accordingly, I was careful to conduct interviews during windows of opportunity at different points throughout the academic year to detect any changes in the assistant principal's attitudes and behaviors as the year progressed. In addition, I conducted at least one observation between each assistant principal interview in an effort to corroborate what had emerged from previous interviews and to allow new areas of interest to emerge for investigation in subsequent ones.

Two interviews were conducted with the principal on site at the beginning of the study who had been at the school with the assistant principal for eight years. Both took place in her office after school. The second interview was a follow-up to further investigate themes that emerged from the initial session. The principal was open and willing to talk about her school and her perceptions regarding its climate. She was also extremely candid with regard to her evaluations of the assistant principal's relationship to that climate.

Two interviews were conducted with the guidance counselor. Both were in her 
office after school. Because of her long-term, close professional association with the assistant principal, she was able to provide insight not only about his current role with regard to the school's climate, but also a great deal of historical perspective regarding his attitudes and behaviors.

The Title I program facilitator and bilingual program coordinator was interviewed in her office after school. In carrying out her wide range of responsibilities in these two positions, she had gained a knowledge and perspective regarding the school's academic program that was possessed by no one else on the campus, except perhaps the principal. As a result, she was able to provide valuable data regarding the school's academic program that was unavailable from other subjects. In addition, her close association with the assistant principal made her a rich source of data regarding his attitudes and behaviors as observed by her on a day-to-day basis.

Two teachers were interviewed after school. Two others were interviewed during regular school hours during their plan periods. All interviews took place in each teacher's respective classroom. Each of the four was open and readily willing to discuss all aspects of their school's climate. All four readily shared their opinions regarding the assistant principal's attitudes and behaviors, including perceptions that were not all positive.

In order to investigate the attitudes and perceptions of classified staff members, I interviewed the school office manager, the clerk-typist in charge of work orders, and the in-school suspension aide. All were very willing to discuss their school and administrators and, in turn, provided valuable insight from the non-credentialed staff's perspective. 
All interviews were tape-recorded. I transcribed each interview as soon as possible after the event while the context of the conversation was still clear in my mind. This served as the first step of analysis, supported research journal entries, and helped to identify areas of inquiry for future interviews.

\section{Observations}

Observations of the assistant principal were conducted in which I functioned as an observer as participant. In this role, I was primarily an observer, but had some interaction with study participants (Bogdan \& Biklen, 1998; Glesne, 1999; Patton, 1990). The purpose of the observations was to corroborate what respondents said in interviews and to identify new themes to be investigated in future interviews. In addition, the observations helped me to understand more fully the role of the assistant principal with regard to the school's climate. They provided insights that led to a clearer understanding of this complex topic to an extent not entirely possible through the use of interviews alone (Patton, 1990).

Observations and interviews were alternated in sequence so that the findings that emerged from data analysis of one guided the inquiry of the next. All observations were recorded by use of field notes that were transcribed into a format that facilitated analysis. Transcription took place as soon as possible after the observation to minimize any loss of content and to support research journal entries. The field notes consisted of chronological scripting of events, diagrams of physical settings, and quotations of comments and conversations when feasible.

\section{Documents and Artifacts}

Documents and artifacts do not intrude upon the setting in ways that a researcher 
might, and they are not dependent upon the cooperation of respondents (Merriam, 1998). Consequently, documents and artifacts were used both for corroboration of findings that emerged from interviews and observations and, in some cases, as primary sources of data. Documents that were accessed were public records such as attendance and discipline statistics, more personal documents such as student referrals or an inter-disciplinary team's classroom expectations, and school-wide documents such as the school's character education program.

Artifacts refer to the physical items or conditions found within the school's setting (Merriam, 1998). These include such things as posters, bulletin boards, broken windows, graffiti in restrooms, and the state of cleanliness of the campus and classrooms. Artifacts were used as indicators of actual behavior to corroborate or discredit assumptions and perceptions reported in interviews. The presence of artifacts was noted in observation field notes for subsequent analysis.

\section{Data Analysis}

The theoretical assumptions and conceptual framework of the study guided data analysis. As argued by Glesne (1999), “Analysis does not refer to a stage in the research process. Rather, it is a continuing process that should begin just as soon as your research begins" (p. 84). My search for meaning thus commenced at the very beginning of the study. Ongoing analysis was conducted throughout data collection in order to keep the process focused, non-repetitious, and manageable in terms of sheer volume of material (Merriam, 1998).

To do this, interviews and observation field notes were transcribed personally within 24 to 48 hours of each event in order to preclude loss of data due to a lapse in time 
and to preserve content within the context of the event. Ongoing analysis was conducted at the time of each transcription to help frame follow-on interviews and observations and to reveal additional areas of needed investigation. Documents and evidence of artifacts were reviewed in similar fashion and used in support of future data collection.

As suggested by Patton (1990), "Analysts have an obligation to monitor and report their own analytical procedures and processes as fully and truthfully as possible" (p. 372). Therefore, I maintained a research journal throughout data collection and analysis that included entries regarding technical aspects of the study and reflections of a more global nature. Both technical entries and the reflections were used to guide the study with regard to focus and strategies.

Transcripts of interviews and field notes and copies of documents were filed in chronological order for continual review and to facilitate future reference as required. Coding was done manually in the margins of the transcriptions within the framework of the four climate descriptors: order and discipline, trust, academic program, and facilities. A spreadsheet was then constructed that indexed the location of each piece of data by interview title and interview transcription page number within each category to facilitate retrieval of specific pieces of data. For example, the entry D-AP3-5 indicated data that emerged from the coding in the category of order and discipline that was located on page five of assistant principal interview three. From this, I was able to identify common themes and confirm them by their repetition and emergence in multiple forms of evidence. Interpretations of these themes in turn formed the basis for the recommendations of the study. 


\section{Limitations of the Study}

\section{Subjectivity}

My positions during the study, first as a middle school assistant principal and later a middle school principal, could lead to suggestions that subjectivity was a problem in this study in view of the fact that I served as the primary data collection instrument. I do not argue that this was not the case. Rather, I agree with Peshkin (1988) when he suggests that subjectivity is inevitable in qualitative research. As described by Glesne (1999), however, I carefully monitored my subjectivity in order to increase my awareness of how it might distort observations and analysis and, in turn, used it to conduct more trustworthy research. As stated by Patton (1990), "The point is to be aware of how one's perspective affects fieldwork, to carefully document all procedures so that others can review methods for bias, and to be open in describing the limitations of the perspective presented" (p. 482).

According to Bogdan \& Biklen (1998), "Different theoretical perspectives that researchers hold shape how they approach, consider, and make sense out of data" (p. 178). Thus, I reflected on my subjectivity continually throughout the study in order to accomplish what Peshkin (1998) described as "a tuning up of my subjectivity to get it into shape" (p. 20). Through this self-monitoring process, I sought to be sensitive to the influences that my professional experiences might have on interpretation of data in order to not only manage subjectivity, but also to use it to help frame areas of inquiry throughout the study.

\section{Backyard Research}

Selection of a school in my own district as the site of this study could lead to 
criticism for conducting backyard research. Glesne (1999) defines backyard research as that which is conducted in one's own institution or agency. Since my own school was not the focus of the study, it was not backyard research in the strictest interpretation of the term. Nevertheless, there was the potential for political consequences as a result of my choice of site in the emergence of what Glesne (1999) has termed dangerous knowledge, or information that was politically risky for an insider in the school district to have. In addition, there was at all times the potential that my position in the district might constrain effective data collection or, at times, lead to confusion as to what role I was playing-principal, professional acquaintance, or researcher.

As with the case of subjectivity, I carefully monitored others and myself in order to maintain a heightened awareness of these problems. I used my research journal throughout the study to carefully document all difficulties arising from backyard considerations and, in turn, structured data collection and analysis processes in such a manner as to minimize their effect.

\section{Generalizability}

Normally when researchers speak of generalizability, they are referring to whether or not findings will apply beyond the specific subjects and setting of a particular study (Bogdan \& Biklen, 1998). Since this was a case study of only one assistant principal, its generalizability might be questioned. In response to such criticism, some qualitative researchers would hold that the issue of reliability or external validity is not really relevant to qualitative studies. Wolcott (1990), for example, argued that the role of the qualitative researcher is to understand rather than convince, stating, "I do not accept validity as a valid criterion for guiding or judging my work" (p. 149). He added, "I think 
we have labored too long under the burden of this concept" (p. 149).

Though I do not agree entirely with this extreme position of Wolcott (1990), I concur with Donmoyer (1990) when he argued that "social scientists' traditional conception of generalizability is problematic for applied fields such as education" (p. 176). In the educational setting, qualitative case studies are particularly useful when the objective is to understand a situation in great depth and where rich sources of information are available. Such studies serve to describe the topic of interest in depth, detail, and context (Patton, 1987). As such, they can suggest possibilities, but not necessarily dictate action (Donmoyer, 1990).

This was a study of a previously unexplored topic. As such, the in-depth, case study approach was appropriate as a first step in investigating that relationship on which future studies can be based. The generalizability of findings that emerged thus lies in the particulars. External validity results from how researchers and practitioners will use the findings in situations similar to those explored by the study. As stated by Patton (1990), "Pragmatic validation means that the perspective presented is judged by its relevance to and use by those to whom it is presented: their perspective and actions joined to the evaluator's perspective and actions" (p. 485).

This empirical process for checking similarity between sending and receiving contexts has been referred to by Guba and Lincoln (1989) as transferability. They argue that what the qualitative researcher does is "to provide as complete a data base as humanly possible in order to facilitate transferability judgments on the part of others who may wish to apply the study to their own situations" (p. 242). To Guba and Lincoln (1981), generalizability "must be with reference to particular audiences. It is up to each 
audience to determine what, if anything, the information means and to determine for itself the information's applicability" (p. 166-167). As such, the concern is not "whether the findings are generalizable, but rather with the question of to which other settings and subjects they are generalizable" (Bogdan \& Biklen, 1998, p. 33).

This study investigated a complex organizational setting in which multiple influences affected the area of interest. It possessed the characteristics of a naturalistic inquiry, as described by Merriam (1998), in that it was grounded in real life situations and, in turn, presented a rich, holistic account of the topic of interest, thereby providing insights and meanings that can help structure future research. The generalizability of findings to emerge thus lies in the particulars. By looking at the specific, it has provided a description and analysis that identifies concepts not previously seen or fully appreciated.

I do not agree with Tolstoy's (1965) opening line of his novel, Anna Karenia: "All happy families are alike. All unhappy families are particular in their own ways" (p. 3). Only a positivist approach would argue that one could make generalizations about all happy families based on findings obtained from a random sample of happy families. I also would not argue that a single case study of a happy family would support generalizations regarding all others. I agree with Merriam (1998), however, when she argued, "The idea that the general resides in the particular, that we can extract a universal from a particular, is also what renders great literature and other art forms enduring" (p. 310). This study was not necessarily concerned with generalizations in the positivist sense or the development of theory. Instead, its purpose was to suggest possibilities for future research and for more informed interpretation of situations and events by both 
practitioners and researchers in the educational setting regarding the relationship between an assistant principal's leadership and school climate. 


\section{CHAPTER IV}

\section{FINDINGS: DOES A POSITIVE SCHOOL CLIMATE EXIST IN}

\section{VALLEY MIDDLE SCHOOL?}

Introduction

Valley Middle School sits on the edge of a flat plain occupied by the city of Mesa Valley, close against the foothills that surround the town. Upper middle class homes that cling to the sides of the hills look down upon the school past lush landscaping, swimming pools, and driveways occupied by Mercedes and BMW's. The housing and conditions on the valley floor from which Valley Middle draws its students provide a study in contrasts, however.

Fifty-two percent of the city's 92,000 residents are apartment dwellers, drawn to the area by an abundance of low rent housing. Over 23 percent of these people receive welfare benefits while living in a city that has the second largest crime rate in the large metropolitan area of which it is a part. In Valley Middle School's attendance area, over 200 percent more child abuse reports were filed in a recent year than in any other part of the city's county. Because of the mobility of the low-income families in the valley, the school's transience rate hovers around 43 percent. Seventeen languages are spoken by the students at Valley Middle, the result of a large immigrant population, mostly Hispanic and Arabic, that has been drawn to the valley by low cost housing.

Because of these demographics, 78 percent of the school's students receive free or reduced price lunches. This qualifies the school for the federal government's Title I Program that provides additional money to schools with large numbers of low-income students. Forty-eight teachers, 32 classified personnel, two counselors, and three 
administrators comprise the staff that attempts to provide Valley's 1,150 students with a school climate that meets the students' many academic, social, and personal needs.

The first research question of this study sought to discover evidence that would indicate whether or not this climate was positive within the framework of school climate indicators. The findings that emerged in response to this question are organized within the framework of the four school climate indicators: order and discipline, trust, academic program, and facilities.

\section{Order and Discipline}

Three themes emerged in the category of order and discipline: expectations, teaching and modeling, and observed student behavior.

\section{Expectations}

Expectations for both students and teachers are stated clearly in numerous ways at Valley Middle School. The school-wide discipline plan is included in the daily planner given to every student. This plan is taught by all homeroom teachers at the beginning of the academic year and periodically throughout the year. Different components of the plan are reviewed daily on the school's television broadcast system each morning. In addition, the principal and assistant principal use the morning broadcasts to reinforce expectations that periodically need extra attention, such as trash on campus or running in the halls.

In accordance with middle school methodologies, teachers are grouped in interdisciplinary teams that teach the four core courses: mathematics, English, science, and history. Teams are required by the principal to have common classroom management plans and behavior expectations. There was evidence of this during an observation I 
conducted of the school's parent orientation night the third week of the academic year. Parents did not move from classroom to classroom to meet their students' teachers, as is the practice in most schools. Rather, they were briefed at one location by their individual student's entire inter-disciplinary team. At that venue, one set of classroom management plans for all four teachers was presented to the parents verbally and in writing for them to take home to discuss with their children.

A review of these plans for all teams within the school revealed many common elements. (This may have been the result of a requirement that all plans be submitted to the school management team for review and approval.) All plans include specific rewards and consequences that are aligned closely to clearly stated behavior expectations. As part of a hierarchy of consequences, each team's plan includes procedures for a team infraction log that specifies consequences for minor behavior infractions. This practice is intended to keep most student discipline within the team, leaving only serious violations to be referred to the assistant principal. (Interviews and document reviews revealed that all teachers do not use this system consistently.) Finally, all teams use reward activities such as pizza parties and field trips to recognize students who consistently meet behavior expectations.

Most teachers have their expectations posted prominently in the front of their classrooms. Rewards and consequences for specific behaviors are also displayed in most classrooms. All teachers and administrators with whom I spoke stated that teachers and teams review these plans frequently with their students. Finally, the teams provide counseling to those students who need additional help in understanding and complying with expectations in meetings with the students that are conducted during the teachers' 
common plan periods.

The Valley Way, a highly structured character education program, forms the basis for school-wide behavior expectations. The program includes 10 character traits: courtesy, commitment, respect, appreciation, initiative, responsibility, self-discipline, honesty, cooperation, and success. All traits are posted in every classroom and in common areas throughout the school. The entire school focuses on one trait per month that is taught in formal classroom presentations within each team, addressed every day on the morning broadcast, and reinforced by staff during teachable moments throughout the month. The trait of the month is also displayed prominently on the school's marquee and throughout the campus on exterior bulletin boards.

Most staff members feel strongly that the Valley Way forms the basis of the school's behavior expectations. The principal, Mary Stewart, was responsible for introducing the program to the school. She explained that it was developed by the teachers and thus had the support of the staff. According to her, "The Valley Way defines very specific attitudes and behaviors, and the kids and the adults are all in unison to follow this code." She stressed that "kids are taught it. The teachers created it, so they pretty much buy into it." She felt that these "behavior standards are publicized, they're taught, they're referred to, probably on an hourly basis in the lives of the kids." Concluding, she said, "There's no ambiguity there. It's very clear cut."

Carol Harris, the school's office manager, agreed with this assessment. During a conversation in which we discussed behavior expectations, she too stressed what she felt to be the critical role of the character trait program. "I think the school as a team focuses on The Valley Way," she said. "We have our character traits," she explained, "and I 
think it permeates the whole staff right down to the students."

All teachers with whom I spoke supported this view. For example, Harry Locke, a veteran teacher who left a traditional classroom setting to help build the technology program at the school, described the entire school's involvement with The Valley Way. Speaking of its implementation, he said, "It got our effort, got everyone involved, custodians, everyone involved in it. That's why I think it works here."

Clint Williams, an eighth grade team leader, agreed with Locke's opinion when he spoke of how "the students in the halls were running the campus" before implementation of the character trait program. "Once The Valley Way was instituted. along with a lot of other things," he said, "the climate changed completely."

Susan Lundstrum is a seventh grade history teacher who has strong opinions on most subjects, including expectations and the Valley Way. Another veteran teacher, she too was present when the character education program was developed in response to the safety and discipline problems that the school was experiencing eight to ten years ago. "I think the Valley Way is the number one thing that keeps the whole school on the same note in terms of character," she said with conviction, pointing to the character trait posters on the classroom walls as she spoke. "And character underlies everything." she stressed, "including safety, discipline, instruction, the feeling of how things look. You know it's everything," she repeated. "The bottom line is character."

\section{Teaching and Modeling}

The leadership and the teachers at Valley expressed a belief in the importance of teaching and modeling expectations. Repeatedly in our conversations, the assistant principal, Jim Wharton, stressed the need to prevent unacceptable student behavior 
through teaching and modeling. He believes that "an ounce of prevention is worth a pound of cure." "If you can put out information, and put out your expectations ahead of time, and the children know what you expect," he said, "most individuals will listen to that and not make those poor choices." The technology teacher, Harry Locke, supported this argument. "What strikes me as significant about this program [speaking of teaching behavior expectations]," he said, "is that often we give it a shot at the beginning of the school year thinking, well, that will be good enough to last all year long. But we know that they [students] need a steady dose of that. We've been making an effort every trimester to reinforce those things."

As indicated by Locke, it is a school requirement that inter-disciplinary teams reteach school-wide and team classroom behavior expectations repeatedly throughout the year. Teachers also inform parents of their expectations through material sent home with students and during school open houses and other times when parents periodically visit the campus. The teams have responsibility for teaching the lesson plans of the Valley Way and incorporating its character traits in their lessons across the curriculum. Each new student receives instruction on his/her team's expectations from a video prepared by the team members that is viewed in the counseling office before the student is allowed to begin classes. In addition, all incoming students who have histories of discipline problems at their previous schools must participate in an orientation conference with the counselor, assistant principal, and the student's parents during which expectations are discussed.

These efforts to teach behavior expectations are not limited to students. New teachers are taught them at the time they join their inter-disciplinary teams or 
departments. Team members participate in the new teacher interview process and attempt to evaluate prospective teachers' receptiveness to teaching and modeling the expectations before agreeing to hire them. As Susan Lundstrum put it, "The teaming stuff matters a lot, which is another contributor to the success of the positive climate in our school."

In support of this effort, the principal provides a written statement to prospective teachers that indicates clearly her expectations of teachers with regard to behavior management. In it, she stresses her expectation that teachers "use a positive-based classroom management plan to minimize the occurrence of discipline problems." At another point in the document, she refers to the character education program, concluding her thoughts with the following comment: "You are the role model for The Valley Way." She summed up this policy in one of our conversations: "They [prospective teachers] are made very aware of what The Valley Way is and how they have to support the philosophy. If they're not willing to have that kind of attitude toward each other as colleagues and toward the students, then they don't want to work here."

Modeling of expected behaviors by adults is evident at Valley Middle School. One morning, I watched Wharton dismiss a student from his office to whom he had just given a consequence for a behavior infraction. He stood, shook the student's hand, and thanked him for his cooperation as he walked the boy to the door. This modeling by the assistant principal was also evident in his interactions with students in the common areas of the campus. I seldom witnessed him intervene with a student who was failing to meet a behavior expectation in the halls or lunch area without concluding the interaction by thanking the child for listening and cooperating. Linda Garcia, the school's Title I 
Program coordinator, agreed with this observation when she stated, 'It doesn't matter the situation that he's [Wharton] dealing [sic] with the student, he's always very positive and very direct. He has a way of maintaining their [sic] integrity no matter what the student has done."

I witnessed another example of this modeling when, one day after school, the principal addressed two students who were riding skateboards on campus illegally by saying, "Boys, please do me a favor and don't ride your boards on campus. That's not allowed." When the two students stopped and picked up their boards, she continued, "Thank you, boys. Now as a consequence for not following the rules, would you please pick up that trash on the ground?" The two boys responded by picking up the trash and saying they were sorry for riding the skateboards on campus.

Harry Locke, the veteran technology teacher, expressed support for this sort of modeling when he said, "The most important thing is how teachers interact with one another, how they interact with the principal, how they interact with parents, and above all, how they interact with students."

\section{Observed Behavior}

Suspension statistics comprise one of the quantitative tools used by most school districts to evaluate order and discipline at individual school sites. A review of district records revealed that Valley's suspension statistics compare favorably with those of the other four middle schools in the district. As demonstrated in Table 1, Valley has significantly lower numbers than two of the schools for suspension incidents, days of suspension, number of students suspended, and percentage of students suspended for the past two academic years (the 1998/1999 school year was the first academic year the 
school district compiled suspension data). Its data in each of these four categories are higher than that of the remaining two schools, thereby placing it in the middle of the five schools for each of the areas tracked by the school district.

Table 1

\section{Comparison of Suspension Statistics Between District Middle Schools}

\begin{tabular}{|c|c|c|c|c|c|c|c|c|}
\hline \multirow{3}{*}{ School } & \multicolumn{8}{|c|}{ Comparisons } \\
\hline & \multicolumn{2}{|c|}{$\begin{array}{l}\text { \# of Suspension } \\
\text { Incidents }\end{array}$} & \multicolumn{2}{|c|}{$\begin{array}{c}\text { \# of Suspension } \\
\text { Days }\end{array}$} & \multicolumn{2}{|c|}{$\begin{array}{l}\text { \# of Students } \\
\text { Suspended }\end{array}$} & \multicolumn{2}{|c|}{$\begin{array}{l}\% \text { of Students } \\
\text { Suspended }\end{array}$} \\
\hline & 98/99 & $99 / 00$ & $98 / 99$ & $99 / 00$ & $\underline{98 / 99}$ & $99 / 00$ & $98 / 99$ & $99 / 00$ \\
\hline Valley & 63 & 59 & 105 & 129 & 51 & 53 & 5 & 5 \\
\hline A & 223 & 253 & 654 & 596 & 151 & 144 & 15 & 14 \\
\hline B & 36 & 21 & 95 & 61 & 28 & 18 & 3 & 2 \\
\hline $\mathrm{C}$ & 130 & 109 & 312 & 181 & 84 & 69 & 9 & 7 \\
\hline D & 36 & 29 & 69 & 46 & 26 & 23 & 2 & 2 \\
\hline
\end{tabular}

Valley's statistics look even more impressive when the difference in size and demographics of the student populations of the five schools is considered. School A, for example, is an inner-city school that is similar to Valley in student body size and socioeconomic status. Despite this similarity, Valley's suspension statistics are significantly lower than those of school A. Schools B and C are located in the suburbs and serve predominately working and middle class families with small minority populations. In addition, both have approximately 300 fewer students than Valley. Nevertheless, Valley's statistics are only slightly higher than those of school B and are approximately 
half those of school C. Only school D, a suburban site with a predominately upper income, homogeneous student population from mostly professional, two parent families, records significantly lower suspension statistics than Valley. Thus, when size and demographics of student populations are considered, Valley's suspension statistics compare even more favorably to those of the other four district schools.

Table 2

Attendance Rates for Academic Years 1997/1998-1999/2000

\begin{tabular}{lccc}
\hline & \multicolumn{3}{c}{ Academic Year } \\
\cline { 2 - 4 } Attendance & $97 / 98$ & $98 / 99$ & 1.7 \\
\hline $\begin{array}{l}\text { Average Unexcused } \\
\text { Absences per Day }\end{array}$ & 2.0 & 2.5 & \\
$\begin{array}{l}\text { Average Excused } \\
\text { Absences per Day }\end{array}$ & 4.1 & 3.5 & 3.6 \\
Actual Attendance & 93.9 & 94.0 & 94.7
\end{tabular}

Note. All figures are percentage of total student enrollment.

The state of California requires all public schools to maintain attendance records to establish funding levels for individual school districts. It also uses attendance statistics to evaluate various components of school effectiveness, including order and discipline on individual campuses. Schools that have problems with school-wide order and discipline normally record low student attendance. This is the case with the other inner-city middle school in Valley's school district that is comparable to Valley in size and student demographics. Valley, however, does not conform to this pattern. For the past three academic years, as demonstrated in Table 2, its attendance rates (actual attendance plus 
excused absences) were between $97.5 \%$ and $98.3 \%$.

Other documents and artifacts support these district statistics. According to 1999 surveys, for example, 87 percent of the school's parents rated it with an A or B on a five point Likert scale in the area of safety. Particularly significant are recorded observations of visiting groups of teachers and school administrators to the school that include comments such as: "The students are so well behaved." "I can't believe this is a Title I school." "The teachers and students show such courtesy to each other."

Early one morning, as the sun was just starting to creep above the jagged horizon of the hills surrounding Mesa Valley, I stood at the school's entrance and observed the students who made such an impression on visitors to their campus. They began arriving at $6: 45$, one hour before the bell that announced the beginning of the school day. Most came on foot, skateboards, or bikes. A handful of parents dropped their students off before rushing to work. By $7: 30$, the campus was alive with children greeting each other, playing games on the asphalt by the locker rooms, and surging into classrooms that were open for tutoring. The noise level generated by over a thousand 11 to 14 year oid adolescents was low, and there was very little evidence of pushing, shoving, and general horse play in most parts of the school that is often seen in the common areas of many middle schools.

The exception to this was in the wing of the school assigned to sixth grade students. Here, the youngest children on the campus ran between the buildings, chasing each other and engaging in considerable horseplay. This, I discovered later, was a sore point for the seventh and eight grade teachers who did not approve of what they perceived to be a lack of supervision on the part of sixth grade teachers. Seventh grade 
teacher, Susan Lundstrum, made this clear when she said in frustration, "There's nobody standing outside, and the sixth graders, instead of being up in the lunch area, are allowed to just play and congregate, play tag. They're squirrelly," she continued in disgust.

"There's no grass in front of those classrooms because the kids are allowed to run amok."

Nevertheless, most students proceeded in orderly fashion to their classrooms when the bell rang, including the sixth graders who lined up outside their classroom doors, elementary school style. The assistant principal or teachers standing at classroom doors slowed the occasional runner. With the second bell, the halls were clear, students were in their desks, and their attention was turned to the morning announcements on the school's television broadcast system. As I walked through the halls, looking into classroom windows, I saw few students who were not paying attention to the announcements and the character education presentations that are a part of every day's program.

On another day, I stood on the lawn between the main school buildings and the lunch area, waiting for the first of two lunch periods to begin. As soon as the lunch bell rang, hundreds of students surged toward me from classrooms and out of halls as they hurried to get into one of seven lunch lines. Another large group weaved between the lunch tables, making their way to the physical education locker rooms or to portable classrooms located on an elevated area on the opposite side of campus from where I stood.

I looked around for the staff members who should have been in place to supervise this hoard of adolescents rushing forward toward the lure of cheeseburgers, all wanting to be first in line. No adult, including the assistant principal, was in sight. As a result, a 
small number of the students were running across the grass and between tables to get as close to the front of one of the food lines as possible.

Lunch duty aides began appearing a short time after the bell rang, but by this time, most of the students were in one of the lines. Once in line, students became orderly and waited patiently with little pushing or shoving. Eleven minutes after the beginning of the period, Jim Wharton, the assistant principal, hurried from the school office into the lunch area, eating a cup of yogurt as he approached. Without breaking stride, he finished his hurried meal, tossed the empty cup into a trashcan, and immediately began supervising the 650 students who were now settling down at their favorite tables for lunch.

Throughout the lunch period, most students remained seated until clearing the area. Few exhibited behaviors such as pushing, running, or not discarding their trash. Those who did drew responses from Wharton such as, "Alex, make certain your trash is picked up," or, "Jim, where are you running to? Walk please." The assistant principal was aided in this process by the school's campus safety supervisor and six lunch duty aides. As a result, the remainder of the lunch period was well supervised and ended without any significant incidents.

This pattern was repeated on a visit to the campus two weeks later. This time $\mathrm{i}$ stood on the edge of the elevated cluster of portable classrooms behind the lunch area. This position afforded me an unobstructed view of the opposite side of the eating area from that of my previous observation. Three minutes before the lunch bell, a teacher in one of the portable classrooms behind me released her students early. As the students rushed toward the ramp leading down to the lunch area below, the campus safety 
supervisor, who was walking up the ramp, stopped them and made them wait at the top. Despite their protests that they should be allowed to pass since their teacher had released them early, the supervisor made them wait at the top of the ramp for the bell. It seemed apparent that this was his duty station at this particular time every day. Subsequent conversations with teachers revealed this to be the case. This information explained why I had not seen him from my vantage point on the other side of the lunch area two weeks earlier.

When the bell rang, the supervisor walked down the ramp, ensuring that the students behind him did not run. There was no one, however, to stop the large number of children who ran at full speed out of the physical education locker rooms. An even larger group raced around the corner of the physical education building and then across the asphalt toward the eating area and the serving lines that had been the catalyst for running during my previous visit. It was evident from the way the students sprinted across the open area that this was common practice every day. On this day, the assistant principal was clearly visible in the eating area when the bell rang. Numerous lunch duty aides could also be seen amongst the tables. As a result, students were orderly and calm once they reached the lunch area.

In one of our conversations, the principal expressed dissatisfaction with what she felt to be excessive horseplay and trash in the lunch area. "It's a real problem," she said in frustration, "and the teachers are not happy. But it's not my job," she concluded, "so I refuse to go out there and do his [Wharton's] job for him."

The evidence did support, to some extent, the principal's opinion regarding student behavior during lunch. Examples of such evidence was the large number of 
students who ran unsupervised to lunch and the heightened level of behavior problems during Valley's lunch periods compared to other times of the day. In addition, on every day that I was in the lunch area, I watched as lunch duty aides and the school custodian picked up trash left behind by departing students.

The assistant principal attributed these problems to the fact that 650 students are wedged during lunch into a confined area originally designed for 400 . It also appeared that the attitudes of the principal and some teachers regarding student behavior at lunch were, at least in part, the result of comparisons of the relatively unstructured and extremely crowded lunch area to conditions at other times of the day when students were in more structured, less crowded environments, such as classrooms, where they could be more easily managed.

There were other less structured settings than the regular classroom during the school day at Valley, however, in which the sort of behaviors evident during lunch did not take place. For example, on the day that I observed a physical education class, students immediately sat down on assigned numbers painted on the asphalt outside the locker rooms at the beginning of the period. They were quiet and still while the teacher took roll. Next, they lined up in rows by number between lines painted on the ground to enter the locker rooms single file under the direction of a teacher. Once in the locker room, the students changed as three adults, strategically positioned so that they collectively had the entire room in view, monitored every move of 150 boys. As soon as each student had changed, he proceeded to a designated spot on the locker room floor and sat down. Those who did not move quickly were hastened along by one of the teachers. When every boy was on his pre-assigned position on the floor, each teacher led his class 
from the room in single file back to the numbers on the asphalt to begin instruction. On the day I observed this procedure, only one incident required teacher intervention throughout the entire process. Two male students began to push each other in line. The teacher quickly intervened, saying, "We just talked about self-discipline. Keep your hands to yourselves." The boys complied immediately.

Trust

According to veteran teacher, Harry Locke, relationships at Valley are built on "openness and acceptance." He spoke of getting "a feeling from the principal that it"s ok to try new things," in contrast to other schools where he had taught in which people were afraid to take risks. He proudly showed me his space shuttle simulator that he built in a room adjacent to his technology laboratory, offering the opinion that at other schools "they'd find 15 different ways why I couldn't do it." He summarized his feelings by saying, "At Valley, we're kind of taking the risk together. Let's enjoy it together."

Eighth grade history teacher, Clint Williams, expressed strong opinions in our conversation, some of which were critical of both other teachers and administrators at Valley. Nevertheless, he agreed with Jim Locke regarding trust at the school. Though he noted, as did many others with whom I spoke late in the study, that contract negotiations were beginning to have a negative impact on trust in the school's community, he still maintained that "trust was very high" at the school. He stated this forcefully when he said, "It is very high between the front office. I'm talking about the principal, the assistant principal, and the teachers; very high between the teachers, the teams, and the other teams. Students and faculty, I would classify it as very, very high."

Katherine Summers, the school's guidance counselor, heid equally strong feelings 
about the nature of the relationships between individuals and subgroups at the school.

She made a point of noting that in her position she worked with the entire school community. "In my job as a counselor," she said, "I work with the administrators, I work with the teachers, I work with the parents, I work with the students." From this perspective, she felt that she could "see the trust that permeates through our school."

Repeatedly Summers returned to a theme of how students come to the counselors and assistant principal to report problems, trusting that their concerns will be addressed. "You can see it in the way that they come and report things to us," she said, "the way that they come and ask us for help." Much of this she attributed to inter-disciplinary teaming in accordance with middle school philosophies and strategies. "They take such ownership," she said, referring to the teams. "They're looking at the whole child," she continued. "They really are teaching children rather than teaching curriculum."

The counselor was equally convinced that parents had the same level of trust that she felt was present within the staff and the students. "Our community is very supportive of us," she said. "I honestly believe there's a great deal of trust." At the end of our conversation, she summed up her strong opinion on this subject by concluding, "I'd say that trust is probably the number one issue that I see permeating through all of our school site."

Linda Garcia, the school's Title I program facilitator and bilingual program coordinator, was another management team member who, like Summers, works with all members of the school community. She echoed the observations of the counselor when she suggested "kids are very trusting of us." She felt that parents "will call and notify us of any concerns that they have." According to Garcia, there exists a "rapport" between 
all members of the school community that fosters trust and confidence that all voices will be heard and all issues will be addressed.

The principal used this term, rapport, repeatedly in describing relationships at Valley. She considered it to be "kind of a corner stone for the school environment that you want to create." The assistant principal also emphasized the need for trusting relationships among the entire school community, restating its critical role, in his view, in almost every conversation that we had. He spoke of working to establish trusting relationships with students. For example, he stated, "If I develop that relationship, I find my job is a lot easier. I'm not fighting with them. It's not me against them." Repeatedly, he emphasized the need to build positive relationships with all of his constituents that were based on their ability to trust that he would address their problems quickly and effectively. "A teacher asks you, a parent asks you to do something, a student asks you to do something, then you do it as quickly as possible," he said.

Trusting relationships with teachers were particularly important to Wharton as evidenced by his statement, "Your relationship with your staff will make or break you." In another conversation, he returned to this theme, concluding his thoughts on the need to have the trust of his teachers by saying, "So it's in your best interest to make sure you really work with them [teachers], not always agreeing with them, but making them feel good about what you are doing."

Another person who was in a position to interact with all members of the Valley community was Carol Harris, the school's office manager. From her vantage point, she was able to observe most of what happens within the school on a day-to-day basis. She also appeared to wield all of the positional power that often comes with the school office 
manager job. This was particularly so as a result of an extremely close professional relationship that seemed to exist between her and the principal. In this capacity, she was more of an executive assistant than a secretary. As a result, she held very strong and insightful opinions. One of these was, "Everybody [at Valley] feels like this is their family."

Like the assistant principal, Harris felt that trust was built on consistently addressing people's concerns quickly and effectively. "If you ask someone to do something, and they do it," she explained, "then they've banked a little bit of trust there." She gave a personal example of the teacher who is late in requesting her to make arrangements for a conference. "I'll make some phone calls, and I'll get you in," she said. "And if I do that," she continued, "then that builds trust with the teacher. They know you're going to do what you say you're going to do."

Harris also felt strongly that parents "like the way they're treated at Valley." "They feel that people care about them and their kids," she said, "that we're always trying to help them solve whatever problems that they have if they're coming in with a problem. I definitely think the parents trust what we're doing here," she concluded. Seventh grade teacher, Susan Lundstrum, did not express the same level of confidence regarding trust as did teachers Jim Locke and Clint Williams. She had mixed feelings regarding trust within the Valley community. Though she felt that "Valley has an incredibly positive atmosphere," she sensed a significant deterioration of the trust she felt had existed in the past at the school. She attributed this to contentious contract negotiations that were creating divisions among the staff, noting, "Some staff members are adhering to what the union wants them to do, and some staff members don't. That's a 
no brainer," she said in explaining how this was affecting trust between subgroups of teachers. She also held the view that a recent change in principals was affecting trust. She felt that the new principal was not conducting regular meetings that she considered critical to building staff unity, nor did she feel he was emphasizing teaming to the degree of his predecessor. This lack of emphasis on inter-disciplinary teams seemed to particularly disturb Lundstrum, because like the guidance counselor, she felt "the teaming stuff matters a lot, which is another contributor to the success of the positive climate in our school."

The perceptions of this influential teacher regarding trust between teachers and the school's administration were somewhat confusing. She referred repeatedly to the trust and respect that she and other teachers had in the recently departed principal and her lack of trust that the new administrator would continue his predecessor's policies. It was unclear whether this expression of lack of trust in the school's relatively new principal was the result of the need to adjust to a new personality after working with one leader for eight years or whether there were long-term substantive issues affecting relationships within the school.

Lundstrum had worked with the assistant principal for almost 20 years. Nevertheless, her opinions regarding Jim Wharton were also somewhat contradictory on the issue of trust. When referring to his interactions with students, she described him as a "pushover," yet at another time stated, "Kids respect him and they respond to his input." "They're afraid to go to his office," she said in the same conversation. At another time, she said simply, "I don't trust him," explaining that this was because she felt he did not follow through on referrals. It was just a short time earlier in our conversation, however, 
that she had stated, "He will always do what I have delineated that I want him to do," when talking about her policy of writing clearly on student referrals the response she wanted from Wharton. It appeared that, on one hand, she felt she could not trust him to do independently what she wanted with regard to student referrals, yet, on the other hand, she had complete trust in him to comply with her clearly stated wishes. As was the case with the new principal, it was unclear if the trust issues that Lundstrum had with the assistant principal were substantive or if they had grown out of relatively superficial concerns, such as a disagreement with Wharton's management style that became increasingly evident as our conversation progressed. Regardless of their origins, it was clear that her relationships with Wharton and the new principal were less than totally trusting.

There was another staff member with whom I talked who did not share Katherine Summers' conviction that trust "permeated" the school. This was the in-school suspension aide, Charlene Waters. Waters expressed strong feelings regarding the trust that she felt the students had in the assistant principal, the counseling staff, and her personally. "The students have a lot of trust," she said. "They want to talk to you, they want to be around you." She spoke, like others, of the students' readiness to take their problems to the adults on campus for help. "And so that's a trust issue, too," she said. It was clear, however, that she felt the need to be cautious in her interactions with other staff members. She expressed complete confidence that the counselors and assistant principal would listen to her and would handle the problems of students she referred to them. "There's a few people here that I do trust," she said, referring to the principal, assistant principal, and counselors. "But you have to be sort of careful," she quickly 
added. "That's a bit tricky sometimes," she said, as she expanded her thoughts regarding her relationships with teachers. "But you see, that's just from my angle," she explained, "because I'm not certificated." She spoke of the criticism that she occasionally received from teachers, but said, “But I don't think it's centered at me sometimes. I think it's centered at other people, or the system. I'm just caught in the middle of it." Regardless of the source of her trust issues, it was clear that she was cautious in at least some of her dealings with the teaching staff.

These comments by Lundstrum and Waters indicated that trust might not be "pervasive" throughout the school community at Valley as suggested by the guidance counselor, Katherine Summers. Nevertheless, my conversations with the staff indicated that all members of the leadership team, most teachers, and most classified staff felt that the level of trust between individuals and subgroups at Valley was very high.

\section{Academic Program}

A walk around Valley Middle School found students engaged in a variety of activities. In one history class, a group of seventh graders was interacting on the internet with students in Asia. In a technology laboratory, four students were in the space shuttle simulator on a mission controlled by other students from a computerized console. Others moved between various workstations that demonstrated different physical science concepts. In the class that manages the school's student run business, students were learning work skills not only by performing duties for which they are paid, but by also keeping the pay records, maintaining inventory, and balancing accounts on computerized systems. In rooms throughout the school, students with special needs were being taught in small groups with curriculum designed to meet their individual needs. These 
observations appeared to support a teacher when he said, "I think where we have gone pretty far here at Valley is that teachers are willing to put out extra time to try something new and different."

The use of technology for the design and delivery of curriculum is pervasive in the school. In addition to the technology laboratory with its space shuttle simulator and technology workstations, a large computer laboratory is dedicated to computer literacy. Three other computer laboratories are devoted to reading interventions, developing student writing, and internet research. In addition, teachers use these facilities on a regular basis for delivery of curriculum in virtually every subject area. Computers are in every classroom, and the school is completely networked. As a result of this extensive use of technology, the school is a district technology magnet school.

Valley offers yearlong courses in Spanish and performing arts. Most students, however, are on an exploratory elective wheel that schedules a different elective each trimester in accordance with middle school strategies. In addition, geometry is offered as a zero period class an hour before school every morning, and tutoring and a homework club are available every day after school. The needs of students who are below grade level are addressed by small size classes designed for remediation and intersession classes over the Winter and Spring breaks and in the summer. The counseling department, inter-disciplinary teams, and the Title I program facilitator and bilingual program coordinator track the academic achievement of all students to ensure the needs of each child are being met. Parent involvement in the school is encouraged through frequent communication with parents and a highly organized parent and community volunteer center that is staffed by full time coordinators. 
Document reviews revealed that in the last district writing assessment, Valley's scores were the highest in the district. California standardized test scores increased by 18 percent in the last full year before this study, leading to the school being cited as an Achieving School by the state of California. The school's Academic Performance Index that resulted from these scores placed the school in the seventh highest decile overall in the state and in the highest decile when compared to schools with similar demographics.

\section{Facilities}

Mary Stewart, the principal of Valley Middle, placed considerable emphasis on the physical condition of her school. "When kids come on to the campus," she said, "they look at the school in a certain way based on how it looks to them." She returned to the themes of security and predictability that emerged continually in our conversations when she said, "That's why it's important to keep it looking pristine, because that gives them [students] a sense of security and a sense of safety and a sense of predictability." She went on to explain:

They've learned to expect that when they come to school. The school will be clean, it will be uncluttered, it will be appealing, it will be esthetically pleasing. It will be like that day in and day out, day in and day out. It becomes very predictable.

Jim Wharton, the assistant principal, seemed to agree with this assessment. "You know, school appearance, how a school appears, at times can help the students in how they feel about their school," he said as we talked in the lunch area, discussing why he had arranged for the lunch tables to be repainted. He continued by stating, "If everything's raggy, run down, graffiti all over the place, you know, that's going to be the 
image of the school." He failed to expand on this observation, however, to voice any clear opinion regarding the precise effects that a "raggy" image might have on students or staff. He seemed to indicate by his comments, however, that he felt the physical appearance of the school did indeed influence student attitudes.

Wharton seemed to feel that the physical condition of facilities was important primarily from the standpoint of safety. Safety of students and staff appeared to be his overarching justification for all that he did, including upkeep of the buildings and grounds of the school. This was evident when he said, "Leaky roofs, bad ballast in lights, anything that could create a safety problem, that is what I consider in the realm of a safe, orderly environment."

In contrast to the principal, who emphasized the effect that the condition of the campus had on staff and student attitudes and behaviors, Wharton focused primarily on this physical safety consideration. For example, when I asked if there were any examples of facility decisions or actions that he had ever taken that were not directly related to physical safety of teachers and students, he initially said yes. The example he offered in support of this position, however, was the role that he played in deciding where to place new portable classrooms on campus. He returned immediately to the issue of safety, however, by saying, "It all goes to campus safety and security. Where would be the place [to site the portable classrooms] and how best to do it?"

Regardless of the motivation, the emphasis of both school and district administration on the condition of the physical plant was evident. The school was modernized five years ago with upgrades in carpeting, lighting, heating, air conditioning, and physical appearance. It was completely networked for internal and external 
electronic communication. In addition, the school district conducted extensive landscaping in the front of the school when it was being considered for recognition as a California Distinguished School. This landscaping improved significantly the image presented to the public, staff, and students. Investment in new office and classroom furniture by the principal and the district also improved appearance throughout the interior of the buildings. The principal and teachers reported that these efforts improved teaching and office operations school-wide.

Procedures to maintain campus cleanliness appeared to be effective. With the exception of the auditorium, which was routinely cluttered with portable food carts from the cafeteria and had large stains on its carpet, all interior spaces were neat and clean. The only readily evident problem was the consistent presence during all of my visits of a small, yet noticeable amount of litter throughout the common areas of the school. The principal expressed frustration over this condition and its lack of attention from the assistant principal. The assistant principal, in contrast, frequently expressed pride in the exterior cleanliness of his campus.

Ongoing maintenance at Valley is a continual challenge. The school is over 50 years old and is representative of the institutional, low cost architecture typical of Southern California schools built in the 1950's to meet the needs of a rapidly expanding population. As a result, it has all the problems of an aging facility as evidenced by a leaking roof in the main office area one day when I visited during a heavy rain. The office manager had strategically placed a trashcan under the leak to collect the steady drip. "These things happen in an old school," she said with a cheerful attitude. "I'll call maintenance," she quickly added, "and they'll be over to fix it." Maintenance procedures 
to address problems like the leak in the roof appeared effective, because, other than a few small, isolated spots of peeling paint or cracks in stucco and sidewalks, the school was attractive and well maintained, despite its age, with little evidence of deferred maintenance in the classrooms or the exterior of the buildings.

\section{Summary}

Valley Middle School compared favorably with the other five middle schools in its district in the climate category of order and discipline when statistics such as numbers of suspensions, expulsions, and teacher referrals were used for comparisons. Other data, such as attendance rates, were consistent with these discipline statistics. In addition, observations of student behavior on the campus and the manner in which students and staff interacted supported the indications provided by these quantitative data obtained through document review.

Staff members reported that a high level of trust has existed the past eight years, in most cases, between individuals and subgroups in Valley Middle School's community. Observations of interactions among administrators, staff, and students supported these perceptions. The dissenting voices of a seventh grade teacher and the in-school suspension aide were not typical of the opinions of most staff members.

A combination of effective inter-disciplinary teaming in accordance with middle school strategies, creative uses of technology, and extensive staff development to refine teachers' curriculum and teaching strategies were evident in the academic program at Valley Middle School. Comparisons with other schools in the state of California, based on nationally normed standardized tests, placed the school academically in the top thirty percent of schools statewide and in the top ten percent of schools in the state with similar 
demographics. Other indicators, such as district writing assessments and longitudinal studies on student achievement in high school, supported this and all other evidence. There was no evidence of significant deferred maintenance at Valley Middle School. There was evidence of routine cleanliness and preservation efforts, and the overall physical appearance of the buildings and grounds of the school was that of an attractive, well-maintained facility. Though most staff members did not seem to equate facility maintenance with school climate, they all indicated that they felt it important that the school be kept clean and in good repair. 


\section{CHAPTER V}

FINDINGS: THE RELATIONSHIP BETWEEN THE

\section{ASSISTANT PRINCIPAL'S ATTITUDES AND BEHAVIORS AND}

\section{VALLEY MIDDLE SCHOOL'S CLIMATE}

Introduction

Jim Wharton is a tall, solidly built man who's mane of thick, black, curly hair flows down below his collar, leading one teacher to describe him as a lion who prowls the halls of the school. His skin is brown and weathered and his hands rough and scarred from years of working on construction projects in the summer months when school is not in session. But a touch of gray in his goatee is the only evidence that he is in his late fifties. Jim's long hair and aversion to ties, which he wears only because they are part of what he calls the assistant principal uniform, are remnants of his self-described hippie days when he worked his way through college after four years in the Navy. With educational backgrounds in international relations, political science, and psychology, he has spent over thirty years in public education, teaching in both special education and regular classrooms at the elementary and middle school levels. With twelve years as an assistant principal at three different schools, including eight years at Valley Middle School, Jim has no ambition to be a principal and plans to retire in two years from his current position to pursue his passion for sailing full time. It was the behaviors of this veteran assistant principal that I examined in an effort to describe the relationship between his leadership and his school's climate. 


\section{Order and Discipline}

Jim Wharton devotes the majority of his workday to the maintenance of order and discipline at Valley Middle School. His behaviors in this pursuit can be categorized as either proactive or reactive. In the proactive category, three themes emerged: (a) visibility, (b) instruction, and (c) relationships with students. In the reactive category, three themes were also evident. These relate to the three constituent groups with which he works: (a) students, (b) teachers, and (c) parents.

\section{$\underline{\text { Proactive Behavior }}$}

\section{Visibility}

My observations suggested that Jim Wharton is nearly always in the halls and common areas of Valley Middle School during passing periods, throughout the two lunch periods, and before and after school. In addition, he frequently visits classrooms when time permits.

As he moves through the halls and common areas during passing periods, he greets students with comments such as: "Hey Nick, saw the thing you did in science. Good job." "Stefan, how was your report card? Your mom happy?" "Hi, David. You're going to have a good day, right? Good." "Let's get to class please," he said one day to a boy still in the hall just before bell. Then, as a girl hurried toward class after the bell rang, he asked, "Hello Elsa, why are you in the hall after the bell?" When Elsa showed him a bathroom pass, he responded, "Thank you, Elsa; good to see you. You look nice today."

Wharton's physical presence is also evident in the middle of the day when 1,150 hungry adolescents rush to their 30 -minute lunch breaks. The school has to have two 
lunch periods due to the physical limitations of its cafeteria and lunch area that were designed for a much smaller student population. With 650 students at the first lunch period and 500 at the second, the eating area is extremely crowded despite the use of two shifts. In addition, Valley's lunch area, like most Southern California schools' eating areas, is outside under two large, open shelters. This outside location creates even greater management challenges than an inside space would present.

Though I often observed him rushing out to the lunch area after the bell had rung, Wharton was always visible during and immediately following these crowded lunches. He would move continually between the tables, greeting students by name. He often shook their hands, particularly the boys', as he asked questions such as, "How's it going, Bob? Are you having a good day?" When the occasional student ran between the tables, the action would produce an immediate response such as, "James, pull your pants up, sir. Where are you running to? Walk, please." These interventions produced immediate results and were always concluded with Wharton thanking the student for his/her compliance. Only during the first few minutes of the lunch periods, when students sprinted from all directions in attempts to reach the long food lines before their competitors in the race, was the assistant principal often not clearly visible.

This need to be constantly vigilant, expressed often by Wharton during our conversations, was particularly important to him during the crowded, unstructured lunch periods. He described this need by saying:

When I'm at lunch talking to students, I'm listening to them, talking to them, keeping my eye on the total situation. So I don't take myself away from that 
situation for more than just a few seconds. That's all it takes for something to occur.

One day as I stood talking to him in the lunch area, I witnessed this practice as he constantly scanned the students, even as we talked. "Hello, Mr. Wharton," a girl said as she passed us. "Hello, Virginia," he replied, looking at her and smiling only briefly before returning his gaze to the lunch area. A short time later, he stopped in the middle of a sentence with me to say to a student, "Garret, make sure your trash is picked up. Thank you." He then resumed our conversation where he had left off before the intervention with Garret. Just seconds later, he interrupted me in mid-sentence to say to a group of four boys engaged in playful pushing, "Gentlemen, find a place and sit down."

This pattern continued until only one student remained in the area after the bell had sounded indicating the end of lunch. As the boy walked by us, hurrying to class, Wharton asked, "Sebastian, where are you going?" "To class," the boy replied. "Hurry up, you're going to be late," Wharton responded in a stern voice. Then, walking away from me at Sebastian's side, he quickly added in a much friendlier tone, "How's that eye? You going to keep snow boarding?" Sebastian and his assistant principal parted at the end of the walkway. With the second bell, the lunch area and halls were clear of students, and Wharton was back in his office to deal with student referrals from teachers for 30 minutes until the next lunch period began.

Wharton stated that his presence in the halls and common areas of campus is to "monitor," to "touch base" with students in order to see "how they are doing" and to establish "the tone of the school." He feels that when students are moving through halls, at lunch, or in other areas outside of classrooms, there is increased potential for "conflict 
and commotion." "If I am being visible," he said, "that really reduces the opportunity for children to misbehave. I feel that it is very important for me to be in the hallway during each passing period." He summarized his views regarding this role best when he said, "That is my job really. Sort of a high priced scare crow."

This effort to maintain a visible presence on campus is not limited to the halls and other areas outside of the classroom. "I also make it a point on a daily basis, when I'm not dealing with students in my office, to walk around and just walk into classrooms," he said, as we continued our discussion on the importance of his visibility. "I'm not evaluating the teachers," he explained. "I'm just walking in to say hi and just kind of make my presence felt, say good morning to the kids."

Eighth grade teacher, Clint Williams, supported Wharton's assertion that he often visits classrooms simply to be seen by students. "He's even out of his office a lot of times when classes are in session," he said. Williams returned to the theme of the assistant principal's visibility a number of times in our conversation. When asked what he thought Wharton's strengths are, the first word he said in reply was "visibility." He voiced strong opinions regarding the state of Valley's campus prior to the arrival of a new management team that included Wharton. "This campus was scary," he said. One of the things to which he attributed the school's subsequent transformation was the new assistant principal's continual physical presence. "One of the things the assistant principal [Wharton] did that came in was he made himself very visible," Williams explained. 'He's out of his office every passing period, and he's walking around campus."

This theme of visibility was evident in the principal's comments about Wharton. 
She said:

$\mathrm{He}$ is out there on the campus very visible, very accessible. [He] wears a walkie talkie so that he can be contacted easily all the time. And he's also there constantly reminding students and redirecting students and holding them accountable and being vigilant and being observant.

Katherine Summers, the school's guidance counselor, supported the principal's perceptions when she returned frequently in our conversations to the theme of the assistant principal's visibility on campus. "He's very visible," she said. "He's always walking through the campus." She attributed this in part to what she regarded as his strengths. "Jim is a master of working with kids," she said. "His strength is in working with kids," she added for emphasis. As a result, she felt that this led him to spend his time in direct contact with students, even to the detriment of some of his other administrative duties. "He's the worst guy in the world in paper work and organization," she said one day with a laugh. "But, you know what, lots of people can do that." Smiling now, she continued her thought with, "His gift is with working with kids, and his gift is discipline."

Summers quickly explained to me that, when talking about this gift, she was referring to Wharton's proactive behaviors with students and most significantly to his personal contact with them. Describing these behaviors, she said:

He's rarely in his office unless he's working with kids. Otherwise, he's out on the campus, and he's poking his head into classrooms so kids see him. He's out every single passing period. So he knows the kids. He knows their groups, he knows their MO's. He's out there, he's watching, he's observing. 
Summers pointed out that, at Valley, teachers and classified staff are also expected to be in the halls before school and after school and that there are lunch duty aides in the lunch area during the two lunch periods. Nevertheless, she noted, "Jim doesn't just sit in his office. He's still out there, walking around."

Linda Garcia, the school's Title I program facilitator and bilingual program coordinator, strongly supported these observations of the guidance counselor. When asked her opinion as to why she thought Valley has a reputation for being a safe and orderly campus, she first talked about school climate, but quickly turned to the theme of Wharton's visibility. "Jim is very visible on campus," she said. Then, like Summers, she spoke of how his physical presence in the halls and other common areas are particularly effective because of how "he reads" students. "He has a real strong sense of student behavior and those indicators that can go up, that could lead one to believe that there might be a problem," she explained. "Jim has a very keen sense of students who could create problems," she said, "and that anticipation of student behavior is critical because, by anticipating, you can often avoid any problems."

Classified employees also agreed that Wharton's visibility was critical to order and discipline on Valley's campus. For example, Carol Harris, the school's office manager took note repeatedly of the assistant principal's availability and visibility. She referred to his classroom visits, his quick responses to emergencies, and his consistent presence throughout the campus. She remarked how, when she or a teacher needs him, she will call and "he comes running." Harris offered the opinion that one of the primary reasons for the order and discipline on campus was the constant supervision of students by Wharton. "The VP [sic] is always out there," she said. "Even if he's in management 
team meetings when the bell rings [for passing period], he goes out for hall duty and comes back in [after the halls are clear]." The In-School Suspension aide supported the office manager's opinions and observations. "He's available to them [the students]," she said. 'I mean he wanders around. He's always very, very, very visible. He's right there, always out there. And the kids, I think, feel secure because he is there."

\section{Instruction}

Wharton visits all classrooms once a month to talk about a variety of topics such as bullying, harassment, fighting, drugs, alcohol, and weapons. He feels it is important to cover these issues face-to-face with students in small groups in order to have maximum impact. In these sessions, he discusses the inappropriateness of such things as bullying, the actions students should take if they ever encounter these behaviors or situations on campus, and the consequences they will face if they are ever the cause of such problems. The presentation is delivered from a script developed in conjunction with the counseling department. Before Wharton leaves the class, every student signs a document that acknowledges that he or she understands the content of the presentation and the consequences for being involved in any of these high visibility disciplinary infractions.

Veteran teacher, Harry Locke, feels that this classroom visitation strategy is effective in teaching and reinforcing expectations. "I like his philosophy," he said in talking about Wharton's practice of visiting the classrooms. 'Put out small fires before they become big and be proactive. Don't wait for big problems to come up. Sometimes you'll never know what effect you have," he continued, "because you don't have the big problems because you've taken care of it with the short, little bursts of energy reinforcing and so on." 
Wharton also appears periodically on the school's morning broadcast that is transmitted to all classrooms on the campus. After the student portion of the broadcast, he comes on to discuss the same topics covered by his classroom presentations, often connecting them to the character traits of the Valley Way. He also uses this medium to talk about current behavior issues that are of concern to the entire school community. One morning when I visited the school, for example, he discussed safety issues regarding the use of skateboards by students as a means of transportation to school. Students had been riding their skateboards in the street, resulting in complaints to the school and police from local residents. Wharton pointed out that this was in violation of a number of the character traits of the Valley Way, such as responsibility and cooperation, and made clear that if the students involved did not solve the problem, he would. I learned later that he ultimately resolved the issue himself by banning skateboards from campus.

The need to instruct incoming students on behavior expectations is also important to Wharton. Every year in May he visits all of the elementary schools whose students will attend Valley the next year. "I have joined my counselors in going to the fifth grade feeder schools," he explained, "giving them [students] a little spiel about my expectations." He feels that this effort, along with the fact that many of these incoming students have had siblings at Valley, helps ensure that the new sixth graders will arrive on campus with knowledge of what is expected of them. As he put it, "They have a sense of what's going on at Valley with me." In addition, Wharton meets personally with every student who transfers into Valley during the school year if there is any history of discipline problems in the child's record. In sessions with the student, his or her parents, and the grade level guidance counselor, Wharton reviews in detail the school-wide 
discipline plan and his expectations regarding student behavior at Valley. According to Katherine Summers, in these conferences "he has a pretty standard speech. He says, there are several things that I will not tolerate on my campus, and disrespect to my staff is the first one." She concluded her comments regarding these meetings with, "He sets that tone from the very beginning."

Linda Garcia feels that these efforts on Wharton's part are particularly effective. She noted that he frequently refers to the character traits of the Valley Way in his counseling of students sent to him for discipline infractions. "If the student is new in school and not familiar with that," she said, "he'll teach them. He'll take that opportunity and give a little lesson right there. If the student has been a student of ours and should know," she continued, "he'll give a refresher course right there." She also took note of his efforts to indoctrinate incoming sixth graders: "He also takes very seriously the incoming sixth grade report from the principals of those students who are at-risk," she said. "And he makes a point of checking in with those students the first couple of weeks of school to see how they're transitioning to Valley."

In our early conversations, Wharton expressed confidence regarding the impact of his efforts to instruct students in expected behaviors when he said:

If I can spend five minutes in the classroom and it affects 35 students in a positive way, it can probably save me a couple of hours dealing with a discipline issue with a child. So it's really good time management.

Later in the study, however, he came to question the effectiveness of his methods.

This self-doubt was relayed to me one afternoon following his participation in a district administrative hearing. He had been a member of the panel convened to consider 
four students from another middle school for expulsion. The students had brought knives to school in anticipation of a fight with high school students later in the day. This experience had clearly affected Wharton in a number of significant and profound ways. One of these was the failure of the other school's proactive interventions to prevent the presence of weapons at school. The reason this disturbed him so was that the school had been using his program. Its principal and assistant principal had been so impressed with the program's contents and its apparent results at Valley, they had duplicated it at their school. Now it had clearly failed to deter the four students from bringing weapons on campus.

With a voice filled with frustration, Wharton shared his feelings. "After all the interventions we've done over the last forty years, guess what? They're still fighting after school," he said. "I guess that's what really hit home to me at that administrative review," he continued. "There, Mason Middle School did everything right, having these kids sign a document after a spiel about weapons. Even one of the boys had apparently watched some video tapes and done some other things about gangs and knife things," he added. "But really, it wasn't having the effect that we thought it would have." $\mathrm{He}$ paused and thought for a moment. "That's kind of interesting," he finally said. "That's something that maybe someone should look into." After another pause, he shook his head and concluded, "We do all these wonderful things, and we think we're doing something, but they probably help the kid out who is never going to do it in the first place."

\section{Relationships with Students}

Despite his concerted efforts to be out on campus acting as "the sheriff," Wharton 
also appears to work hard to establish and maintain positive relationships with students. "I like to be proactive with the students," he said. "If I develop that relationship, I find that my job is a lot easier. I'm not fighting with them. It's not me against them."

It was evident that, to Wharton, strong, positive relationships with students form the foundation of his proactive efforts to modify potentially disruptive student behaviors and maintain an orderly campus. He returned repeatedly in our conversations to this theme. "I walk around talking to the kids," he said one day as he described his relationship-building strategies. "This means talking to them," he explained, and asking questions such as: “How's it going? How's Mom and Dad? What did you do last night?" He described how, at the end of the day while monitoring students departing campus, he will say, "Bye, have a nice day. Say hi to Mom and Dad for me." He viewed the lunch period as another opportunity to build relationships. "Lunch is another time for me to be visible, talking to the children, cracking jokes with them," he said. "Whatever, just to let them know that I'm there."

Wharton feels that an important way to make these personal connections is to know students' names. 'I make it a point to know as many of my children by their first names as possible," he explained. "So I see them in the hall. I say how's it going, Jose? How's it going, Sally, David? They seem to appreciate that." He feels he is very successful in this effort, offering the opinion:

If I talk to a child once and he tells me his name, there's about a nine out of ten chance I'm going to remember his name when I see him again. It gives a personal relationship between me and a student.

I initially found it very difficult to believe that the assistant principal of a school 
the size of Valley could know the names of most of his students. Frequent observations of Wharton in common areas of the campus, however, revealed that he did indeed seem to know most of the school's students by name. Even early in the year he greeted those we encountered in the hall with comments such as: "Hello, Tiffany. How are you?" "How's it going, John? Having a good day?" Interventions with students in the hall were nearly always personalized through use of the students' names with comments such as: "Let's get to class please, David." "Hello, Elsa. Why are you in the hall after the bell?"

The same was true during other times of the day. I seldom witnessed Wharton ask a student his/her name. For example, one afternoon, as we left his office two hours after school was over, we found a student sitting alone in front of the school. "Why are you still on campus, Victor?" Wharton asked the boy by name. Victor replied that he was waiting for his ride that he expected to arrive any minute. "Thank you, Victor," Wharton replied before reminding the student to wait there and not wander around the campus.

In conversations with the guidance counselor, Katherine Summers, these observations were supported by her comment: "I think he knows just about every child on campus. Even the kids that he doesn't deal with." This, she explained, was "because he is always in the hallways. He is always in the lunch area, and he is dealing with kids more than just the ones who come to his office for discipline." The In-School Suspension aide concurred with this assessment. "He knows every student in this school by name," she said. "He knows pretty much what's going on with each student." Wharton summarized his continuing efforts to establish and maintain relationships with students by saying: 
I spend time talking to the students, redirecting them, trying to find out what we can do together to make their stay here at Valley a better one. To help me with that is establishing relationships with children. It's not me against them. I'm not the bad guy even though they know I'm willing and am perfectly capable of being the bad guy if they want me to be.

The principal of Valley supported this self-assessment of Wharton's when she referred to him as the "ultimate enforcer" at her school, but also quickly described his successful efforts to "build that rapport which is kind of a corner stone for the school environment that you want to create." Katherine Summers expressed even stronger opinions in this regard when she said, as noted above, "Jim is a master of working with kids. His gift is discipline." She was quick to explain, however, that by discipline, she meant "the true word of discipline, and that is in teaching, and setting up expectations, not just in doling out the consequences." At another time, she returned to this theme, saying, "Jim is a marvel at working with kids. His gift is in working with kids, forming relationships." Laughing, she described to me how he would have his secretary call him on his radio 15 minutes into meetings as if he were needed in the office so that he would have an excuse to leave. "He hates meetings," she explained. "He doesn't have the patience for the politics part of the job. But I think he is really in his own element when he is working with the kids."

Linda Garcia, the Title I program facilitator and bilingual program coordinator, attributed Wharton's positive relationships with students to what she saw as a consistently positive approach. 'It doesn't matter the situation that he's dealing with the 
student," she said, "he's always very positive and very direct. He has a way of maintaining their integrity no matter what the student has done." She continued by giving me an example of a student with whom Wharton had dealt that day. The boy had brought a knife to school. Garcia recounted how, despite this serious discipline infraction, Wharton "made a comment to the parent that he noticed something really positive about her son." She went on to say that Wharton “just wants the students to accept the consequence, deal with the consequence, hopefully move on and learn from it, and at the same time always maintain their dignity." She noted that in dealing with the boy with the knife earlier in the day, he had said to the student that the boy had made a bad choice. "He uses that phrase a lot, you've made a bad choice," she said, referring to this strategy of Wharton's. She finished her thoughts by saying, "I think the students, when they look at him and he interacts with them, they sense that and they feel that from him."

Charlene Waters, the in-school suspension aide, held equally strong opinions regarding Wharton's ability to connect with his students. She described this ability by saying:

He has a relationship with them. Even some of our kids that [sic] were really incredibly hard will come back when they're in high school and head straight for his office, and he's always pleased to see them. He sees things in kids that you can latch on to. He sees that one thing that you can use to bring that kid out of where he is, or where she is, and he latches on to that and uses that to start up a dialogue and communication.

She concluded her thoughts regarding Wharton's ability to establish relationships with 
students with the comment: "He's really good at that."

The teachers with whom I spoke agreed that one of Wharton's strengths was his ability to establish relationships with students. When I asked eighth grade teacher, Clint Williams, if he had seen this trait in the assistant principal, he answered without hesitation, "Yeah. And that's the key." He then spoke of how it was hard to articulate the things that he felt empowered Wharton to build connections with students, but finally offered an opinion as to why he thought the assistant principal was able to connect so well with students. "If you look at Jim's history as a classroom teacher," he said, "he started off in special education teaching very tough kids where there's no place to send them. You're it." Finishing this thought later, he said:

I think that's one of the things that helps this assistant principal. He was at that point of knowing that I have this kid, there's nowhere to go. I'm going to have to try and make a connection with this kid.

Even Susan Lundstrum, the seventh grade teacher who had a number of complaints about Wharton's performance, agreed that his relationships with students are special. After expressing her frustration with what she felt to be his inattention to paperwork and miscommunications with teachers regarding teacher referrals, she pointed out the contrast of how "it is so interesting how he can communicate with kids." Laughing, she continued, 'Maybe it's why do people work with kids? Because they're not good with adults," she said, answering her own question. After laughing at this possibility once again, she grew serious and concluded her thoughts with, "But he obviously has something special that he's able to do and work through with these kids." 


\section{$\underline{\text { Reactive Behavior }}$}

\section{$\underline{\text { Students }}$}

In describing his job during our first conversation, Wharton focused on the first word of his title of assistant principal. He felt 'the term assistant means you're there to assist." He expanded on this when he said, "I'm here to assist children, to assist parents, to assist staff, to assist my principal, to assist any person or persons on our campus to make the school run efficiently." This concept was reinforced at a different point in the same talk when he described his job by saying:

It's kind of like being a sheriff. You've got to be reactive. You've got to be prepared to make a decision, and always the decision has to be made in the best interest of children and the school, the safety of the school.

This appeared consistent with the principal's comment that Wharton is "kind of like the ultimate enforcer." Wharton's observation that "whenever an emergency situation comes up, I drop everything, and I'm there in a heart beat" seemed to support the concept that a large part of his job is reactive.

The principal, Mary Stuart, made note of the reactive nature of the assistant principal's job when she spoke of how Wharton is "very accessible; wears a walkie talkie so that he can be contacted easily, all the time." This accessibility was clearly important to the guidance counselor, Katherine Summers, when she said, "I really count him as my major administrator because he does more of the day-to-day running of the school." She explained this attitude by noting that the principal normally operated out of view, but with the assistant principal "we're there side by side." Later in this conversation, she returned to this theme when she said, "If I have a burning issue [regarding a student], I 
run and get him [Wharton]."

The classified staff appeared to have this same opinion regarding Wharton's accessibility when there was a need to deal with student behavior. For example, the office manager spoke of how, when a teacher contacts the office for assistance with a student, she will "call, and he [Wharton] comes running." Later, as we discussed the school's procedures for handling upset parents who come into the office, she described how she would say to a parent, "Let's see if I can get the vice principal [sic] for you. And I get Mr. Wharton in here." She concluded with, "I mean the VP's [sic] here instantaneously."

The In-School Suspension aide, another classified staff member, expressed similar confidence that Wharton will respond quickly to her needs that involve students. When describing her procedures with students who require immediate attention, she said, "My first line of defense is Jim. I'll get him on the phone." She explained how she would attempt to work with students before going to Wharton, but said, "If it's urgent, and that means right now, then I'll call straight away. And I think that's really good, because Jim does respond."

Eighth grade teacher, Clint Willians, expressed particularly strong opinions regarding Wharton's responsiveness. As he put it:

If I got on the phone, and I said to the assistant principal's secretary, I need Jim down in my room now, he'll be there in three seconds. It wouldn't be, he'll be here when he can, he'll get back to you, he's with a student, he's with a parent. If I said I need him now [with emphasis on the word now], he'd be here. That's the kind of support teachers want. 
Seventh grade teacher Ken Rizzo also held this confidence that Wharton will respond immediately to teachers' needs. Rizzo teaches a self-contained classroom of students who are with him all day because of a history of academic and behavior problems. As a result, he requires support from the assistant principal in addressing student behavior issues more often than most teachers. "I always feel supported by Jim," he said, as we discussed his group of students. "The minute I get him on that phone," he said, nodding toward the phone on his desk, "I get immediate help."

In all of these discussions, the focus was on Wharton's reaction to student behaviors. As Wharton put it, 'It's like playing poker, but you're dealt a hand in the morning and they cheat, they change the cards on you throughout the day. You constantly have to be prepared for a surprise. The children are very unpredictable."

The unpredictable nature of the assistant principal's job was evident one morning before school as Wharton and I talked in his office while he prepared to begin his morning walk about campus. A teacher on duty in the play area called on the radio asking for his help. Wharton clipped his radio to his belt as he walked out the door and proceeded immediately to the asphalt lot adjacent to the locker rooms where a large number of students were playing various games under the supervision of the duty teacher. When Wharton arrived, the teacher explained that a student was refusing to follow her directions. There had been a conflict between the boy and two other students that she had interrupted. The other two students had complied with her directions, but Brad had refused and was now standing in silent defiance. The other students were watching to see what would happen.

Wharton's first action was to direct all other children away from the immediate 
vicinity. When they had all moved, he said to the defiant student in a calm, nonthreatening voice, “Good morning, Brad. What's the problem?" Brad refused to speak. After further attempts to get Brad to talk without result, Wharton gave him two choices, either accompany him to the office or wait until the bell rang at which time his mother would be called to come to school to help resolve the issue.

All efforts to engage Brad in conversation failed, and he remained passively defiant, staring down at the asphalt and refusing to communicate. During this time, Wharton called over a large, male physical education teacher who was in the area and used his radio to request the school's custodian to join him. With the arrival of these two staff members, the three men surrounded Brad as he stood in sullen, quiet defiance. When the bell for class rang, Brad picked up his backpack off the ground and began walking toward his class. Wharton made no effort to stop him. Instead, he called the office on the radio and directed his secretary to call Brad's mother and request that she come to school immediately. The three adults walked with Brad to his class where Wharton stood before the door so that the boy could not enter. The other men remained immediately adjacent to them. This stand off ended with the arrival of Brad's mother. With her there, Brad agreed readily to proceed to the office where he was sent home for the day after a parent conference was arranged for the next morning.

After the incident was over, Wharton shared with me that Brad was a severely emotionally disturbed special education student who had a history of violent behavior. His behavior in the play area was similar to past incidents that had ultimately resulted in violence. Wharton knew from past experience that Brad's mother was available at home in the morning and that the boy normally responded positively to the parent. These were 
the reasons, he explained, that he had used the strategies I observed such as getting the support of the two large adult males while being careful not to say or do anything that might escalate the student. After returning to his office, he scheduled a meeting the next day with the special education department and Brad's mother to expedite the process that had begun earlier in the school year to place Brad in an alternative setting away from Valley's campus.

By the time the incident with Brad was over, the assistant principal's office was filling with students called from classrooms to see Wharton regarding referrals from teachers. After quickly filling his coffee cup, he sat at his desk and called in the first student to begin working his way through the referrals stacked neatly on the edge of his desk until interrupted by the next emergency.

On another day, I watched Wharton deal with such a referral. Sam and Alex, two sixth grade boys, were called to the assistant principal's office because of a report from a teacher that Sam had been bullying Alex. Wharton spent a considerable amount of time listening to each boy tell his story without interrupting him before beginning an extensive session of conflict resolution and counseling. He talked about respect and courtesy, connecting them to the Valley Way character traits program in the manner that Katherine Summers and Linda Garcia had described in my conversations with them about Wharton's strategies. He discussed feelings with the boys and referred to the "golden rule" guidelines for treatment of other people. Nevertheless, he concluded the session by saying to Sam, "Can you do me a favor, Sam? Don't call names. It's not acceptable." This was done in the same calm, non-threatening voice he had used throughout the session. But then he leaned forward in his chair, placing himself in close physical 
proximity to Sam, continuing now in a low, stern voice. 'Next step if you don't stop, Sam," he said, "I'm going to have to call your parents and take further action. You understand, Sam?' It seemed apparent from Sam's reaction that he understood.

Wharton did not give Sam a punishment for his behavior, but rather ended the counseling session with this warning followed by thanking Sam for his attention and cooperation. This strategy with Sam reflected Wharton's often-stated opinion that education, not punishment, is the most effective way to change students' behaviors. The session with Sam was also an example of the kind of scenario, that had emerged in teacher interviews, that created the potential for conflict between Wharton and teachers who send a student to the assistant principal for punishment, only to find out later that the student had received counseling and a warning from Wharton rather than a consequence.

It appeared to me that Wharton was playing a role in this situation as he went from quiet and supportive in most of the conference to stern, and even threatening, at its conclusion. By this time, I had often witnessed him modify his behavior quickly and dramatically in dealing with students. He seemed to be tailoring his persona to the particular student and situation. Katherine Summers, from her perspective as a guidance counselor, supported this observation when she described how she would go to Wharton for support with interventions she was attempting with students in the counseling office. "I get to be the good cop, and he gets to be the bad cop," she said, describing how he would assume the role she requested. She returned to this theme in a later conversation when she again referred to how Wharton assumes different roles. She spoke of how he will assess a student and "play the role, the benevolent father giving your son a talk or come on with the mean face." "And I love it," she continued, "when he'll come on with 
the mean face and look over at me and wink. So he knows how to work the kids and give them what they need."

Such efforts to work with students to help them change their behaviors seemed to be built on a combination of Wharton's underlying philosophical and pragmatic approaches to discipline. One day in his office, he described his philosophy regarding student discipline as follows:

You know, discipline is an interesting process. I look at discipline and count discipline as more of a tool, not a club. I try to use, to set up a discipline program here where I really work with kids on making choices. We have to keep in mind they're still children and they're still prone to using poor judgment, and our job is to help them make better choices.

This attitude was consistent with his repeatedly stated position that "if punishment worked, we would have no one in jail." At one point, when offering this opinion, he added, "You do punish children. You do give consequences, but there has to be more."

I decided one afternoon, as we neared the end of a conversation, to test this position regarding punishment by asking Wharton an opinion question. I described a scenario that was one I had recently encountered at my own school. After considering the effect that my own subjectivity might have on the topic, I decided to use that subjectivity to advantage and put the question before Wharton to see how he would handle the situation. I described a hypothetical student who transferred to his school from a neighboring district after spending the previous two years in that district's alternative school for children with extreme behavior problems. The student and her parents maintained that she had changed and would meet his school's expectations if only 
given a chance. After providing details regarding the girl's academic and behavior history, without revealing that this was a real scenario from my own school, I asked Wharton his opinion as to what should be done with such a student and how he would react to this situation were it suddenly presented to him by the appearance of the child and her parents in his office. Without hesitation, he answered emphatically, "I would give her a chance."

As we continued our discussion, he offered the opinion, "If the child has expressed a willingness to turn it around, I particularly want to give a person a chance." This was consistent with his frequently stated position that punishment alone does not work, that students are going to make bad choices occasionally, and that his job is to help them do the right thing. As almost an afterthought, however, he noted he would be careful to investigate why the girl had been in an alternative setting and then stated firmly, "If it was [sic] for some violent act, I might think differently."

This was indicative of Wharton's frequently stated policy regarding how he reacts to violent or potentially violent students. When violence was an element present in student behavior, he consistently expressed a distinctly different attitude regarding punishment. Pursuing this theme one day, our conversation turned to four students who had been brought before an administrative hearing for expulsion in which he had recently participated. When I asked what he would do with these four boys, who had brought knives to school, he answered immediately and without hesitation, "Remove them." $\mathrm{He}$ then continued by saying, "You send a really strong message that they don't go to any school in the state of California for at least a period of time." He went on to explain that he had studied each boy during the hearing and had decided, based on the testimony and 
body language of each, that "these kids are going to do it again." He expressed a strong opinion that, even with counseling and intervention programs, the boys would not change. Though he acknowledged there was a possibility that such strategies might work, he concluded that "looking at the boys, watching them, push comes to shove, they were in a state of denial that they were even intending to do anything, and I just feel like their kind eventually would be a danger to society."

In the case of these students, it was clear that a second chance was not an option Wharton was willing to consider, and, consequently, he was not prepared to have them on a regular school campus with the potential of violent behaviors to which the assistant principal would have to react. In the case of violent or potentially violent students, punishment in the form of removal from school was not only a viable alternative to Wharton, it was the only acceptable course of action.

Wharton finished our discussion of the four boys by relating the story of a former student, Charles. He described how he had first met Charles as the student was riding his bike through the bus circle in violation of school rules. "I pulled him into my office. Right away I knew I was dealing with someone who had a different point of view," he said. He moved quickly to the end of his account by saying, "To make the story short, Charles is now in jail on one million dollars bail for shooting someone in Valley Center." After relating Charles' history between Valley Middle School and his current incarceration, Wharton concluded, "So there are those few students who simply we're not going to reach, and we can recognize them, and we need to make sure that they don't hurt kids in school." In the case of students he placed in this category, it was clear that Wharton's reaction to their behaviors did not include counseling and that a second chance 
was not an option he was willing to consider.

Despite this ready willingness to remove students whose behaviors he viewed as a threat to the safety of his campus, Wharton nevertheless continued to return often in our conversations to his position that punishment is not the answer to student behaviors that do not meet school expectations. Late one afternoon in his office, he related his pigeon story to illustrate this philosophy. In a psychology course in college, his class did an experiment that sought to determine how much of a punitive consequence it would take to eliminate a learned behavior. To do this, the students trained a pigeon to peck a disk in its cage to release food. After the pigeon had mastered the behavior, they began to administer an electric shock to the bird each time it pecked the disk. The level of shock was increased over time to observe the point at which the bird ceased its behavior because of the negative consequence. Only when it went into convulsions, did the pigeon stop.

Though the experiment had questionable transference to humans, this experience had remained strong with Wharton over the years and was reflected in his conviction that "it's not the consequence itself that is going to get that child to stop doing what you don't want them to do." "Give the pigeon an option," he concluded. "In other words, you're going to convince this individual you want the new behavior to become their behavior because they want it to be their behavior, not because you're telling them this is what you should do." On another day, he returned to this theme when he said, "We expect them to do what we want them to do. Well, they've got a whole other game plan, so their plan has got to be your plan." This philosophy seemed to form the basis for Wharton's strategies in reaction to students with unacceptable behaviors. 
Regardless of the offense, Wharton clearly spent a major portion of his day reacting to student behaviors in one way or another. The conference with Sam and Alex was an example of reaction to students over which he had some control in terms of personal time management. The intervention with Brad was a rather extreme example of the reactive nature of his job over which he had no control with regard to timing. Both were typical of what I observed during my visits to Valley in that Wharton rarely went more that a few minutes during the day when he was not required to respond to an emergent student issue. He summarized this situation as follows:

I find it extremely difficult to plan. Let's say I have to sit down and write something or that would take a lot of concentration on my part. I really can't do that because I will be interrupted probably at least three or four times in a 15minute period of time.

This self-assessment was supported by my observations. One day, for example, I arrived at Valley shortly after the second lunch period to spend the remainder of the day shadowing Wharton. I had chosen this afternoon because he was scheduled to participate in a Student Study Team meeting, and I wanted to observe him in that environment. I found him at his desk on the phone with a parent. A half empty container of soup from the school cafeteria sat cold and uneaten on the edge of his desk. When he hung up the phone, I noted the uneaten food and asked when he had bought it. "I got it at lunch time," he replied. "Then why is it still sitting there?" I asked. Laughing, he answered, "Well, I arrived back from my administrative hearing [at the district office] about half an hour before lunch." He then explained that he hadn't had time to eat before lunch duty. "After lunch was over," he continued, "I went in and got a bowl of soup, but I had a 
concert [in the school auditorium] that started." He went on to explain that as soon as the concert was over, he had gone back to his office to return an urgent parent phone call. This was where I found him, the soup still uneaten.

We reviewed his day up until this time. It had started at 7:00 a.m. with three parent meetings in succession. Two were intake meetings for new students who were transferring from other school districts, one of whom had an extensive discipline history. From prior conversations and observations, I knew that Wharton always met with new students and their parents to, as he put it, "size them up" and to make clear the school's expectations. The third meeting was with the parents of a school phobic child, conducted to develop an action plan for the boy to help him overcome his phobia. From here, Wharton dashed to the district office, approximately three miles away, where he spent the remainder of the morning in the administrative hearing.

The rest of his day was equally full. After the Student Study Team meeting, which lasted almost an hour, he spent the remainder of the school day in conference with a special education classroom assistant who had received a poor evaluation. The conference was interrupted twice by phone calls from parents demanding to talk to the assistant principal. Just prior to the bell that signaled the end of the school day, he picked up his radio as he hurried out of the office to go to a busy intersection near the school to monitor students crossing the street. As he was returning to campus, he received a call on his radio informing him that there was an altercation between two students in front of the school. As a result, he picked up his pace and quickly arrived at the scene. After defusing the confrontation, he sent the two students home, informing them that he would see them in his office first thing in the morning. Entering the office, he was greeted by 
his secretary with the news that two irate parents had called, demanding a return call immediately. He contacted both and, in each case, appeared to resolve the problem. As he hung up the phone after the last conversation, he turned in his chair to me, leaned back, and relaxed for the first time since his workday had begun. It was now four o'clock as we began an interview. The soup remained on the side of his desk, still uneaten.

\section{Teachers}

In discussions with the principal and teachers at Valley, all placed great emphasis on the need for teachers to deal personally or within inter-disciplinary teams with students who do not meet expectations before sending them to the assistant principal. Veteran teacher, Harry Locke, brought a unique perspective to this issue not only because of his long tenure as a teacher, but also as a result of having served as an assistant principal and principal of middle schools during a short time in his career before returning to the classroom. He used a metaphor to illustrate his feelings when he spoke of a principal he once knew who said, when referring to discipline, "I prefer teachers who are willing to skin their own skunks." Locke felt strongly that "in instruction, in your classroom, you're going to get so much more done if you invest the time to take care of the discipline side of it."

Seventh grade teacher, Susan Lundstrum, expressed equally strong opinions regarding the need for teachers to handle discipline problems within their classrooms. "I write very few referrals," she said firmly with a stern voice that I could imagine her using with difficult students. With an equally serious demeanor, she stated emphatically, "I don't have behavior problems in my classroom." This was said despite the fact that we had just been talking about her referrals to the assistant principal. Nevertheless, it was 
clear that Lundstrum agreed with Locke that discipline should reside first with the classroom teacher. The principal echoed this attitude when she said:

We urge teachers to give redirection as a first step rather than a referral. Talk to the students, tell them what they did wrong, tell them how they should have done it, coach them to be what they know they can be.

Discipline statistics, observed classroom behaviors, and inter-disciplinary team procedures, including an "infraction log" to deal with minor behavior problems, seemed to support these positions. The assistant principal's role with regard to teacher support with discipline problems appeared to be reserved for major issues. The principal reinforced this when she spoke of her insistence that teachers teach and model the school expectations and consistently enforce them in the classroom. In the same conversation, however, she emphasized:

It gives the teachers a sense of security seeing that AP out there and around and knowing that they have his support in case a student does make a bad choice. They know that AP is very, very easily at hand and can be there physically to help intervene if there's a need to.

On numerous occasions, Wharton expressed his agreement with this school policy that discipline should reside as much as possible with the teachers and the interdisciplinary teams. Nevertheless, there was a consistent theme throughout all of our conversations: the imperative to be available at all times to meet the immediate needs of the teaching staff. "I feel like my job is support to the staff and the school," he said one day as we discussed this aspect of his position. "So if there is a problem," he continued, "I feel it's in my best interest to address it when it's happening and not to put it off." 
On another day, when we were discussing meetings that he is required to attend, Wharton described how this philosophy affects his ability to participate in such group sessions. He explained that he could not be confident of ever completing a meeting because of the need to respond immediately to calls from teachers. "If there is a problem in the classroom, and I am needed right away in an emergency," he said, "I can't say, hold it. I'll be there in a minute." He returned to this thought later in the year as we discussed the school's emergency procedures. "A teacher can call me directly when a student is having some difficulty or there's a serious situation that's about to occur in a classroom," he said. "Then I'm on my way immediately." After describing the sorts of things that constituted emergencies involving teachers, he concluded, "Whenever an emergency situation comes up, I drop everything, and I'm there in a heart beat. I think the teachers respect that." This statement was consistent with teachers' comments, such as Clint Williams' when he said, "If I need him [Wharton] now, he'd be here," and Ken Rizzo's when he stated emphatically, "The minute I get on that phone, I get immediate help [from Wharton]."

There was evidence, however, that Wharton deals at times with issues sent him by teachers that are not necessarily as extreme or urgent as Brad's defiance in the play area before school. One afternoon in his office, he shared with me the content of a stack of student referrals on his desk that had been sent to him by various teachers. These included behavior infractions such as: "Rude, sexual behavior behind a coach's back. He flipped a double bird." "Was given a note to be signed by his parents. He never returned it." "Jose and Miguel are constantly bickering with each other. I told them the next time it happened, I would ask Mr. Wharton to help them work it out." Regarding these 
referrals, Wharton said with a smile, "As you can see, some of these things, I would not consider them life threatening."

On a number of occasions, Wharton expressed frustration with such minor teacher concerns. He illustrated this by describing a recurring event in the halls as follows: You're constantly walking down the hall and a teacher will come up with a concern. And another teacher, by the time I get to the end of the hall, has another concern as I'm being bombarded by people with concerns.

He quickly indicated an understanding of his teachers' perspectives, however, by adding, "Of course, all of their concerns are major concerns to them without realizing that I am having to juggle all of their concerns."

Despite such frustrations, Wharton summarized his feelings regarding student issues sent him by teachers when he said, "I never really second guess the teachers on the referrals, even though sometimes I have to chuckle to myself what they are sending kids up here for." Guidance counselor, Katherine Summers, supported this stated position. "He will back them up," she said, referring to the teachers. "The teachers know if they feel strongly about a consequence for a child, if they write that on there [the referral], then he'll carry through with that consequence."

Seventh grade teacher, Susan Lundstrum, agreed with this assessment. She described how she always attaches to each referral a "sticky" that specifies the consequence she would like the student to receive from Wharton. "He will always do what I have delineated, what I want him to do," she said, referring to the assistant principal's response to her strategy. "He does it," she added with emphasis. Ken Rizzo agreed with Lundstrum when he said, "He will always do what I ask him to do." 
Wharton's explanation for this policy for complying with teacher requests such as Lundstrum's and Rizzo's was, "You have to work on a relationship with them [teachers] that when they have a problem, you're there. You're taking care of the problem, and they realize that you have their concern, their best interests at heart."

In other conversations, however, Wharton appeared to contradict this position. He stressed repeatedly the importance of putting the interests of students first rather than those of teachers, even at the risk of upsetting the teachers. For example, one day as we discussed his strategies for handling parents and teachers who disagreed with decisions he might make, he stated, "I feel like the decisions that I make are in the best interests of the school and the best interests of the student, and I'm not running a popularity contest." This was said very forcefully almost immediately after commenting, "You can't make all teachers happy all of the time. Sometimes they feel like I'm not supporting them, but that just goes with the territory."

In apparent support of this observation that teachers' requests cannot always be met, he returned a short time later in our conversation to the theme of considering the students first in all of his decisions. He quoted a former administrator for whom he had worked who said, "As long as you are doing things that are in the best interest of children, you can't go wrong." He concluded his thoughts on this subject with, "That's the bottom line." Nevertheless, he said just minutes after making this strong statement: You have to know your clients, and the main client here is the teacher. I mean the parents come and go, the children come and go. You live with the teachers. They can either work with you, or can work against you, and they can make your experience here difficult if they choose to. So it's in your best interest to make 
sure you really work with them.

This tension between the need to do what teachers want done, on the one hand, and what is in the best interests of students, on the other hand, that emerged in our conversations was evident when I spoke with other members of the staff who worked closely with the assistant principal. One of these was Linda Garcia who used the term "juggle," the same term used a number of times by Wharton, to describe his efforts to respond to the many demands of his teachers while always trying to do what he felt was best for students. "He really does balance that, and it's interesting, too, to watch him do that," she said, referring to these efforts. Explaining his philosophy, she added:

He says, you've got to make everybody happy, and so what I don't do today on this end with the teacher, I'll have to make it up somewhere else. That's a real juggle. He's a student advocate, a teacher advocate, a parent advocate all at the same time. And it's interesting and amazing to watch him juggle.

Katherine Summers agreed with Garcia's observations. "Yeah, they [teachers] can always find fault. They get mad at him," she said, talking about what happens when Wharton takes actions with students sent to him by teachers with which the teachers do not agree. "They gnaw on him and chew his ear and get him kind of rankled," she said. "But they know he's a safe person to do that to. He listens, and he's always very respectful to them," she continued. "And if they're driving him crazy, he goes in his office and bangs his head. He doesn't let them know it."

Wharton's constant challenge to juggle his stated need to support the teachers with his conviction to always do what is best for children was clearly evident in the opinions of seventh grade teacher, Susan Lundstrum. "I know that he's often infuriated 
teachers by not coming down hard," she said one day with irritation that suggested she shared this position at times. "Teachers are pissed off about it," she said at another point while discussing a recent decision Wharton had made regarding a problem with two students. Similarly, at yet another time, she followed the positive comment, "I think that kids generally like him, and they respect him," with the negative observation: "Except the problem is, that he's a pushover by parents and by kids." She expanded on this by explaining that, in his dealings with students who have committed discipline infractions, "he'll say, 'ok, ok, one more time"" and keep giving the students another chance. (This tendency on Wharton's part to give students another chance was evident in the counseling of Sam, the bully, noted above.) After pausing for a moment, however, she said, "Although he must have a presence there in his office, because there aren't that many kids who push that one more time." Then just moments later, she made her comment noted above that "he will always do what I have delineated that I want him to do. He does it."

\section{$\underline{\text { Parents }}$}

According to Wharton, parent concerns, to which he has to respond, come in many forms. Examples he provided include student harassment by other students, student grades, and complaints regarding the manner in which teachers interact with students. It was evident that his involvement with issues regarding grades is minimal, consisting primarily of referring the parent to the guidance counselor who facilitates communication with the appropriate teacher or teachers. Parent concerns regarding problems between students are handled in the manner used with Sam the bully. An investigation is conducted followed by a conference with the student or students that 
includes counseling and assignment of consequences if applicable. On completion, a phone call is made to the parents of all students involved detailing his actions with requests to let him know if the problem recurs.

The procedure he described for dealing with complaints about teachers includes first asking if the parent has addressed the issue with the teacher. If the answer is no, Wharton offers to have the teacher contact the parent. If the parent refuses to discuss the matter with the teacher without an administrator's participation, he then arranges a meeting between teacher, parent, and the guidance counselor that he facilitates.

This requirement to deal with parent concerns appears to be a significant part of Wharton's job. Describing what many of his mornings are like, he said:

A lot of times in my morning I'll have a surprise when I arrive. A parent is usually here greeting me with some concern, some safety issue that they'd like me to address or possibly a concern about a teacher. They just show up, so I have to sit down with them and just sort of go through the process of what is their concern, how can I help them, and let them know that I will work on the problem and get back to them later in the day.

This getting back to parents was a recurring theme in our conversations. Wharton explained his policy by saying:

I like to respond when the parent calls. I want to get the message right away, so I can return that call as soon as possible within that day. I don't like keeping parents waiting until the next day, because I feel that if they are concerned enough to call me, then I should be calling them.

Wharton's responsiveness to parents who bring him problems was evident one 
morning when Mrs. Gonzales, a Hispanic mother who spoke only Spanish, appeared at his door accompanied by her daughter, Maria. Although they had no appointment, they were escorted immediately into his office. A bilingual classroom aide interpreted as the mother explained that her daughter was not allowed to walk home from school but was not picked up by her older brother until an hour after her last class. Mrs. Gonzales did not want Maria waiting in front of the school during that time. She wanted her in homework club for both academic and safety considerations. Maria was refusing to go. Wharton stated to Mrs. Gonzales that he did not know Maria. That was a good sign, he added, since it meant that she had no discipline problems. He asked Maria how her grades were. She replied B's and C's. "Good," Wharton responded. "But you can do better." He next discussed with Maria why she did not want to go to homework club. She explained that she did not feel she needed it and preferred to visit with her friends while waiting for her ride. With this, Wharton leaned forward in his chair and said firmly to Maria, "Your mother wants you in homework club. You will go." Mrs. Gonzales smiled as the aide interpreted this for her. Maria agreed that she would attend. "Good," Wharton replied, "I'll be checking." Through the interpreter, Mrs. Gonzales then added that Maria had told her that another reason that she did not want to attend homework club was because of a problem that students were having with the teacher who ran the program. "I've taken care of that," Wharton replied. "Let me know if Maria has any problems with the teacher," he added. With that he thanked Mrs. Gonzales through the interpreter for her interest and support in Maria's education and said good-bye in Spanish.

According to Katherine Summers, the guidance counselor with whom Wharton 
works closely regarding parent concerns, Mrs. Gonzales' satisfaction with the outcome of her conference is typical at Valley. "When people come to do business with the school," she said, "rarely do we have an upset parent. When we have upset parents come, rarely do we have an upset parent leave." She attributed this to the fact that she and Wharton handle things in a way "that the parents feel that they've been listened to and that the situation has been handled to their satisfaction."

Mrs. Gonzales appeared typical of parents who come to Wharton seeking help with problems regarding their students. It became evident after just a few visits to the campus, however, that the majority of his parental contacts are with parents whose students have had to see him for behavior infractions. Late one afternoon, as we sat in his office long after the rest of the staff had departed, I witnessed Wharton in one such conference. We were waiting for Katherine Summers to arrive for their weekly "at-risk students" meeting. I was there to observe this conference during which the two of them share information regarding students with discipline problems and brainstorm strategies to meet the students' needs. As we talked about what I could expect to see, a parent walked in and introduced himself as Mr. Edwards, father of Jenny.

Mr. Edwards apologized for arriving without an appointment. He explained he had come to the school from work hoping to be able to talk to Wharton about his daughter. His business suit, the cell phone on his belt, and his confident manner all identified him as a parent of one of the few students at Valley who are not in the low socio-economic category. Despite the impending meeting with the guidance counselor, Wharton welcomed him, thanked him for coming to talk about his daughter, and invited him to sit down. After introducing me and getting Mr. Edward's permission for me to sit 
in on their conference, the discussion regarding Jenny began.

Wharton reviewed succinctly, but completely, for Mr. Edwards what had transpired that day with his daughter. A student had noticed that Jenny had a small Swiss army knife on a key chain in her backpack and reported it to a teacher. Wharton had immediately brought Jenny to his office and confiscated the knife. He stated to her father that he had determined from her teachers that she was a straight A student who had no discipline history. She knew the knife was in her backpack but had not taken it out or brandished it. Contact with Jenny's mother, who was divorced from Mr. Edwards and had custody of Jenny, had revealed that the key chain and knife were a gift from Mr. Edwards and had been in the backpack since the previous weekend when Jenny had been with her father. Wharton next explained the actions that he was required to take as a result of the education code of the state of California and school district policy, quoting the specifics of both. He stated that, though having a knife at school could result in a lengthy suspension and possible expulsion, he had suspended Jenny for only one day in view of her prior record, the circumstances surrounding the incident, and the strong support he felt would provided by both of her parents.

When he finished this monologue, Wharton asked Jenny's father if he had any questions. Mr. Edwards thought for a moment, and then replied, "She has no defense." He then initiated a discussion with Wharton regarding school discipline that lasted for 10 minutes. Throughout, Wharton mostly listened without offering any substantive response to Mr. Edwards' views. He simply nodded periodically and replied with comments such as, "Yes, that is a problem in our schools today," and "You have a very good point there." When Mr. Edwards stood, obviously ready to depart, Wharton stood also, shook 
Mr. Edwards' hand, and said that Jenny was a wonderful girl who had simply made a bad choice. He added that he was sure this would be a learning experience for her and that what she needed to do now was to put the incident behind her and get back on track at school. Finally, he thanked Mr. Edwards for coming and for all of his support. As he departed, Mr. Edwards responded by apologizing for the trouble this had caused the school and thanked Wharton for considering all aspects of the incident and for only suspending Jenny for one day.

Wharton's conference with Mr. Edwards appeared to validate Summers' position that Wharton handles parents in such a manner that they rarely leave the school upset. Linda Garcia's comments also support Summers' assessment and what I observed in the conference with Jenny's father. In describing Wharton's interactions with parents, Garcia stated, "He is unemotional when he deals with the parent. He's just straight here's the facts. This is what they did. Here are the consequences. If you have any questions or concerns, my door's open." She described his phone calls to parents as "brief, very to the point, and factual oriented." "He listens. He listens very, very well," she said in describing his parent conferences. "Most incidents that I've witnessed with him," she concluded with a smile, "the parent conferences, he has them in his hand."

Trust

In all of our conversations, Wharton referred repeatedly to himself as a resource. "When I first arrived at Valley Middle School, I was referred to as the vice principal," he said. "That term doesn't really describe what we are all about in this particular job. We are assisting," he emphasized. "You're just there as a person, a resource for anyone who has a problem on the campus." As he and I explored this attitude in our conversations, 
what emerged was evidence of three major subgroups within the school community that Wharton serves as a resource: staff, students, and parents. It was these three identifiable groups with which he worked to build and maintain trust through his efforts as a resource provider.

\section{$\underline{\text { Staff }}$}

Wharton feels that the critical element in maintaining trusting relationships with his teaching staff is to ensure that they always feel they have his support. "They look to me for support," he said in referring to the teachers. "Now, they may not always agree with me," he added, "but at least they know that I'm there to support them."

Katherine Summers emphasized this theme of support when she described Wharton's behaviors in meetings that they conduct with at-risk students and their parents. "He has a pretty standard speech," she said. "He says there are several things that I will not tolerate on my campus, and disrespect to my staff is the first one." Wharton noted this emphasis on support for the staff when he said:

I may be a little emotional to children if they're being disrespectful to a teacher or could injure another student. Those sorts of things I will not tolerate on campus, and I have to let the students know that won't be acceptable.

It was clear that Summers feels strongly that Wharton will not tolerate disrespect of Valley's teachers by students when she again returned to this theme in another of our conversations. "He says to kids, there aren't very many things that make me really mad," she began. Then lowering her voice to a stern tone in imitation of Wharton, she finished with, "But one thing that really makes me mad is when students disrespect my staff." In addition to this sort of support with regard to students, Wharton also feels that a 
vital part of maintaining trusting relationships with teachers is timely responses to any requests they might have. He spoke of his time as a teacher when his principal responded the next day to a request that Wharton considered of little significance. He said:

I really appreciated him taking the time. Even the littlest thing that I needed, he was right there the very next day making sure I had it. I always felt that was very important, a teacher asks you, a parent asks you to do something, a student asks you to do something, that you do it as quickly as possible.

On another occasion, he returned to this theme, saying:

If you respond to little things like that [referring to problems in classrooms] for your staff, you build relationships with your staff. When you take care of little things that may not seem like a little thing to them, they are very responsive to that.

Wharton feels that this attitude and his timely response to any request play a large part in his efforts to build trust with his teachers.

It was evident in a conversation that I had with Linda Garcia that Wharton had expressed this opinion to her. She said:

He once said to me that if a teacher asked you for something, that it's really important that you follow through and get it for them. Because fulfilling some of their requests, if you can, is very, very important in terms of relationships.

She went on to conclude her thoughts on this topic by saying, "He's very attuned to the needs of the teachers."

As noted above, however, Garcia emphasized at another time the "juggling act" that she felt Wharton had to play. "He does interact very well with the teachers....[But] 
sometimes they'll get upset with him because they'll feel that the student needed some other kind of discipline or something more serious [as a consequence]." She explained why this happened by saying:

Jim knows the student and the parent and the law and what all of that entails. So he's very good about talking with the teacher and having them maybe not necessarily agree with him, but at least open their eyes a little to see why he does what he does. And that's very important to do, and he does it very well. Charlene Waters, the in-school suspension aide, is keenly aware that Wharton does not always agree with teachers' positions regarding student discipline. She explained this by saying that he believes 'the kids come first, and he's sort of more into how the kids are feeling rather than how the adult is feeling." "He likes to try and sort the kids out," she said. "You know, find out what's going on and why it's going on." She voiced the opinion that the result of such efforts is that "Jim will know more about the student than the teacher will." This leads often to a situation in which "the teacher will perceive that Jim is not punishing the student." She added that his empathy for the students is also a factor affecting his decisions. "He just gets really upset," she said. "I've seen him. You know, some of the horrid situations these kids are in. He gets really upset. He's a very kind person, and he gets very upset."

The principal agreed with the position of Garcia and Waters that Wharton is supportive of the teachers, except when he disagrees with their positions, when she said, "The teachers feel very supported by him, except, of course, in those cases in which their positions are indefensible." Katherine Summers also agrees with Garcia's assessment. "I think the teachers very much respect him and trust that he will back them up. So teachers 
know that he's available. They know he is out there," she said, when we discussed Wharton's relationship with his staff. Because of this trust that Summers thinks exists between Wharton and his teachers, she feels that "they [teachers] know that they can tell him just about anything, and they use him as a sounding board a lot if they're upset about something." She described his listening skills as follows:

They gnaw on him and chew his ear and get him kind of rankled. But they know he's a safe person to do that to. And he listens, and he's always very respectful to them. But not any of the teachers would ever know that, that they were upsetting him, because he has that rapport with them and that demeanor when they're talking to him.

It was evident from my conversation with eighth grade teacher, Clint Williams, that he may not, as Summers suggested, realize that teachers occasionally upset Wharton. His observations regarding the assistant principal's willingness to listen closely paralleled those of Summers. "[He is] willing to listen; willing to take criticism," he said. Williams described how, in team meetings, "the assistant principal takes a lot of criticism" and offered the opinion that "if I were in his seat, I don't know if I could just sit there and listen like he listens without coming back." It was evident that Williams had discussed this topic with Wharton when he said, "I think a lot of times, he's mentioned to me before, a lot of times, teachers just need to get it off their chests." He noted how Wharton had stated, "My job is to sit there and listen." "He's good at that," Williams said. "I'd say that's probably one of his bigger strengths."

It became clear that Katherine Summers' opinion regarding Wharton's willingness to listen to teachers is a strong one when she expressed it once again months 
later in another conversation. "If they need to vent, they can," she said, referring to the teachers. "They know that they can say anything that they want to him. But he is ok with that. He understands that they just need to vent," she explained. She finished her thoughts with the following comments:

They feel comfortable with him and feel that they can say anything that they want to say. And I know as a counselor, I feel that same way in that I really feel that I can say anything I want to him. If I don't agree with what he did, I can say that. On another day, she returned to this theme when she said:

I see trust as I work with Jim because we consult daily, hourly probably. I know that he always respects my opinion and the opinions of his teachers, and he respects the opinion of the kids and their parents. And there isn't really anything that I couldn't go to him with or say to him.

The classified staff seems to share the opinion that Wharton can be trusted to respond to their needs. As the office manager, Carol Harris, and I discussed office procedures, she described the manner in which she responds to upset parents who might come into the office. "I say [to the parent], let's see if I can get the vice principal [sic] for you," she said, "and I get Mr. Wharton in here. I mean, the VP's [sic] in here instantaneously." When asked if she would normally go to Wharton in such cases instead of to the principal, she replied, "Yeah, I think I would. To me, usually the VP [sic] is kind of my first line."

Charlene Waters, the in-school suspension aide, agreed that Wharton could be relied upon to meet her needs. As we talked of trust, she voiced trust in the counseling staff and in Wharton, but made it clear that Wharton is the person she turns to first with a 
problem. "I'll call him usually," she said. "That's my first line of defense is Jim, you know. I'll get on the phone to him." She went on to describe how she might go to the counselors or others for help, but stated emphatically, "If it's urgent, and that means right now, then I'll call straight away, and I think it's really good, because Jim does respond."

At least one staff member does not agree that Wharton is trustworthy. When asked to describe the relationship between the assistant principal and the teachers, Susan Lundstrum replied immediately, "I don't trust him." She went on to explain, "No, because I don't think that he follows through with the referrals. Or he'll, like, one day detention, or, you know, whatever," she continued, trying to give examples as to why she felt this way. After additional thought, she said, "I think his turnaround time is slow. You might get the referrals back with his signature on it a month later. So you don't know what's happened."

What emerged from this conversation was that Lundstrum feels that Wharton is too easy on students whom she sends him when awarding them consequences, the situation described earlier by Garcia and Waters. "I know that he's often infuriated teachers by not coming down hard," Lundstrum said at another point. It was then that she noted her policy of specifying the consequence she expected when sending him one of her students. At the same time, she noted that he always does what she asks regarding consequences.

Lundstrum also feels that parents too easily influence Wharton when he addresses their students' discipline infractions. "He's a pushover with parents," she said in disgust. Yet she stated later in our conversation, "In the parent conferences that I've been in with him, he has always supported me as the teacher." She added quickly, however, "In times 
when the teacher is not there, it is my sense that he will back down to a parent if it means it might cause some difficulty."

In order to determine if other teachers felt, like Lundstrum, that Wharton was a "pushover" with parents, I asked Ken Rizzo directly if he felt supported by the assistant principal when confronted by parents. "Jim always backs me up with parents," he replied. "If a parent has something to say about me, Jim always backs me up and supports me."

Clint Williams also expressed none of Lundstrum's concerns when we discussed his relationship with Wharton. He expressed a high level of trust in the assistant principal when he said, "Basically, what he says, he does. When he said he was going to do something... he never did anything to where people felt that he would say one thing and do another. He kept his word." When I asked Williams if he had ever had a disagreement with Wharton over consequences given students, he replied, 'No, actually. I have never had that experience." He described for me, however, how he had been in team meetings in which other members of his inter-disciplinary team had taken issue with decisions of Wharton's. "The team has said, well, we disagree with you, and we think this should take place and this should happen," he said. He described how "sometimes the assistant principal has changed his mind" and how at other times he would say, "You know what, I really don't have any recourse on this. I don't have any wiggle room."

Ken Rizzo agreed with Williams' assessment and expressed none of Lundstrum's concerns. "I always feel supported by Jim," he said. At another point in our conversation, he said, "If Jim says something will be done, it will be done. He will follow through. He's real good at that." 
Toward the end of my conversation with Williams, he expressed an opinion that suggested a possible source of the conflict between the assistant principal and some teachers such as Lundstrum with regard to student consequences. He said that one of Wharton's greatest strengths was that "he really cares about young people." This supported the perceptions of other staff members such as Linda Garcia, Katherine Summers, and Charlene Waters. But then he qualified this statement when he said, "Sometimes that goes into the weakness category, because I think he's willing to cut kids some breaks that maybe classroom teachers think should not be there. So I guess that could be a strength or a weakness depending on how you want to look at it."

Wharton seems keenly aware of his challenge, illustrated so well by Lundstrum and Williams, to do what he thinks best for individual students while attempting to meet the often-conflicting expectations of teachers. "Sometimes you have to juggle priorities," he said. He explained this need to prioritize by saying:

Sometimes a teacher's concern, you might not deal with as quickly as they [sic] would like you to, but you have to prioritize. If a child is not doing his schoolwork, or a child is pounding on another child, then you have to deal with the child pounding on the other child and not put it on the back burner for the child not doing schoolwork or maybe being late to school.

In another conversation. Wharton shared with me his dilemma of not being able to satisfy everyone, including his teachers. He said:

I would like everyone to like me. But when you're making some of the decisions that I make, somebody's not going to like me. If I make the parent happy, I'm going to make the teacher unhappy. So it's a juggling act. You have to try to 
meet the needs of each one of the parties you deal with.

In yet another conversation, he expressed his frustration in trying to always make the teachers happy. "One minute you can be their knight in shining armor," he said, "and the next minute, you will be the person they're throwing darts at, all depending on what kind of decision you make."

Nevertheless, Wharton emphasized the importance that he placed on maintaining the trust of the staff at Valley when he said, "Your staff morale and your relationship with your staff will make or break you, and it's ongoing." He summarized these feelings succinctly at a different point in our talks when he said, "If you don't have the confidence of your crew, probably you're going to have a very difficult time getting anything done." Yet another time, he summed up his feelings regarding the need to maintain his teachers' trust with the following comments:

You have to know your clients, and the main client here is the teacher. I mean parents come and go, the children come and go, but you live with the teachers.

They can either work with you or can work against you. And they can make your experience here difficult if they choose to.

He concluded his thoughts with the following comment: "So it's really in your best interest to make sure you really work with them [teachers]; not always agreeing with them, but making them feel good about what you are doing."

\section{$\underline{\text { Students }}$}

Wharton places great emphasis on his efforts to establish and maintain trusting relationships with students. "I like to be proactive with the students," he said. "If I develop that relationship, I find that my job is a lot easier. I'm not fighting with them. 
It's not me against them." On another occasion, he related the story of a student who came to him asking for help in avoiding a fight, expressing confidence in the assistant principal's ability to address the issue. Wharton explained his success in such situations as being the direct result of "consistently being positive, working with the kid, consistently working on having a relationship with the child." "That's the word," he concluded. "The key word is establishing relationships."

Katherine Summers, who as a guidance counselor works closely with Wharton on student issues, has strong opinions regarding the trust that she feels Valley students have in the assistant principal. She expressed the opinion that Wharton generates this trust with students because "he is a marvel in working with kids." At another time she described him as "a master of working with kids." She feels that "he knows the kids, he knows their groups, he knows their normal MO's." She described how "he is relational with kids," and how "he cuts deals with kids all the time." "You know, kids never forget those kinds of things," she said. "So I think it goes back to that trust again. The kids know that even when they misbehave, they have that trust in him that they're going to be dealt with." She quickly added, "But I think that they can also trust that they are going to be dealt with fairly." "There is that trust there from all the kids," she said at another point in our conversation, "that he's going to see that this campus is safe and orderly. He doesn't do it alone, but I think everyone kind of looks to him."

Linda Garcia, who also works closely with Wharton on student related issues, shares Summers' opinions regarding his ability to connect with the students at Valley. "He reads them," she said, "and he knows he needs to check in with this kid more." She spoke of how "he'll talk to the student, try to find out what's going on, what's bothering 
him." She described how "he'll find out what interest the student has, and as time goes on, if he has the need to interact more and more with the student, he'll capitalize on that." Toward the end of our conversation, she described his interactions with students with the following comments:

I think it doesn't matter the situation that he's dealing with [with] the student, he's always very positive and very direct. He has a way of maintaining their integrity no matter what the student has done. His passion and commitment to the kids, it's phenomenal.

Charlene Waters, the in-school suspension aide was almost reverential in articulating her perceptions regarding the ways that Wharton builds trusting relationships with students. She described his strategies by saying:

He sees things in kids that you can latch on to, that's worth latching on to. And he sees that one thing that you can use to bring that kid out of where he is, or where she is, and he latches on to that, and uses that to start up a dialogue and communication. He's really good at that.

Waters agreed with Summers that "the students have a lot of trust," giving much of the credit for this to the assistant principal. She spoke of how "he can look at a student and say, there's something wrong with that kid. And he'll go over and say, what's up, what's happening?" "You know," she said, "he just zeros in on that." She described how he "knows every student in the school and pretty much what's going on with each student." "He spends a lot of time trying to sort out things for these students," she said. "You know, he doesn't just do the lip service, he actually walks the walk as well. He's in there, in the trenches. But you know, I think that's basically what he does." 
Even Susan Lundstrum, despite her issues with Wharton, commented throughout our conversation on the positive relationships that he has with students. "I think kids generally like him, and they respect him. They listen to what he says," she said, as we discussed Wharton's contribution to the safety and order of the campus. Later, after voicing vigorous complaints about him being too easy on the students, she added:

But I also think that he must have a skill that the kids feel respected and valued. I think when he works with kids, he must have a skill where he is able to rap with them or whatever he does, because the kids respect him, and they respond to his input.

A short time later, she suggested that part of the reason that Wharton has the respect of the students is "he's physically intimidating because he's tall. He's a man." "But he obviously has something special that he's able to do and work through with these kids," she said, "because they, it's not like they fear him. But they don't want to go to his office." She finished her thoughts with the following opinion:

But I think that really if someone [a student] would sense a severe threat, I think he's open enough that they [sic] would go to him. I do. And I don't know where I get that, but I do have that sense.

\section{$\underline{\text { Parents }}$}

His relationship with parents was a common topic in conversations with Wharton when we discussed trust. He spoke on numerous occasions of his emphasis on making prompt responses to parent concerns with timely feedback. This is important, he feels, because "if they are concerned enough to call me, then I should be calling them." He also talked about the importance of the need to "get back to the parent and let them know 
what I've done." This emphasis on maintaining parent trust was also evident as he referred repeatedly to his policy of encouraging parents to call him if they have any problems or concerns.

I often observed evidence of Wharton's policy of returning parent calls promptly during my visits to Valley. It was common for the secretaries in the office to contact him on his radio as we moved about campus to inform him of such calls. He expects the secretaries to do this, he said, because he wants to always know when a parent calls and finds him unavailable in the office. He explained his policy by saying:

I like to respond when the parent calls. I want to get the message right away, so I can return that call as soon as possible within that day. I don't like keeping parents waiting until the next day, because I feel that if they are concerned enough to call me, then I should be calling them.

At another time as we discussed his responses to parent contact, he emphasized the importance to "get back to the parent and let them know what I've done, and if there's any future problems, please feel free to give me a call."

The importance that Wharton places on trust-building relationships with parents is evident. In one of our conversations, he described parents like Mrs. Gonzales who come to his door without appointments as follows:

They just show up, so I have to sit down with them and just sort of go through the process of what is their concern, how can I help them, and let them know that I will work on the problem and get back to them later in the day.

This attitude was evident in his reaction to the unscheduled visit of Mrs. Gonzales with her daughter, Maria. Shortly before their arrival, Wharton had reviewed for me 
what was a very busy schedule for the remainder of his day. Nevertheless, he welcomed Mrs. Gonzales into his office, even though she did not have an appointment. After addressing her needs, he concluded the conversation by encouraging her to call him any time if she had any further problems with Maria.

As Mrs. Gonzales departed, Wharton stood to call in a student who had been waiting patiently in the outer office. Before this could happen, his secretary came to the door to inform him that another parent had arrived and wanted to talk to him about her son. Mrs. Leppe, another Spanish-speaking parent, was there to ask Wharton's help with her son, Jesus. Calling the interpreter, who was about to leave, back into his office, Wharton asked Mrs. Leppe to tell him the problem. It turned out that Jesus was refusing to go to homework club after school, despite all of his mother's efforts to get him there. Wharton replied, "We can fix that." After calling Jesus out of class and counseling him in a supportive way regarding his grades and the need to go to homework club, Wharton leaned forward in his chair, as I had now seen him do many times, looked directly at Jesus, and said, "Jesus, you will go to homework club, you will maintain your planner current, and you will go to the student support center for help." After a short pause, he finished with Jesus by saying, "And, Jesus, you will do what your mother tells you to do. I will be checking."

As the interpreter translated all of this for Mrs. Leppe, the smile on the parent's face grew bigger and broader as Wharton finished this final phase of his counseling with her son. As Mrs. Leppe stood to leave, she thanked Wharton repeatedly for his help. As was the case with Mrs. Gonzales, he concluded the conference with a request that she call him if she had any more trouble with Jesus. 


\section{Academic Program}

In all of our conversations, Wharton never initiated any discussion of the academic program at Valley Middle School nor did I ever witness him participate in any event that was even remotely related to curriculum development or its delivery in classrooms. When I finally asked one day if he ever had any involvement in curricular matters, he replied, "Not very much. We have approximately 1,150 students here," he explained. "That pretty much takes up all of my time just maintaining a safe, orderly environment." He did at one point state that he, on occasion, provides input regarding the academic program during weekly management team meetings. That was the single piece of evidence to emerge from our conversations that suggested any involvement with the academic program of the school.

Wharton's lack of involvement with the school's academic program was also evident in my conversations with principal Stuart. In her many comments regarding the assistant principal, she never indicated that he played any part in the development of curriculum or the evaluation of its delivery. She summarized her view of his role by saying, "He, at my particular school, prides himself on wanting to keep the school safe, and he views that as his primary responsibility." When I asked her how he contributed to curriculum and instruction, she replied, in obvious irritation, "He has demonstrated minimal success in terms of helping me lead teachers in the accomplishment of the school's academic goals."

This frustration on the part of Stuart with Wharton's reluctance to participate in leadership roles outside of the area of order and discipline is evident to Katherine Summers. "You know, every now and then, without saying anything ill of Jim," she said, 
"sometimes I sense Mary's frustration that she wants more of an equal partner in principaling [sic] rather than just, I do this and you do this. And I think that is kind of nice about having Linda [Garcia]," she added, "in that she kind of fills in that gap between Jim way over here and Mary way over here." What she meant by this is that Garcia, in her roles as Title I program facilitator and bilingual coordinator, works closely with Stuart on curricular issues and other management decisions regarding the schoolwide academic program. By her statements, Summers appeared to support other evidence that suggests Garcia plays a significant role with regard to the school's academic program while at the same time acknowledging Wharton's lack of involvement in academics or other aspects of school leadership. Summers concluded her thoughts on Wharton's failure to assist the principal in areas such as instructional leadership with the following comments:

That's an important aspiration of an assistant principal, to be a principal. And Jim doesn't make too many bones about it. He doesn't have that interest. He loves the kids, and he loves that part of his job. He is probably the epitome of the old fashioned vice principal, and he doesn't have the interest in being the assistant principal.

In view of the consensus on the part of the school's management team, including the assistant principal himself, that Wharton is uninvolved with curriculum and instruction at Valley Middle School, there did not appear to be a need to pursue the theme any further. Nevertheless, I asked seventh grade teacher, Susan Lundstrum, and eighth grade teacher, Clint Williams, what role they thought Wharton played with regard to the academic program. 
Lundstrum paused for a long time before replying to my question, finally answering, "My impulsive, first response is none at all, absolutely nothing. But thinking about it," she continued, "I would say he's involved in teacher evaluation." At this point, she sighed, and then continued, "Although even in his evaluation style, because he observed me last year, he didn't come and sit, you know, for a whole period." She then went on to describe how Wharton would come into her classroom for a few minutes at a time, then quickly depart without staying long enough to, in her opinion, accurately evaluate content or delivery of her curriculum. "Does he know how I'm addressing content?" she asked. 'No," she said, answering her own question. "Does he know any of the standards?" she asked. "No. None," she said, in response to her own question again.

I asked Lundstrum why she thought Wharton chose to be uninvolved in the academic program at Valley. "Interest. I don't think he's interested in it," she replied immediately. She then explained that Mary Stuart's strength is in "keeping a finger on the more academic sides of things." She expanded on this opinion with the following comments:

That is kind of her domain. And so, Jim's domain and territory is campus safety, discipline, and those kinds of things. But other than teacher evaluations, contributing to the climate, you know, a safe and ordered climate on our campus, that contributes to delivery of instruction. That would be his way of contributing to instruction.

Clint Williams' response to my question asking him what he felt the assistant principal's role in curriculum and instruction to be was very similar to Susan Lundstrum's. His reply was, "I say none." Then, like Lundstrum, he offered the opinion 
that Wharton's "job is to keep the climate, the order on the campus." To Williams, this emphasis on school safety is appropriate for the assistant principal and is his primary responsibility toward maintaining a positive school climate. He expressed the following opinion in this regard:

Personally, I don't have a problem with the assistant principal not being involved in curriculum. He's got enough to do. Help him focus on what his job is, school climate, and let him focus in on that, and let him do his job well.

It seemed clear that Williams preferred that Wharton devote most, if not all, of his effort to order and discipline when he concluded his thoughts by saying, "Don't get him bogged down in these other things....As a classroom teacher, I appreciate when he's just geared toward that one focus."

\section{Facilities}

Wharton feels that he is better qualified than most educators to supervise the maintenance and upkeep of school facilities because of his background in construction. "I was an electrician. I have my own contractor's license for roofing, which I did in the summer when I was a teacher. So I do have a little bit of expertise in some areas of construction," he explained. Because of his experience in construction, he believes, "I can look at some things and actually get some ideas as to what needs to be done probably where the average administrator without that background wouldn't. I can get things moving.

Wharton often uses analogies from the sea to describe his role with regard to the buildings and grounds at Valley, an apparent result of his time in the Navy and his current hobby of sailing. He used the following sea-based analogy in our discussions of 
facility maintenance:

You've got the upkeep, the maintenance that's sort of like a ship, and someone's got to be monitoring and taking care of the ship to make sure it's operating. That's sort of left up to me. I've got to make a decision to shut down a bathroom or maybe move students out of a class because of a safety issue.

These comments were typical of Wharton's attitude regarding the subject of the physical plant. Each time the theme of facilities emerged in a conversation, Wharton returned to the position that he is the person with primary responsibility on campus for ensuring that maintenance problems are addressed. This was the case when he stated clearly, "So I'm pretty much the person left to do that."

The principal, Mary Stuart, does not appear to agree with this assessment. She seems to think that the custodian has the major role to perform in this area, not Wharton. "One of the primary responsibilities of the school custodian every day is to survey the campus," she said. "He looks for any damage and signs of vandalism," she explained, "and he has to take note of that and immediately repair it or take the steps to get it repaired." At no point did she attribute such responsibilities to Wharton.

Work orders for all required repairs on campus come to the school office where a clerk records them and then submits them to the district office for completion. Carol Harris, the office manager, supervises this process, and thus has an ongoing knowledge of the current physical condition of the school's buildings and grounds along with the status of required repairs. Like Stuart, Harris does not appear to view Wharton as a major element in this process.

To pursue this issue, I used the leak in the office roof, noted above, to investigate 
her perceptions regarding the role of different staff members with regard to maintenance of facilities. She explained that most calls notifying the office of problems come from teachers. She then reviewed the procedure whereby an office clerk submits work orders and tracks their completion. Harris did take note, that "if it's really serious, I would go to an administrator." She explained that she would ask that person to personally look at the problem in order to "get someone at the district office involved much quicker than a work order would." She did not specify Wharton, however, as the administrator she would call, but rather stated that the particular management team member whom she would notify would "depend on who walked by my desk first." This was followed quickly by the comment, "And of course, we'd get a hold of the custodian." She concluded her review of the process by noting that if someone wanted to know at any given time the status of repairs at Valley, that person would have to go to the clerk in charge of work orders for such information.

In contrast, Linda Garcia viewed Wharton's role to be central to the maintenance of facilities at Valley. She said, "He will give directions to the custodian if there's a need." In addition, she stated, "He'll follow through on work orders with the secretary. As teachers turn things in, he'll see that they happen in a timely manner." She also voiced the opinion that "he works with the night custodial staff if there are concerns that things aren't cleaned as well as they should be." Particularly noteworthy was her comment that "I know he will come to the campus on the week-end just to do a walkthrough and check." Despite these perceptions on her part, Garcia was unable to give me many examples of recent maintenance actions taken as a result of Wharton's involvement. After some thought, she noted his efforts to replace damaged lunch table 
benches. Other than that, all she could point to was his contribution to the installation of a new shelter over the lunch area by saying, "I think he was pretty instrumental in the lunch cover."

Teachers did not appear to share Garcia's opinions regarding the assistant principal's role in facility maintenance and upkeep. Neither Ken Rizzo or Susan Lundstrum indicated in any way in our conversations that they believed Wharton is involved in this role. Clint Williams, when asked if he thought facility maintenance was an assistant principal responsibility at Valley Middle School, replied, "No. As far as I know, it is not part of his job." He voiced the opinion that "if you are talking about school climate, and school climate is part of having a nice facility, then that should probably be part of his job description." Williams did not indicate in any way, however, that he thought facility maintenance was one of Wharton's responsibilities.

Nevertheless, there was evidence of Wharton's active participation in maintaining the facility. One morning, as we took a walk around campus, he noticed a lunch table with a broken bench and immediately contacted the custodian using his radio to notify him of the problem. He was directive in nature with detailed instructions to the custodian as to how to repair the bench. On another day, he showed me an area that had been dug up to repair a clogged sewer drain, describing how he had detected the problem, closed down the affected bathroom, and contacted the district office to arrange repair. On yet another occasion during lunch duty, he pointed out various features of the new lunch cover and what he intended to do differently with a second one to be built soon. His detailed knowledge of the two projects seemed to indicate close involvement with both.

Despite this evidence, however, I was unable to ever determine from Wharton 
many specific examples of recent actions on his part regarding facility upkeep or repair, particularly those that were not directly related to safety issues. In one conversation when I asked for such examples, he noted his involvement in the decision making process regarding placement of new portable classrooms but then moved on to a lengthy account of safety issues that had little to do with facilities. In another conversation weeks later, I again asked for examples of recent maintenance actions that he had facilitated. Once again, he could only mention the same portable classrooms. In yet a third attempt, again weeks later, to identify specific actions indicating his involvement in facilities at Valley, he once again pointed to his part in placement of the portables and then immediately moved into a detailed review of the many problems that the additional special education students who would be occupying the new classrooms would bring to the campus.

In these conversations, Wharton consistently returned to the theme of safety in explaining the emphasis that he places on facility maintenance at his school, despite the fact that many of the things that we discussed, such as a burned out light in a classroom, did not appear related directly to safety. He even maintained that the example to which he repeatedly returned, placement of new portable classrooms, was ultimately safety related. This, he explained, was why he paid such close attention to such things, because of the safety aspect. When I suggested that some people would not consider the location of a portable classroom or a burned out light in a classroom to be a safety issue, he replied in some exasperation, "With respect to leaky roofs, bad ballast in lights, anything that could create a safety problem, that is in what I consider the realm of a safe, orderly environment." His tone suggested that he did not want to explore this theme any further. 


\section{Summary}

The findings indicate that the behaviors of this assistant principal have significant influence on order and discipline at his school. There exists among the staff a consensus that his visibility on campus is a powerful deterrent to unacceptable student behavior. All evidence indicates that, to the school community, he is indeed the "scare crow," "sheriff," and "ultimate enforcer."

The findings reveal that opinions of staff members are equally strong regarding the assistant principal's ability to establish connections and personal relationships with students that, in turn, deter behaviors detrimental to order and discipline. The results of observations support these opinions. Evidence indicates that his efforts to build relationships with students reflect his frequently stated position that punishment will not produce a safe and orderly campus. Instead, he appears to make considerable effort to personally connect with students in such a way as to change student attitudes and behaviors before punishment becomes necessary. Nevertheless, the evidence is clear that he is not hesitant to remove a student from his campus if he thinks the student to be at risk of committing a violent act.

The third theme to emerge regarding the assistant principal's proactive activities to maintain order and discipline is instruction of students in expected behaviors. Though the findings indicate that he does not devote much of his time to addressing students in a classroom environment on this topic, his perception, and that of staff members, is that his efforts in this way have considerable effect on student behaviors. The evidence suggests that his teaching and modeling of expected behaviors to students in unstructured settings throughout the campus and in his office are even more effective in promoting order and 
discipline among the student population than his efforts during classroom visits.

In the reactive category of the assistant principal's contribution to order and discipline on campus, the findings reveal that he has three constituent groups: students, teachers, and parents. Evidence indicates that, by far, most of his time spent in the reactive mode is devoted directly to students in addressing their behavior infractions. The majority of these interactions with students are associated with student-related concerns brought to him by teachers and parents. The findings indicate that he places great emphasis on addressing these concerns in a timely, effective fashion that provides support to teachers in maintaining an orderly classroom environment and to parents in their efforts to contribute to their children's education. Observations and opinions of staff members reveal a perception on the part of the staff that this emphasis plays a significant role in maintaining order and discipline on campus.

The findings indicate that the assistant principal considers trust to be the basis of effective relationships between him and all members of his school's community. Accordingly, he makes considerable effort to always meet the needs of his constituents quickly and effectively in order to build and maintain trust with all subgroups within the school. Openness to criticism from teachers and willingness to listen and to change are also personal characteristics of the assistant principal that appear to contribute to trusting relationships with staff members. The findings suggest that his successful efforts to build personal relationships with children are particularly effective in maintaining trust with students. The evidence indicates that particularly strong trusting relationships do indeed exist between the assistant principal and the school's management team and classified staff. The same is true on the part of most of the teachers. The findings reveal, however, 
that some teachers, at times, do not trust him to provide consequences to students that they feel are appropriate. They attribute this to his being too willing to give students another chance to correct unacceptable behavior without punishment. This perception on the part of some teachers is consistent with evidence that indicates the assistant principal places greater emphasis on education and counseling to address behavior infractions than on the use of consequences. The evidence indicates that he is aware of the conflict between trying to meet the requests of his teachers regarding punishment of students while carrying out his stated intent to always do what is best for the children. The findings suggest, however, that he is not always successful in managing this conflict.

The findings reveal that the assistant principal has very little involvement in the academic program at his school. He does not consider this component of school climate to be part of his job description, nor does he think it should be. He feels strongly that he simply does not have any time to devote to curriculum and instruction after meeting what he views to be his primary responsibility of maintaining order and discipline on campus. A number of staff members agree with his assessment that his sole function should be maintenance of a safe and orderly campus, and that to do so effectively, he must devote himself entirely to this goal. There is also a strong opinion among many staff members that the assistant principal simply does not have an interest in curricular matters and works almost entirely on student discipline by choice. The evidence indicates that his lack of attention to any component of the instructional program is a combination of both of these factors. It suggests that there is very little time left in his workday after dealing with issues regarding order and discipline. Nevertheless, there is no evidence that he attempts in any to way to become involved in curriculum and instruction in the limited 
time that he does have available to devote to non-discipline issues.

The assistant principal is of the opinion that he is the staff member at his school with primary responsibility for facilities maintenance and upkeep. The evidence, however, indicates otherwise. Only one management team member agrees with the assistant principal's position that he contributes in a significant way to the cleanliness and routine repair of the school buildings and grounds. The classified staff, who are responsible for submitting maintenance requests to the school district and tracking their progress to completion, do not consider the assistant principal to have a significant role in this process. Evidence reveals that these support staff members and the site principal rely primarily on the school's custodian to identify and report needed repairs. In addition, no teacher appears to consider the assistant principal to be significantly involved in care of the facility. Nevertheless, the evidence suggests that he does take prompt action on maintenance issues that he discovers personally or that happen to be brought to his attention. As a result, he contributes to facility maintenance and upkeep. His contribution does not appear to be as significant, however, as he thinks it to be. 


\section{CHAPTER VI}

\section{SUMMARY, DISCUSSION, RECOMMENDATIONS FOR POLICY AND}

PRACTICE, AND SUGGESTIONS FOR FUTURE RESEARCH

\section{Summary}

\section{Background}

Organizational theorists have for years conducted studies on the effects of environment on the attitudes and behaviors of both individual members and subgroups within organizations. What has emerged from this research is a concept that most researchers have termed organizational climate (Kozlowski \& Doherty, 1989; McGregor, 1960; Tagiuri, 1968). In recent years, leadership and management theorists working in the areas of business and industry have increasingly substituted the term culture for climate (Bennis, 1997; Heifetz, 1994; Kotter, 1996). Educational researchers and practitioners, however, have continued to use the original concept of climate to study the relationship between the environment in a school setting and the attitudes and behaviors of members and subgroups within school communities (Freiberg, 1998; Griffith, 1999; Hoy \& Hannum, 1997).

Scholars and educators who have studied school climate have had difficulty in achieving consensus on what the primary climate descriptors should be. Nevertheless, some agreement has emerged from school research that there exists a set of internal climate characteristics that is unique to each school site, that influences the behaviors of all members of the school organization, and that affects student academic achievement and behavior (Anderson, 1982; Hoy, Tarter, \& Bliss, 1990). Attempts to identify these characteristics have led to a wide range of descriptors (Anderson, 1982). Four broad 
climate categories, however, recur throughout school climate research literature: order and discipline, academic program, trust, and facilities.

Research in the field of middle level education, grades six through eight, suggests that school climate has particularly significant and wide-ranging effects on middle school students' academic performance and social development (Hoy \& Hannum, 1997; Lake, 1989; Tarter, Sabo, and Hoy, 1995). Indeed, the central theme that appears to tie all middle school philosophies and strategies together is the concept of school climate (Hoy, Hannum, \& Moran, 1998; Lake, 1991). Accordingly, it seemed important to examine the critical elements that influence climate in the middle school setting.

Intuitively, leadership would be expected to be one of these critical elements that influence school climate. This assumption is supported by the work of many organizational and leadership theorists (see, for example, Graen \& Scandura, 1987; Kozlowski \& Doherty, 1989; Likert, 1967; McGregor, 1960). The research of such theorists suggests that the assumptions and actions of school leaders will result in processes that play a critical role in the establishment and maintenance of the climate in their schools. These processes, in turn, can be expected to have a profound impact on the behavior of members and subgroups within the school organization.

Though extensive research has examined this relationship between climate and leadership in business, industry, and government, relatively few studies have examined the linkages between school climate and leadership within the school setting (Griffith, 1999). The research that has been conducted in the realm of education has tended to focus exclusively on the influence of the school principal (see, for example, Griffith, 1999; Hoy \& Feldman, 1987; Tarter \& Hoy, 1988). Noticeably absent from the literature 
on the relationship between school leadership and climate is any reference to the relationship between an assistant principal's behaviors and school climate. This omission seems problematic since an assistant principal is exceeded in positional authority by only the principal at a school site and, thus, could be expected to have a significant effect on his/her school's climate. The fact that the assistant principal of a school is normally charged with the responsibility for managing order and discipline, one of the four factors thought to contribute to a school's climate, only adds to the argument for studying the role an assistant principal may have in establishing a positive climate in a school.

This research was a case study that began to address this absence of inquiry into the relationship between a middle school assistant principal's leadership and school climate. It was conducted in a middle school considered by its district leadership and county office of education to have a positive climate. It looked for evidence to either support or refute judgments about the positive nature of this school's climate and examined the relationship between the site's assistant principal's assumptions and behaviors and the school's climate within the context of the four climate indicators: order and discipline, trust, academic program, and facilities.

\section{Research Questions}

The following research questions guided the study: (a) Did the evidence support the assumption that a positive climate existed in this school, and (b) if so, what assumptions and behaviors of the assistant principal appeared to contribute to the establishment and maintenance of that climate?

\section{Research Design}

This study was a qualitative case study. A case study is an "empirical inquiry that 
investigates a contemporary phenomenon within its real life context when the boundaries between the phenomenon and context are not clearly evident and in which multiple sources of evidence are used" (Yin, 1984, p. 23). Educational research has normally focused on such complex, information-rich problems and situations in the real life context of the educational setting (Merriam, 1998). Case studies in education provide the thick description and experiential perspective that are critical to qualitative research. They are holistic and life-like and therefore present a clear picture of the actual participants and their behaviors in their natural setting (Guba \& Lincoln, 1981).

This study was bounded conceptually by the construct of climate and the four factors the literature suggests contribute to a school's climate. It was bounded physically around the single entity of a middle school assistant principal. The study's intent was to examine the relationship between the assumptions and behaviors of the assistant principal and his school's climate in the context of the complex social setting of the school's organization. I sought to gain an understanding of this relationship and, in turn, provide a thick, rich description of the findings. Since all of these considerations are elements of a qualitative case study, I chose a qualitative case study design for this research.

\section{Theoretical Assumptions}

Two theories that emerged from the literature guided this study in its investigation of the attitudes and orientations of insiders in a school organization regarding the effect that the school's assistant principal's actions and behaviors had on the school's organizational climate. The first was that a unique climate existed at the school that could be described using qualitative strategies. Organizational theory supported this assumption in that it argues that every organization has a distinct climate that affects the 
attitudes and behaviors of organizational members (Indik, 1968; Likert, 1967; McGregor, 1960). The second theoretical assumption was that leadership and climate are intertwined. This position, argued by theorists such as Evans (1968) and Schien (1992), guided the study in its attempt to address the central question of how the assistant principal's assumptions and actions influenced his school's climate.

\section{Methodology}

The literature-based notion that school climate can be examined using the descriptors order and discipline, academic program, trust, and facilities was used to frame this study. Organizational members' attitudes regarding these four factors and members' perceptions of how the assistant principal's actions affected the four descriptors guided the data collection and analysis processes. Observations and document and artifact reviews were also framed by the concept that school climate can be evaluated using the four climate descriptors.

Since this was a qualitative case study, I was the data collection instrument. The primary research strategy used was in-depth interviews; the conversational interview (Patton, 1990) was most frequently employed. The primary subject of my inquiry was the school's assistant principal. In order to increase confidence in findings from interviews and observations of the assistant principal, I also interviewed other members of the school's management team, teacher leaders from different grade levels and academic disciplines, and key support staff. Participant observation and document and artifact reviews (Bogdan \& Biklen, 1998; Glesne, 1999; Patton, 1990; Rubin \& Rubin, as 1995) were also used both for corroboration of findings that emerged from interviews and primary sources of data. 


\section{Findings}

\section{The Climate at Valley Middle School}

There is a consensus among all staff members with whom I spoke that eight years ago Valley Middle School was a school in trouble. It had serious academic and discipline problems and a staff that was isolated and distrustful of each other and the school's leadership team. As one teacher put it, "This campus was scary. Teachers would close their doors and not come out during the passing periods or anything. I mean, basically, the students in the halls were running the campus."

The findings indicate that this is no longer the case. Valley compares favorably with the other four middle schools in its district using such statistics as numbers of suspensions, expulsions, and teacher referrals. Observations reveal a quiet, calm campus that is in complete contrast to the situation described above as "scary." In the halls, students display little of the shouting, pushing, and shoving that are often seen in middle schools. Inter-disciplinary teaming, in accordance with middle school philosophies and strategies, is required by the school's principal and is practiced and supported by most of the teaching staff. As a result, student discipline and counseling are team based and the level of teacher referrals of students to the assistant principal for behavior infractions is significantly lower than that in other middle schools in the school district.

According to every staff member with whom I spoke, another factor contributing to order and discipline throughout the campus is the school's character education program, The Valley Way. The program's ten key character traits are taught, modeled, and consistently reinforced daily by nearly all staff members. As a result, the program is pervasive throughout the school and is evident in the positive interactions between all 
members and subgroups of the school community.

Neariy all staff members agree that a high level of trust characterizes relationships at Valley Middle School. With few exceptions, teachers feel supported by the school's administration. Observations indicated that parents feel comfortable bringing their concerns to the school's leadership with confidence that their concerns will be addressed. Two voices of dissent, one from a classified staff member and one from a teacher, indicated that not all staff members feel that all people at Valley Middle School could be trusted. The perceptions of most staff members and the interactions that I observed among administrators, staff, and students, however, indicated that a high level of trust exists, with few exceptions, between individuals and subgroups in the school's community.

Comparisons with other schools in the state of California, based on nationally normed standardized tests, place Valley Middle School academically in the top 30 percent of schools statewide and in the top ten percent of schools in the state with similar demographics. Other indicators, such as district writing assessments and longitudinal studies of student achievement in high school, support the findings that the school has a challenging academic program with high expectations for students who, based on their socio-economic status, are statistically at risk for academic failure.

There is no indication of any significant deferred maintenance at Valley Middle School. The classrooms and common areas, with the exception of the auditorium, are clean and attractive. Many staff members are not satisfied with the level of trash found routinely on the grounds of the campus, and observations indicate that improvement is needed in this area of facility upkeep. Nevertheless, the problem is relatively minor and 
appears to have a level of visibility among the staff that is the result primarily of the high standards being met in nearly every other way in the area of campus cleanliness and overall physical appearance.

The Relationship Between the Assistant Principal's Attitudes and Behaviors and Climate at Valley Middle School

The findings indicate that the proactive behaviors of Valley Middle School's assistant principal have significant influence on order and discipline at the school. The school's staff, almost to a person, believes that his visibility throughout the school day serves as a powerful deterrent to unacceptable student behavior. There is also agreement among all participants in the study that he is particularly strong in the establishment and maintenance of close personal relationships with children that, in turn, help students meet the school's behavior expectations. His modeling and instruction of expected behaviors also emerge as factors that staff members feel contribute to the maintenance of an orderly environment at the school. Observations of the assistant principal in common areas of the campus, such as the halls and lunch area, support the perceptions of the staff regarding the preventative nature that his continual visibility has on unacceptable student behavior. These observations, and others conducted in his office during interactions with children, support the belief of all staff members that he has the ability to establish close relationships with students that empower him to influence the students' attitudes and subsequent behaviors.

It is evident from the study that the assistant principal has three constituent groups: students, teachers, and parents. Most of his time in the reactive mode is devoted to students; specifically, he responds to their behavior infractions. Often these responses 
are to student behaviors that he witnesses during times he is out of his office, such as during passing periods and lunch periods. Most of these responses, however, are in reaction to student referrals from staff members, primarily teachers. Interviews and observations revealed that, regardless of the means by which students' behavior infractions are brought to his attention or the nature of the problems, the assistant principal feels strongly that punishment is a strategy that will not necessarily change student behavior. Rather, he believes that changing students' attitudes and core values is necessary to make a lasting impact on their conduct. This belief, at times, leads to conflict with some teachers who feel that the consequences he gives students are not severe enough in that he is too willing to give children another chance before resorting to punishment. In contrast, every member of the school's management team feels that his methods of dealing with students are a combination of compassion, fairness, and firmness that normally lead to positive results. Despite the occasional disagreement on the part of some teachers regarding the assistant principal's strategies, there is consensus among the subjects of the study that he possesses the ability to modify, in a positive way, student behavior.

Though most of this assistant principal's time is spent with students, it is evident that he is always prepared to listen to the concerns of teachers and places emphasis on the need to meet those concerns in a timely, effective manner. Issues brought to him by teachers fall primarily into three categories: concerns with students, personal needs, and conflicts with parents. As noted above, he spends most of his time addressing student behavior that does not meet expectations, including that which takes place in the classroom. All teachers who participated in this study expressed complete confidence 
that the assistant principal would respond immediately and effectively to a call for assistance with a student in their classrooms. The assistant principal also expressed a strong belief in his need to respond quickly and effectively to teachers' personal requests regarding such things as burned out lights or classroom cleanliness. Though there was no indication that he participates to any significant degree in parent conferences, all participating teachers indicated that he is always supportive of them in any conflicts they might have with a parent.

The findings indicate that the assistant principal considers trust to be the basis of effective relationships between him and all other members of the school community. He works to build trust with students by establishing connections and building positive relationships that allow him to influence their behaviors. The two primary strategies that he uses to build trust with his staff and with parents are to always try to meet their needs quickly and effectively and to remain open to criticism and be willing to change his decisions when appropriate. The evidence indicates that he is extremely successful in these trust-building strategies with the school's management team, classified staff, parents, and most teachers. His methods are not always successful with some of the teaching staff, however, primarily because of periodic disagreements, as noted above, over what constitutes appropriate consequences for student behavior infractions. The assistant principal recognizes the presence and the source of this conflict and understands that it is a continual challenge to support his teachers while still doing what he feels is best for the students and complying with state legislated mandates and school board policies. The evidence indicates that he is normally successful in managing this conflict, but he does not consistently satisfy the expectations of every teacher. 
The findings reveal that the assistant principal of Valley Middle School has very little direct involvement in the academic program of his school. The one notable exception to this situation is his participation in teaching The Valley Way, the school's character education program. Otherwise, he does not consider the instructional component of school climate to be part of his job description and feels strongly that he does not have time to devote to curriculum and its delivery even if it were. Staff members all agree that his participation in the instructional program is nearly nonexistent. Some concur with the assistant principal that he has little time for anything other than maintaining order and discipline on campus. Others, from both the teaching staff and the management team, feel that he simply has no interest in curricular matters and that this is a major reason that he does not provide any instructional leadership. The findings reveal that the assistant principal's day is indeed almost entirely consumed with maintaining order and discipline on campus. Nevertheless, the evidence suggests that he has little interest in curriculum and instruction and would not give it much attention even if he did have the time to do so. Participants of the study do agree with the assistant principal's position that he does make a major, though indirect, contribution to the school's instructional program by maintaining a safe and orderly environment on the campus that supports effective delivery of instruction by teachers in the classroom.

The assistant principal feels that he is the person on campus with primary responsibility for supervision of facility maintenance. Most staff members, however, including the principal and office staff, consider the custodian to be the person with primary responsibility for facility maintenance. Indeed, they gave little indication in interviews, even when asked about the matter directly, that they feel the assistant 
principal plays any significant role with regard to the maintenance and upkeep of the school's buildings and grounds. Nevertheless, observations indicated that he does take prompt action on maintenance issues that he discovers personally or that happen to be brought to his attention. As a result, he appears to contribute in a meaningful way to facility maintenance and upkeep.

\section{Discussion}

\section{The Climate at Valley Middle School}

The results of this study are consistent with the literature on organizational climate formulated by researchers such as McGregor (1960), Likert (1967), and Indik (1968). The findings support the theoretical assumption, suggested by the work of these organizational theorists, that a unique climate exists within an organization and that this climate affects the attitudes and behaviors of individual members and subgroups within the organization. Such a climate does exist at Valley Middle School, and it directly and indirectly affects both the professional and personal lives of organizational members, in this case, in decidedly positive ways. This process is interactive and reciprocal in nature in that it produces responses from individuals and groups within the school organization that, in turn, tends to alter the nature of the original climate. This interactive process is most evident in the manner in which the staff, in response to a previously negative climate, supports the school's character education program that, in turn, influences the climate of the school in positive ways.

According to Hoy and Hannum (1997), attempts to evaluate school climate must focus on the properties of a school's physical and social environment that are experienced by all organizational members and the collective perceptions of these participants 
regarding the climate of their school. As argued by Anderson (1982), such attempts are difficult because of the lack of consensus regarding school climate descriptors. It is therefore important that the descriptors used to evaluate a school's climate are selected carefully and in a manner that is consistent with the methodologies employed. The four broad climate categories of order and discipline, trust, academic program, and facilities were well suited for this qualitative case study of one school's climate.

\section{Order and Discipline}

All participants in this study consider an orderly and disciplined student body to be a critical component of a safe and secure environment that allows teachers to teach and students to learn. Their perceptions support the position of Kaplan and Evans (1997) that "only when teachers and students feel safe can learning occur." These attitudes are particularly powerful because most of the staff remembers the environment at the school prior to the arrival of an entirely new management team eight years earlier when the campus was described as "scary" with "the kids running the school." A consensus exists among all study participants that Valley is now a safe school with students who, with few exceptions, understand and meet behavior expectations. This consensus is generally attributed to the leadership of the principal, the effectiveness of the assistant principal with regard to student discipline, and the participation of the teaching staff in the discipline process, particularly on the part of inter-disciplinary teams that no longer "close their [classroom] doors and not come out."

\section{$\underline{\text { Trust }}$}

Trust is a climate indicator that is second in importance only to order and discipline to the participants in this study. The attitudes and perceptions of teachers who 
were interviewed appear to support the argument of Tarter, Sabo, and Hoy (1995) that an atmosphere of openness and professionalism that leads to trust and cooperation among teachers and leadership is critical to effective schools. Equally significant are the opinions of other subgroups within the school that indicate the importance of the schoolwide climate of trust, described by Bulach and Malone (1994), that includes collaboration, openness, and trust among all members of the school community. With few exceptions, the perceptions of administrators, teachers, and support staff support the claim that a high level of trust exists within the staff, students, and parents at Valley Middle School.

\section{$\underline{\text { Academic Program }}$}

The principal at Valley Middle School is the only staff member to articulate an understanding of the argument of researchers, such as Howard, Howell, and Brainerd (1987) and Hoy and Hannum (1997), that the academic program of a school is a critical factor affecting its climate. Nevertheless, the emphasis placed by teachers and support staff at Valley Middle School on the content of the instructional program, effectiveness of its delivery, and high academic performance standards is evident in students' achievement on such multiple assessment instruments as nationally normed standardized tests and district mathematics and writing assessments. This strongly suggests that there is at least tacit acceptance among the staff of the importance of a quality academic program in establishing and maintaining a positive climate within a school.

\section{$\underline{\text { Facilities }}$}

The principal at Valley Middle School agrees with Brown (1984) that the physical appearance and state of repair of school facilities are critical factors that not only 
contribute directly to a school's climate, but also are clear indicators of deeper underlying symptoms of other climate indicators. Other members of the school's management team do not have as clear an understanding of this theoretical position with regard to the effect of maintenance and upkeep of facilities on overall school climate. Particularly noteworthy is the fact that the assistant principal argues, as he does with regard to virtually every other aspect of school climate, that facility maintenance is important primarily because of safety considerations. Nevertheless, all members of the management team place emphasis on keeping the school clean and in good repair in order for students, staff, and parents to feel good about their school and want to be there. In so doing, management team members appear to be in tacit agreement with Foster-Harrison (1997) and Welsh (1997) that the cleanliness and state of repair and modernization of a school's buildings and grounds are critical elements of school climate. The teachers and support staff at the school seem to share this opinion of the management team as indicated by the cleanliness and good repair of their classrooms and workspaces and their attention to detail in reporting problems. The overall results of the staff's attitudes regarding facility maintenance are reflected in the cleanliness of the campus and good state of repair of its buildings and support systems.

The Relationship Between the Assistant Principal's Attitudes and Behaviors and the Climate at Valley Middle School

The second question guiding this study was: What assumptions and behaviors of the assistant principal appear to contribute to the establishment and maintenance of positive climate at Valley Middle School? The results of the study, that relate to this question, are consistent with the findings of human relations and leadership theorists who 
argue that a leader's assumptions and behaviors and the processes that result from those assumptions and behaviors are primary determinants of the climate of an organization and, in turn, affect the attitudes and behaviors of organizational members (see, for example, Kozlowski \& Doherty, 1989; Likert, 1967; Litwin \& Stringer, 1968; McGregor, 1960). The findings indicate that the assumptions and actions of the assistant principal of Valley Middle School have wide-ranging and profound effects on all four school climate indicators: order and discipline, trust, academic program, and facilities. In some categories, such as order and discipline, his influence is particularly direct and influential as a result of his extensive efforts and emphasis on maintaining a safe and orderly campus. In others, such as facilities and the academic program, his impact is often indirect. In each case, however, his assumptions and actions have school-wide implications with regard to the school's climate. The findings thus support the study's second theoretical assumption, proposed by theorists such as Evan (1968) and Schien (1992), that leadership and organizational climate are intertwined.

\section{Order and Discipline}

The attitudes and behaviors of the assistant principal of Valley Middle School suggest that he is in agreement with Borger, Lo, Oh, and Walbert (1985) and Bernstein (1992) that a safe and orderly campus is the most important component of school climate. He considers the maintenance of a safe environment on campus to be his primary responsibility. All other components of his job description, in his mind, are secondary to his role as the primary enforcer of student discipline and protector of the school from any unsafe influences such as weapons, drugs, and violence. As a result, most of his time is devoted to this endeavor. 
A large portion of the time dedicated by the assistant principal to order and discipline on campus is consumed by his efforts to be highly visible, both in classrooms and common areas of the campus, throughout the school day. His physical presence appears, on the one hand, to be a powerful deterrent to unacceptable student behavior and is reassuring to staff and students alike that he will be immediately available to intervene in any crisis. On the other hand, it detracts from his ability to participate in other aspects of school leadership because of the amount of time it demands of him during his normal workday.

The assistant principal's conviction that modeling and instruction of expected behaviors, rather than punishment, to influence student conduct is central to his strategies for maintaining order and discipline. Nevertheless, he is not hesitant to do everything in his power to remove from the school those students he feels are a physical threat to others. These strategies are consistent with his conviction that his primary responsibility is the safety of students and staff. As is the case with his emphasis on being visible on campus, however, his focus on counseling to change student behaviors consumes far more time than would be required if he functioned simply as a disciplinarian, thereby detracting from his time available to participate in other school leadership activities.

The success the assistant principal achieves in modifying student behaviors appears to be, in large part, the result of relationships that he builds with students, especially those who are behaviorally at-risk. The consensus among the staff that he possesses an unusual ability to connect with students seems to result from a genuine fondness on his part for children and concern for their well being, combined with 30 years of experience of dealing with challenging students with behavior problems. His 
efforts to influence students' norms and values appear to produce positive outcomes and, in turn, have a particularly strong influence on order and discipline at Valley Middle School.

$\underline{\text { Trust }}$

The findings of this study support the position of Hoy, Tarter, and Witkoskie (1992) that effective middle school leaders must establish and maintain a climate of trust that is supportive of staff and that maintains an orderly learning environment. The assistant principal's focus on order and discipline on the campus of Valley Middle School and his emphasis on responding to the staff's needs in a timely, effective fashion have resulted in a high level of trust between him and the school's staff. The result of this focus and emphasis is collaborative interpersonal relationships that, in turn, have positive effects on the school's overall climate.

The one exception where such trust does not always exist between the assistant principal and staff is with some teachers who do not consistently have confidence that the assistant principal will assign consequences to children that these teachers consider appropriate. This occasional disagreement over the issue of punishment is the result primarily of philosophical differences on the part of these teachers with the assistant principal regarding strategies for altering student behaviors. At other times, the tension arises from teachers not understanding the limitations on the assistant principal's range of options regarding punishment that stem from state legislation and school district policies. Regardless of the source, this conflict to do what he feels best for students, within state and district mandates, and at the same time to meet teacher expectations regarding punishment is a continual challenge to the assistant principal that must be managed 
effectively to maintain a trusting relationship with the teachers. This situation notwithstanding, there exists a high level of trust on the part of teachers at Valley Middle School that the assistant principal will take prompt, effective action to address student behaviors that are a direct threat to order and discipline on the campus.

\section{Academic Program}

The assistant principal of Valley Middle School feels that the content of the school's instructional program, the effectiveness of its delivery, and the level of academic performance expected of its students are critical to the school's effectiveness. He views this as a technical matter, however, that is the responsibility of the principal and teaching staff and does not appear to agree with Stockard and Mayberry (1992) and Hoy and Hannum (1997) that a school's academic program is a critical factor affecting school climate. His position that he simply does not have any time to devote to the school's instructional program has some validity in that, as the only assistant principal at the school, his responsibility for maintaining order and discipline in a school of 1,150 , mostly low income and minority students consumes the significant majority of his workday. Nevertheless, there is some time in his day to participate in instructional leadership were he to choose to do so. The evidence is strong, however, that he lacks any significant interest in the academic program and distances himself from it by choice, a perception shared by most of the staff. As a result, his involvement in curriculum and instruction at Valley Middle School is virtually nonexistent.

The findings suggest that the emphasis on a quality academic program at Valley Middle School is the result primarily of the principal's direct involvement in curriculum and instruction as the instructional leader at the school. Her leadership in this area of 
school climate is in direct contrast to the assistant principal's lack of involvement in any meaningful way in the school's academic program. It may well be that this clear distinction in roles, in which the principal focuses on instruction and the assistant principal concentrates on order and discipline, is in large part responsible for the high level of results achieved by the site in both of these school climate categories. If so, the findings would suggest that such a division of responsibilities between a principal and assistant principal in a large, urban school is the best model for achieving a positive climate in the two critical areas of order and discipline and academic program. On the other hand, such a clear division of responsibilities would work only if curriculum and instruction were an area of strength of the principal and the assistant principal's skills equally strong in the area of order and discipline as is the case in this school.

\section{Facilities}

The assistant principal of Valley Middle School views himself as the person on campus with primary responsibility for cleanliness and maintenance of the school's buildings and grounds. It may well be that the assistant principal of a large middle school, such as Valley, is indeed the person on campus best suited to fill this role. He/she is the one person who has routine contact with all members of the school community throughout every day and who, if like the assistant principal at Valley, is in every part of the campus on a daily basis in the course of fulfilling responsibilities in the area of order and discipline. This continual contact and presence makes the assistant principal the person best positioned to detect problems with the facility. In addition, the assistant principal has the positional authority to take effective action to correct facility-related discrepancies that other staff members do not have. 
Despite being in position to fill this role, the assistant principal at Valley Middle School is not the person on campus with the primary responsibility, as he believes, for the facility. If there is any one person with such responsibility, it is the school's custodian. This conflict between the assistant principal's perception regarding his role in this area of school climate and reality on his campus may result from his concept of how facility maintenance affects overall school climate. Unlike many staff members, who agree with Brown (1984) and Black (1997) that the condition of the facility is critical to overall school climate, the assistant principal views facility maintenance almost entirely through the lens of school safety. This association of upkeep and repair with safety of students and staff is not entirely justifiable, but is consistent with his emphasis on order and discipline and his conviction that his primary responsibility is to maintain a safe and orderly campus. This association could, in turn, lead him to minimize the importance of non-safety related issues such as trash in the hallways or stains on the auditorium carpet. Regardless of his motivation, the assistant principal does play an important role in all aspects of school maintenance at Valley Middle School by consistently taking note of deficiencies brought to his attention or detected as he moves about campus and, in turn, taking appropriate action to have those deficiencies corrected.

Recommendations for Policy and Practice

The findings of this study lead to the following recommendations for policy and practice:

1. The assistant principal of Valley Middle School considers his primary responsibility to be the maintenance of a safe, orderly environment in both the classrooms and common areas of the school. This focus on order and discipline involves time consuming 
activities on his part, such as his practice of being highly visible throughout the campus and his behavior modification strategies that stress guidance and counseling conducted within the context of positive relationships with students. As a result of this focus, he is left little time for other leadership roles related to school climate, such as instructional leadership in support of the school's academic program. On the other hand, were this assistant principal to not place as much emphasis as he does on being visible on campus as a deterrent to unacceptable student behavior, he would have more time to devote to activities outside the realm of order and discipline. Strategies such as the increased use of campus safety supervisors could free him from some of these supervisory duties, thereby providing additional time to participate in other leadership roles. Similarly, the time that he spends on time consuming behavior modification strategies, such as instruction of expected behaviors and counseling of students, could be reduced by having others, such as guidance counselors, take more responsibility for these functions. Indeed, some educators might argue that this assistant principal's guidance and counseling strategies are more appropriately the responsibility of the school counselors, not the assistant principal. This study suggests that an assistant principal, within the framework provided by the site principal, should consider these tradeoffs in deciding on the focus of his/her efforts within the limited time available in the school day in order to maintain a safe and orderly campus while still having enough time to participate in other aspects of school leadership.

2. The findings indicate that this assistant principal is highly successful in maintaining order and discipline on this school's campus, thereby suggesting that his primary emphasis on this school climate descriptor might be the model for assistant principals of 
similar schools. Site and district level administrators should carefully consider this proposition. On the other hand, the extensive amount of time devoted during the school day by this assistant principal to the climate category of order and discipline suggests that schools similar to the one examined in this study should consider what constitutes an appropriate student to assistant principal ratio. For example, the responsibility for order and discipline at a school the size and demographics of Valley Middle School might be divided between two assistant principals. This sharing of responsibility by two assistant principals for order and discipline could provide for the focus on a safe and orderly campus practiced by this assistant principal, while still allowing both administrators time to participate in other leadership activities. Budgetary constraints might preclude this option. This is the case in the school district in which this school is located.

3. The effectiveness of this assistant principal's strategies, that are grounded in his philosophy that punishment alone will not change student behaviors, suggests that a combination of teaching and modeling of expected conduct, supported by a hierarchy of consequences tailored to the needs of each individual student and his/her family, is critical to a positive school climate. The complex skills evidenced by this assistant principal in providing this kind of support to the school community were acquired during his many years as a teacher of emotionally disturbed and behavior disordered children prior to becoming an assistant principal. These skills are not necessarily attained in more traditional classroom settings. The ranks of school administrators are almost always filled from the ranks of classroom teachers, most of whom have not had the kinds of teaching experiences that this assistant principal has had. The study therefore suggests that administrator training and credentialing programs need to provide aspiring 
administrators the opportunity to learn and refine these skills prior to assuming the position of assistant principal.

4. At this site, the principal serves as the school's instructional leader with virtually no assistance from the assistant principal in the critical climate category of academic program. On the other hand, the reason that the principal is free to devote her time to the instructional program is because of the strengths and effectiveness of the assistant principal in the climate category of order and discipline. This suggests that such a division of responsibility between a principal and assistant principal at a similar school might be the most effective organizational structure with regard to maintenance of positive school climate. A clear division of responsibilities for different climate categories is possible, however, only if, as is the case in this school, each administrator has the requisite skills to fulfill effectively his/her respective responsibilities. This is a zero sum game in which the weaknesses of one administrator in any given climate category would have to be compensated for by the other to maintain an overall positive climate. Accordingly, the findings suggest that the hiring of individuals for administrative positions should not take place without regard to the context in which they will work; rather the principal and assistant principal(s) of any given school should be assigned with careful consideration given to the strengths and weaknesses of the existing administrative staff in the school. This will help ensure that administrators work well as a team and complement each other in the establishment and maintenance of positive school climate.

5. The climate on the campus of this school appears to be, in large part, the result of the effectiveness of the assistant principal's efforts to establish positive, trusting relationships 
with students, staff, and parents. This trust arises from many factors, such as his competence in modifying student behaviors and his responsiveness to concerns from any member of the school's community. It is in large part, however, the result of his highly refined interpersonal skills that he employs in all interactions with staff and parents, some of whom at times disagree with his actions. These skills appear critical to the maintenance of the trusting relationships he has with both individuals and subgroups within the school community. This suggests that the current system in the state of California for training new administrators might be inadequate in that it has no component that provides classroom teachers, who comprise nearly all entry-level administrators, the skills needed by an assistant principal to interact effectively with various constituent groups in the diverse and complex scenarios that are evident in the strategies of this assistant principal. Accordingly, administrator training and credentialing programs need to provide aspiring administrators the opportunity to learn and practice these skills prior to assuming an administrative position.

6. In the process of working with students to alter their behaviors, this assistant principal, who emphasizes counseling rather than punishment, at times places himself at risk of conflict with teachers over the issue of consequences. When he does not give a punishment to a student in response to a referral from a teacher, or assigns a consequence that a teacher considers not severe enough for the offense, he is at risk of losing the teacher's trust. He faces a similar dilemma with parents who might question his decisions regarding their children. The findings suggest that coping with the tension that the assistant principal confronts as he/she strives to do what is best for each individual student, while at the same time attempting to satisfy the expectations of teachers and 
parents, is one of the greatest challenges he/she must face in maintaining trust with all constituent groups at the same time. It appears an assistant principal requires a combination of skills to meet this challenge effectively, including, but not necessarily limited to, a thorough knowledge of legislation and policy, an ability to communicate effectively, willingness to iisten and compromise, and the ability to instill in others a confidence that he will always attempt do the right thing for all constituent groups. Aspiring administrators should be provided the training and mentoring in both clinical and real world settings to attain these skills prior to assignment as a school administrator. 7. This assistant principal was not the person on campus with primary responsibility for the climate category of facility cleanliness and maintenance despite his perception that he did indeed perform this role. Nevertheless, this study suggests that an assistant principal at a similar school site, who uses strategies comparable to those of this assistant principal to maintain order and discipline, is in a better position than any other staff member to maintain a clean facility that is in good repair. Frequent contact with all members of the school community and the practice of maintaining high levels of visibility throughout all parts of the campus on a routine basis result in the assistant principal being the person best positioned to detect cleanliness and maintenance problems. The positional authority of the assistant principal also empowers him/her to attain results more quickly and effectively than any site level personnel other than the principal. Accordingly, at a large middle school with an assistant principal who uses strategies similar to those employed by the subject of this study, consideration should be given to assigning the assistant principal primary responsibility for the climate category of facility cleanliness and maintenance and adjusting reporting lines of communication so that custodial staff report 
directly to the assistant principal.

8. The findings of this study suggest that the assumption held by many school administrators that all assistant principals should be aspiring principals may not be valid in all cases. The subject of this study has held the position of assistant principal for 13 years and has no aspirations to become a principal. He seems to recognize that his strengths and interests are in working directly with students, teachers, and parents on issues related primarily to the climate category of order and discipline. He has little desire to be a part of any component of school leadership outside of the maintenance of a safe and orderly campus. As a result, he focuses almost entirely on order and discipline. $\mathrm{He}$ is able to do so at this school because of the strengths of the principal in curriculum and instruction and her refined leadership skills in other areas. His effectiveness in maintaining a safe and orderly campus allows her to be the school's instructional leader and to attend to all of the many other demands on a principal's time, both on and off the campus. This suggests that the emphasis, when selecting assistant principals, should be on assembling a leadership team with complementary skills, as discussed above, rather than basing selection of assistant principals in large part, if not entirely, on their potential to ultimately become principals. Nevertheless, sites with principals who have broad repertoires of interests and skills should be identified in each school district to serve as training grounds for aspiring principals in order to provide the guidance, supervision, and leadership opportunities necessary to prepare assistant principals for the role of principal.

\section{Recommendations for Future Research}

This was a study of a previously unexplored topic. Though some research has been done that examined the relationship between the leadership of a school principal and 
school climate (see, for example, Griffith, 1999; Hoy \& Feldman, 1987), the effect of an assistant principal's assumptions and behaviors on school climate had not been investigated. Accordingly, this was a first attempt to begin to describe and understand the interaction between an assistant principal's actions and the climate of a school. In view of the critical nature of climate to middle school strategies, the study focused on the middle grade level.

Future research should build on the findings of this single case study by studying additional large, urban middle schools and their assistant principals. A larger sample size will increase the level of transferability of findings to similar settings. The next step should be to investigate middle schools of different sizes and student socio-economic status and demographics to examine the effect that variations in these factors have on the relationship between assistant principals' attitudes and behaviors and school climate. Finally, research should be conducted at the elementary and high school levels to study the relationship between assistant principal actions and school climate in the elementary and high school settings where students are significantly different physically, socially, and emotionally from middle school students.

This was a qualitative case study that was a first step in an attempt to describe a middle school assistant principal's influence on school climate. Quantitative studies, such as Hoy, Tarter, and Witkoskie's (1992) use of a revised form of Halpin \& Croft's (1963) Organizational Climate Questionnaire, would be useful to expand the sample size of inquiries beyond that possible with qualitative methodologies. Qualitative studies would continue to be needed, however, to provide the contextual component necessary to explain quantitative results. 


\section{References}

Anderson, C. S. (1982). The search for school climate: A review of the research. Review of Educational Research, 52(2), 368-420.

Bennis, W. (1997). Leadership is like herding cats. Provo, UT: Executive Excellence.

Benton, E., \& Bulach, C. (1995). How an elementary school improved school climate. ERS Spectrum, summer, 32-38.

Bernstein, L. (1992). Where is reform taking place? An analysis of policy changes and school climate. Educational Evaluation and Policy Analysis, 14(3), 279302.

Black, S. (1997). Creating Community. Children learn more, researchers find, in schools with positive culture and climate. The American School Board Journal, 184(6), $32-34$.

Bogdan, R. C., \& Biklen, S. K. (1998). Qualitative research for education. Boston: Allyn and Bacon.

Borger, J., Lo, C., Oh, S., \& Walberg, H. (1985). Effective schools: A quantitative synthesis of constructs. Journal of Classroom Interaction, 20(2), 12-17.

Brough, J. (1990). Changing conditions for young adolescents: Reminiscences and realities. Education Horizons, 68, 78-81.

Brown, T. F. (1984). Improving school climate-The symptom vs. the problem. NASSP Bulletin, 68(472), 3-7.

Bulach, E., \& Malone, B. (1994). The relationship of school climate to the implementation of school reform. ERS Spectrum, 12(4), 3-8. 
Burns, J. M. (1978). Leadership. New York: Harper and Row.

Deming, W. E. (1983). Quality, productivity, anä competitive advantage. Cambridge: Massachusetts Institute of Technology, Center for Advanced Engineering.

Dietrich, A. P., \& Bailey, E. L. (1996). School climate: Common-sense solutions to complicated problems. NASSP Bulletin, January, 16-25.

Donmoyer, R. (1990). Generalizability and the single case study. In E. Eisner \& A. Peshkin (Eds.), Qualitative inquiry in education: The continuing debate (pp. 1752000). New York: Teachers college Press.

Evan, W. M. (1968). A systems model of organizational climate. In R. Tagiuri \& G. H. Litwin (Eds.). Organizational climate. Explorations of a concept (pp. 107-124). Boston: Graduate School of Business, Harvard University.

Felner, R. D., Jackson, W. A., Kasak, D., Mulhall, P., Brand, S., \& Flowers, N. (1997). The impact of school reform for the middle years: Longitudinal study of a network engaged in turning points based comprehensive school transformation. Phi Delta Kappan, 78(7), 528-550.

Foster-Harrison, E. S. (1997). Professional climate. How does your school compare? Schools in the Middle, 6(5), 4-8.

Fox, R. S. (1973). School climate improvement: A challenge to the school administrator. Denver: CFK Ltd.

Freiberg, H. J. (1987). School climate. Measuring, improving, and sustaining healthy learning environments. Bloomington, $\mathrm{IN}$ : Phi Delta Kappa.

Freiberg, H. J. (1998). Measuring school climate. Educational Leadership, $55(12), 22-26$ 
George, P., \& Oldaker, L. (1985). Evidence for the middle school. Columbus, $\mathrm{OH}$ : National Middle School Association.

George, P., \& Shewey, K. (1994). New evidence for the middle school. Columbus, $\mathrm{OH}$ : National Middle School Association.

Greenfield, W. D. (1985). Studies of the assistant principalship. Toward new avenues of inquiry. Education and Urban Society, 18(1), 7-27.

Glesne, C. (1999). Becoming qualitative researchers. New York: Longman.

Graen, G. B., \& Scandura, T. A. (1987). Toward a psychology of dyadic organizing. Research in Organizational Behavior, 9, 175-208.

Griffith, J. (1999). The school leadership/school climate relation: Identification of school configurations associated with change in principals. Educational Administration Quarterly, 35(2), 267-291.

Guba, E. G., \& Lincoln, Y. S. (1981). Effective evaluation. San Francisco: Jossey-Bass.

Halpin, A. W. (1966). Theory and research in administration. New York: Macmillian.

Halpin, A. W., \& Croft, D. (1963). The organizational climate of schools. Chicago: Midwest Administration Center of the University of Chicago.

Heifetz, R. A. (1994). Leadership without easy answers. Cambridge, MA: Harvard University Press.

Howard, E., Howell, B., \& Brainerd, E. (1987). Handbook for conducting school climate improvement projects. Bloomington, IN: Phi Delta Kappa Educational Foundation. 
Hoy, W. K., \& Feldman, J. A. (1987). Organizational health: The concept and its measure. Journal of Research and Development in Education, 20(4), 30-37.

Hoy, W. K., \& Hannum, J. W. (1997). Middle school climate: An empirical assessment of organizational health and student achievement. Education Administration Quarteriy, 33(3), 290-311.

Hoy, W. K., Hannum, J. W., \& Moran, M. (1998). Organizational climate and student achievement: A parsimonious and longitudinal view. Journal of School Leadership, 8, 337-358.

Hoy, W. K., \& Sabo, D. J. (1998). Quality middle schools: Open and healthy. Thousand Oaks, CA: Crown Press.

Hoy, W. K., Tarter, C. J., \& Bliss, J. R. (1990). Organizational climate, school health, and effectiveness: A comparative analysis. Educational Administration Quarterly, 26(3), 260-279.

Hoy, W. K., Tarter, C. J., \& Witkoskie, L. (1992). Faculty trust in colleagues: Linking the principal with school effectiveness. Journal of Research and Development in Education, 26(1), 38-45.

Indik, B. P. (1968). The scope of the problem and some suggestions toward a solution. In B. P. Indik and F. K. Berrien (Eds.), People, Groups, and Organizations, 3-30. New York: Teachers College Press.

Kaplan, L. S., \& Evans, M. W. Sr. (1997). Changing school environment: Restructuring one virginia high school. NASSP Bulletin, 81(589), 1-9.

Kotter, J. P. (1996). Leading change. Boston: Harvard Business School Press. Kozlowski, S. W. J., \& Doherty, M. L. (1989). Integration of climate and 
leadership: Examination of a neglected issue. Journal of Applied Psychology, 74(4), 546553.

Lake, S. (1989). The rationale for the middie level school. Irvine, CA: California League of Middle Schools.

Lake, S. (1991). Defining an effective climate for a middle school. Irvine, CA: California League of Middle Schools.

Lewin, K., Lippert, R., \& White, R. K. (1939). Patterns of aggressive behavior in experimentally created social climates. Journal of social psychology, (10), 271-299.

Likert, R. (1967). The human organization. Its management and value. New York: McGraw-Hill.

Litwin, G. H., \& Stringer, R. A. (1968). Motivation and organizational climate. Boston: Graduate School of Business Administration, Harvard University.

Maciver, D. (1990). Meeting the needs of young adolescents: Advisory groups, inter-disciplinary teams, and school transition programs. Phi Delta Kappan, 71(6), 458464.

Maynard, G. (1986). The reality of diversity at the middle level. The Clearing House, 60, 21-23.

McGregor, D. (1960). The human side of enterprise. New York: McGraw-Hill. Merriam, S. B. (1998). Qualitative research and case study applications in education. San Francisco: Jossey-Bass.

Miles, M. (1969). Planned change and organizational health: Figure and ground. In F. D. Carver \& T. J. Sergiovanni (Eds.), Organizations and Human Behavior, 375391. New York: McGraw-Hill. 
Patton, M. Q. (1987). How to use qualitative methods in evaluation. Newbury Park, CA: Sage.

Patton, M. Q. (1990). Qualitative evaluation and research methods. Newbury Park, CA: Sage.

Peshkin, A. (1998). In search of subjectivity-one's own. Educational Researcher, October, 17-21.

Plodzik, K., \& George, P. (1989). Inter-disciplinary team organization. Middle School Journal, 22(5), 21-31.

Rubin. H. J., \& Rubin, I. S. (1995). Qualitative interviewing. The art of hearing data. Thousand Oaks, CA: Sage.

Schein, E. H. (1992). Organizational culture and leadership. San Francisco: Jossey-Bass.

Spradley, J. P. (1979). The ethnographic interview. Fort Worth: Harcourt Brace.

Stockard, J., \& Mayberry, M. (1992). Effective educational environments. Newbury Park, CA: Sage.

Superintendent's Middle Grade Task Force (1987). Caught in the middle. Educational reform for young adolescents in california public schools. Sacramento: California State Department of Education.

Tagiuri, R. (1968). The concept of organizational climate. In R. Tagiuri \& G. H. Litwin (Eds.), Organizational climate. Explorations of a concept (pp.10-32). Boston: Graduate School of Business Administration, Harvard University.

Tarter, C. J., \& Hoy, W. K. (1988). The context of trust: Teachers and the principal. High School Journal, 72, 17-24. 
Tarter, C. J. Hoy, W. K., \& Kottkamp, R. B. (1990). School health and organizational commitment. Journal of Research and Development in Education, 23(4), 236-242.

Tarter, C. J., Sabo, D., \& Hoy, W. K. (1995). Middle school climate, faculty trust, and effectiveness: A path analysis. Journal of Research in Education, 29(1), 41-49.

Task Force on Education of Young Adolescents (1989). Turning points:

Preparing american youth for the $21^{\text {st }}$ century. New York: Carnegie Corporation of New York, Carnegie Council on Adolescent Deveiopment.

Toepfer, C. (1988). What to know about young adolescents. Social Education, $52,110-112$.

Toepfer, C., Lounsbury, J., Arth, A., \& Johnson, J. (1996). Editorial. The Clearing House, 60, 6-10.

Tolstoy, (1965). Anna karenina (G. Garnett Trans.). New York: Random House. (Original work published 1878)

Welch, C. (1997). A safe place to learn. Thrust for Educational Leadership, $27(1), 24-25$

Wolcott, H. F. (1973). The man in the principal's office. New York: Holt, Rinehart, and Winston.

Wolcott, H. F. (1990). On seeking-and rejecting-validity in qualitative research. In E. Eisner \& A. Peshkin (Eds.), Qualitative inquiry in education: The continuing debate (pp. 121-152). New York: Teachers College Press.

Yin, R. K. (1984). Case study research. Design and methods. Beverly Hills, CA: Sage. 